\title{
Mechanical Characterization of Densely Welded Apache Leap Tuff
}

Manuscript Completed: March 1991

Date Published: June 1991

Prepared by

K. Fuenkajorn, J. J. K. Daemen

Department of Mining and Geological Engineering

University of Arizona

Tucson, AZ 85721

Prepared for

Division of Engineering

Office of Nuclear Regulatory Research

U.S. Nuclear Regulatory Commission

Washington, DC 20555

NRC FIN L1476

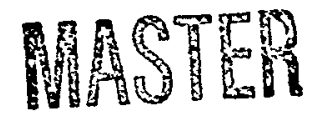





\section{DISCLAIMER}

This report was prepared as an account of work sponsored by an agency of the United States Government. Neither the United States Government nor any agency thereof, nor any of their employees, make any warranty, express or implied, or assumes any legal liability or responsibility for the accuracy, completeness, or usefulness of any information, apparatus, product, or process disclosed, or represents that its use would not infringe privately owned rights. Reference herein to any specific commercial product, process, or service by trade name, trademark, manufacturer, or otherwise does not necessarily constitute or imply its endorsement, recommendation, or favoring by the United States Government or any agency thereof. The views and opinions of authors expressed herein do not necessarily state or reflect those of the United States Government or any agency thereof. 


\section{DISCLAIMER}

Portions of this document may be illegible in electronic image products. Images are produced from the best available original document. 


\section{ABSTRACT}

An empirical criterion is formulated to describe the compressive strength of the densely welded Apache Leap tuff. The criterion incorporates the effects of size, L/D ratio, loading rate and density variations. The criterion improves the correlation between the test results and the failure envelope. Uniaxial and triaxial compressive strengths, Brazilian tensile strength and elastic properties of the densely welded brown unit of the Apache Leap tuff have been determined using the ASTM standard test methods. All tuff samples are tested dry at room temperature $\left(22 \pm 2^{\circ} \mathrm{C}\right)$, and have the core axis normal to the flow layers. The uniaxial compressive strength is $73.2 \pm 16.5 \mathrm{MPa}$. The Brazilian tensile strength is $5.12 \pm 1.2 \mathrm{MPa}$. The Young's modulus and Poisson's ratio are $22.6 \pm 5.7 \mathrm{GPa}$ and $0.20 \pm 0.03$. Smoothness and perpendicularity do not fully meet the ASTM requirements for all samples, due to the presence of voids and inclusions on the sample surfaces and the sample preparation methods. The investigations of loading rate, $L / D$ ratio and cyclic loading effects on the compressive strength and of the size effect on the tensile strength are not conclusive. The Coulomb strength criterion adequately represents the failure envelope of the tuff under confining pressures from 0 to $62 \mathrm{MPa}$. Cohesion and internal friction angle are 16 $\mathrm{MPa}$ and 43 degrees. The brown unit of the Apache Leap tuff is highly heterogeneous as suggested by large variations of the test results. The high intrinsic variability of the tuff is probably caused by the presence of flow layers and by nonuniform distributions of inclusions, voids and degree of welding. Similar variability of the properties has been found in publications on the Topopah Spring tuff at Yucca Mountain. 
TABLE OF CONTENTS

Page

iii

LIST OF FIGURES ......................... . vii

LIST OF TABLES . . . . . . . . . . . . . . . . . . . ix

ACKNOWLEDGMENTS . . . . . . . . . . . . . . . . . . . xi

LIST OF SYMBOLS ........................ xiii

EXECUTIVE SUMMARY . . . . . . . . . . . . . . . . . 1

CHAPTER ONE: INTRODUCTION . . . . . . . . . . . . . . 7

1.1 Objectives .................... . . . 7

1.2 Scope and Limitations... . . . . . . . . . . . . . . 7

1.3 Organization ................... 7

1.4 Source Location and General Description of Tested Tuff 8

CHAPTER TWO: CHARACTERIZATION TESTING . . . . . . . . . . 15

2.1 Uniaxial Compression Test . . . . . . . . . . . . 15

2.1.1 Uniaxial Compressive Strength and Elastic

Properties . . . . . . . . . . . . . . . . 15

2.1.2 Effect of Length to Diameter Ratio on Uniaxial

Compressive Strength ........... . 17

2.1.2.1 Rock Sample and Test Method.... . . 17

2.1.2.2 Test Results ............ 17

2.1.3 Effect of Strain Rate on Compressive Strength . 26

2.1.3.1 Rock Samples and Test Method . . . . . 26

2.1.3.2 Test Results ............ . 28

2.1.4 Effect of Cyclic Loading on Compressive Strength 28

2.1.4.1 Rock Samples and Test Method . . . . . 28

2.1.4.2 Test Results .. . . . . . . . . . . . 28

2.1.5 Size Effect on Uniaxial Compression Strength . . 36

2.1.5.1 Rock Samples and Test Method . . . . . 36

2.1.5.2 Test Results ............ 38

2.2 Brazilian Tension Test .............. 38

2.2.1 Brazilian Tensile Strength . . . . . . . . 38

2.2.2 Size Effect on Brazilian Tensile Strength . . . 38

2.3 Seismic Velocity Measurements . . . . . . . . . . 48

2.4 Triaxial Compressive Strength Test . . . . . . . . . 53

2.5 Strength Criteria for Apache Leap Tuff . . . . . . . . 53

2.5.1 Coulomb Criteria .. . . . . . . . . . . 56

2.5.2 Bieniawski Criterion... . . . . . . . . 56

2.5.3 Hoek and Brown Criterion . . . . . . . . . 58 
TABLE OF CONTENTS--Continued

Page

2.5.4 Yudhbir Criterion ............. 61

2.5.5 Griffith Criterion. . . . . . . . . .... 61

2.5.6 Discussion of the Strength Criteria of Tuff . . 64

2.6 Proposed Compressive Strength Criterion . . . . . . . . 66

2.6.1 General Form of the Proposed Failure Criterion . 66

2.6.2 Formulation of Proposed Failure Criterion . . . 67

2.6.2.1 Heterogeneity Effect - Key Parameter . 67

2.6.2.2 Effect of Length-to-Diameter Ratio . . 71

2.6.2.3 Effect of Loading Rate . . . . . . . 73

2.6.2.4 Size Effect............ . 75

2.6.2.5 Effect of Confining Pressure . . . . 77

2.6.2.6 Failure Envelopes .......... . 80

2.6.3 An Evaluation of the Predictive Capability

of the Proposed Criterion . . . . . . . . . . 80

2.6.4 Strength Criterion for Nonlinear

Heterogeneous Rocks . . . . . . . . . 85

2.6.5 Discussion . . . . . . . . . . . . . . 86

2.6.6 Conclusions . . . . . . . . . . . . . . . . . 86

2.7 Discussion of the Characterization Test Results . . . . 87

2.7.1 Heterogeneity of the Apache Leap Tuff . . . . . 87

2.7.2 Comparison Between Topopah Spring and Apache

Leap Tuffs.............. . 89

CHAPTER THREE: SUMMARY, CONCLUSIONS AND RECOMMENDATIONS FOR

FUTURE RESEARCH . . . . . . . . . . . . . . 91

3.1 Summary of Test Results . . . . . . . . . . . . . . . 91

3.2 Recommendations for Future Tuff Characterization . . . 92

REFERENCES . . . . . . . . . . . . . . . 95

APPENDIX A: PROPERTIES OF NON-WELDED UNIT OF THE A-MOUNTAIN TUFF 101

APPENDIX B: PROCEDURE FOR SEISMIC VELOCITY MEASUREMENTS . . . . 107

APPENDIX C: ROCK SAMPLE DESIGNATION CODING SYSTEM . . . . . . 110 


\section{LIST OF FIGURES}

Eigure

Page

1.1 Locations where the Apache Leap tuff specimens have been collected :.................... 9

2.1 Apache Leap tuff specimens tested in uniaxial compression 19

2.2 Circumferential strain as a function of axial strain . . . 21

2.3 Axial stress-strain of Apache Leap tuff obtained from four uniaxial compression test specimens . . . . . . . . .

2.4 Uniaxial compressive strength as a function of lengthto-diameter ratio .............. 25

2.5 Uniaxial compressive strength as a function of axial strain rate ................. 30

2.6 Elastic modulus as a function of axial strain rate . . . . 32

2.7 Poisson's ratio as a function of axial strain rate . . . . 33

2.8 Young's modulus as a function of loading cycle number . . 37

2.9 Uniaxial compressive strength as a function of sample diameter................. 39

2.10 Young's modulus as a function of sample diameter for densely welded Apache Leap tuff, tangent modulus measured at $50 \%$ failure stress ... . . . . . . . . . 40

2.11 Poisson's ratio of welded Apache Leap tuff as a function of sample diameter, calculated at 508 failure stress . .

2.12 Brazilian test specimens of Apache Leap tuff after failure .. . . . . . . . . . . . . . . .

2.13 Brazilian tensile strength of Apache Leap tuff, obtained from different sample sizes . . . . . . . . . . .

2.14 Evans' power law fit to Brazilian tensile strength data as a function of disk diameter . . . . . . . . . . . . .

2.15 Lundborg's logarithmic expression fit to Brazilian tensile strength data as a function of disk diameter . . . 52

2.16 Coulomb criterion: curve fit and experimental data . . . 57

2.17 Bieniawski criterion: curve fit and experimental data . . 59 


\section{LIST OF FIGURES--Continued}

Eigure

Page

2.18 Hoek and Brown criterion: curve fit and experimental data 60

2.19 Yudhbir criterion: curve fit and experimental data . . . 63

2.20 Griffith criterion: curve fit and experimental data . . . 65

2.21 Uniaxial compressive strengths as a function of sample density for various sample diameters . . . . . . . . 69

2.22 Slope of the relation between strength and density, as a function of volume, experimental results and curve fit. .

$2.23\left(J_{2 D}\right)^{1 / 2}$ at failure as a function of L/D ratio, from uniaxial test samples with density of $2.46 \mathrm{~g} / \mathrm{cc} . . \quad$. 72

2.24 Comparison between $\left(J_{2 D}\right)^{1 / 2}$ from actual data and from those after isolating from effects of $\rho$ and $L / D$; curve fits to adjusted strength data... . . . . . . 74

2.25 Comparison between $\left(J_{2 D}\right)^{1 / 2}$ from actual data and from those obtained by removing the effects of $\rho, L / D$ and $\epsilon_{R}$; curve fits to adjusted strength data . . . . . . .

2.26 Failure envelope: $\left(J_{2 D}\right)^{1 / 2}$ as a function of first stress invariant, triaxial test samples $\rho=2.46$, $\mathrm{L} / \mathrm{D}=2.5, \epsilon_{R}=0.29 \times 10^{-6}$ per second .........

2.27 Failure envelope for tuff samples with a volume of $0.00025 \mathrm{~m}^{3}$. . . . . . . . . . . . . . . . .

2.28 Failure envelope for tuff samples with a volume of $2.46 \mathrm{~g} / \mathrm{cc}$. . . . . . . . . . . . . . . . . . . .

2.29 Unconfined compressive strength in terms of $\left(J_{2 D}\right)^{1 / 2}$ as a function of sample size for various densities . . . . . .

2.30 Comparison between $\left(J_{2 D}\right)^{1 / 2}$ from biaxial test results and from predictions by proposed criterion and by Coulomb criterion . . . . . . . . . . . . . .

2.31 Inclusions in Apache Leap tuff . . . . . . . . . . . 88 
Table

EXECUTIVE SUMMARY

I Summary of Results of Mechanical Characterization

Tests on Apache Leap Tuff, Brown Unit . . . . . . . . .

CHAPTERS $1-3$

1.1 Chemical Composition of Tuffs . . . . . . . . . . . 11

1.2 Chemical Composition of Brown Unit of Apache Leap Tuff . . 12

1.3 Mineral Composition of Apache Leap Tuff . . . . . . . . 13

1.4 Water Hydraulic Conductivities of Saturated Tuffs . . . . 13

1.5 Porosity and Density of Tuffs ............. 14

2.1 Perpendicularity and Smoothness of Apache Leap Tuff

Samples Used in Uniaxial Compression Test, Compared

with ASTM Requirements ............. 16

2.2 Results of the Uniaxial Compressive Strength Tests on Apache Leap Tuff . . . . . . . . . . . . . . . .

2.3 Tangent Elastic Modulus and Poisson's Ratio of Apache Leap Tuff Obtained from Uniaxial Compression Tests:

Measured at 508 Peak Stress . . . . . . . . . .

2.4 Perpendicularity and Smoothness of Apache Leap Tuff Cylinders Compared with ASTM Requirements . . . . . . .

2.5 Results of Uniaxial Compression Test of Apache Leap Tuff Cylinders with Different L/D Ratios . . . . . . . .

2.6 Dimensions of Apache Leap Tuff Specimens Used in Strain

Rate Effect Study .... . . . . . . . . . . .

2.7 Uniaxial Compressive Strength of Apache Leap Tuff

Determined at Various Axial Strain Rates . . . . . . . .

2.8 Results of Linear Regression Analysis; Uniaxial

Compression Tests on Apache Leap Tuff 


\section{LIST OF TABLES--Continued}

Table

Page

2.9 Dimensions and Density of Apache Leap Samples (Brown

Unit) Used in Cyclic Loading Test . . . . . . . . . . . 34

2.10 Perpendicularity and Smoothness of Apache Leap Tuff

Samples (Brown Unit) used in Cyclic Loading Test,

Compared with ASTM Standard D2938 Requirements . . . . . . 34

2.11 Results of Cyclic Loading Tests on Apache Leap Tuff . . . 35

2.12 Results of Brazilian Tensile Strength Tests on Apache

Leap Tuff . . . . . . . . . . . . . . . . . . 42

2.13 Brazilian Tensile Strengths of Apache Leap Tuff

Samples with Nominal Diameters of $25 \mathrm{~mm}$. . . . . . . . 45

2.14 Brazilian Tensile Strengths of Apache Leap Tuff

Samples with Nominal Diameters of $95 \mathrm{~mm}$. . . . . . . 45

2.15 Brazilian Tensile Strengths of Apache Leap Tuff

Samples with Nominal Diameters of $150 \mathrm{~mm}$. . . . . . . . . 46

2.16 Brazilian Tensile Strengths of Apache Leap Tuff

Samples with Nominal Diameters of $181.5 \mathrm{~mm}$....... 46

2.17 Brazilian Tensile Strengths of Apache Leap Tuff

Obtained from Different Sample Sizes... . . . . . . 47

2.18 Elastic Modulus and Poisson's Ratio of Apache Leap Tuff,

Obtained from Brazilian Tests . . . . . . . . . .

2.19 Results of Size Effect Calculation of Brazilian Tensile Strength of Apache Leap Tuff . . . . . . . . . . .

2.20 Results of Seismic Velocity Measurements of Apache Leap Tuff

2.21 Results of Triaxial Compressive Strength Tests on Apache

Leap Tuff Specimens . . . . . . . . . . . . . .

2.22 Summary of Strength Analyses of the Brown Unit of Apache Leap Tuff . . . . . . . . . . . . . . .

2.23 Mechanical and Physical Properties of Brown Unit of Apache Leap Tuff and of Topopah Spring Tuff 
The research reported on has been performed by the University of Arizona, Department of Mining and Geological Engineering, for the U.S. Nuclear Regulatory Commission (NRC). Project monitor for the NRC is Mr. Jacob Philip. The project is under Mr. M.M. Silberberg, Chief, Waste Management Branch, Division of Engineering, Office of Nuclear Regulatory Research.

Dr. Jaak J.K. Daemen, Associate Professor, Department of Mining and Geological Engineering, University of Arizona, is the Principal Investigator. Dr. James G. McCray, Acting Director, Nuclear Fuel Cycle Research Program, Department of Nuclear and Energy Engineering, University of Arizona, has provided project management assistance and nuclear waste technical assistance. Dr. Kittitep Fuenkajorn has performed the theoretical and experimental work. Experimental assistance has been provided by Robert Armstrong, David Crouthamel, Chongwei Ran, Shyh-shyan Hsu, and David Smith. Mike Porter has typed, assembled, and produced the report.

We gratefully acknowledge the permission of Mr. Frank Florez of Magma Copper Co., Superior, Arizona, for allowing us to collect rock samples for testing purposes. 
每 


\section{LIST OF SYMBOLS}

\section{Roman Symbels}

a constant factor in proposed compressive strength - strain rate function

A constant factor in Bieniawski's strength criterion

$A^{\prime}$ constant factor in Lundborg's strength-volume expression

b constant factor in proposed compressive strength - strain rate function

B constant factor in Bieniawski's strength criterion

c cohesion

C stress exponent in Bieniawski's strength criterion

$C_{0}$ uniaxial compressive strength calculated from regression analysis

CT correction term in proposed strength criterion

d constant factor (slope) in proposed elastic modulus - strain rate function

D sample diameter

$D^{\prime}$ constant factor in Yudhbir's strength criterion

e constant factor (intercept) in proposed elastic modulus - strain rate function

E Young's modulus

$\mathrm{E}_{\mathrm{d}}$ dynamic Young's modulus

$E^{\prime}$ constant factor in Yudhbir's strength criterion

$f$ stress exponent in Yudhbir's strength criterion

g gravitational acceleration

i constant factor (slope) in proposed Poisson's ratio - strain rate function

I1 first stress invariant

j constant factor (intercept) in proposed Poisson's ratio - strain rate function

$\mathrm{J}_{2 \mathrm{D}}$ second invariant of stress deviation

$k$ stress exponent in Bieniawski's strength criterion

$k^{\prime}$ constant factor in Evans' Brazilian strength equation

$\mathrm{K}$ stress concentration factor at inner radius of ring sample

I sample length

m constant factor in Hoek and Brown's strength criterion 


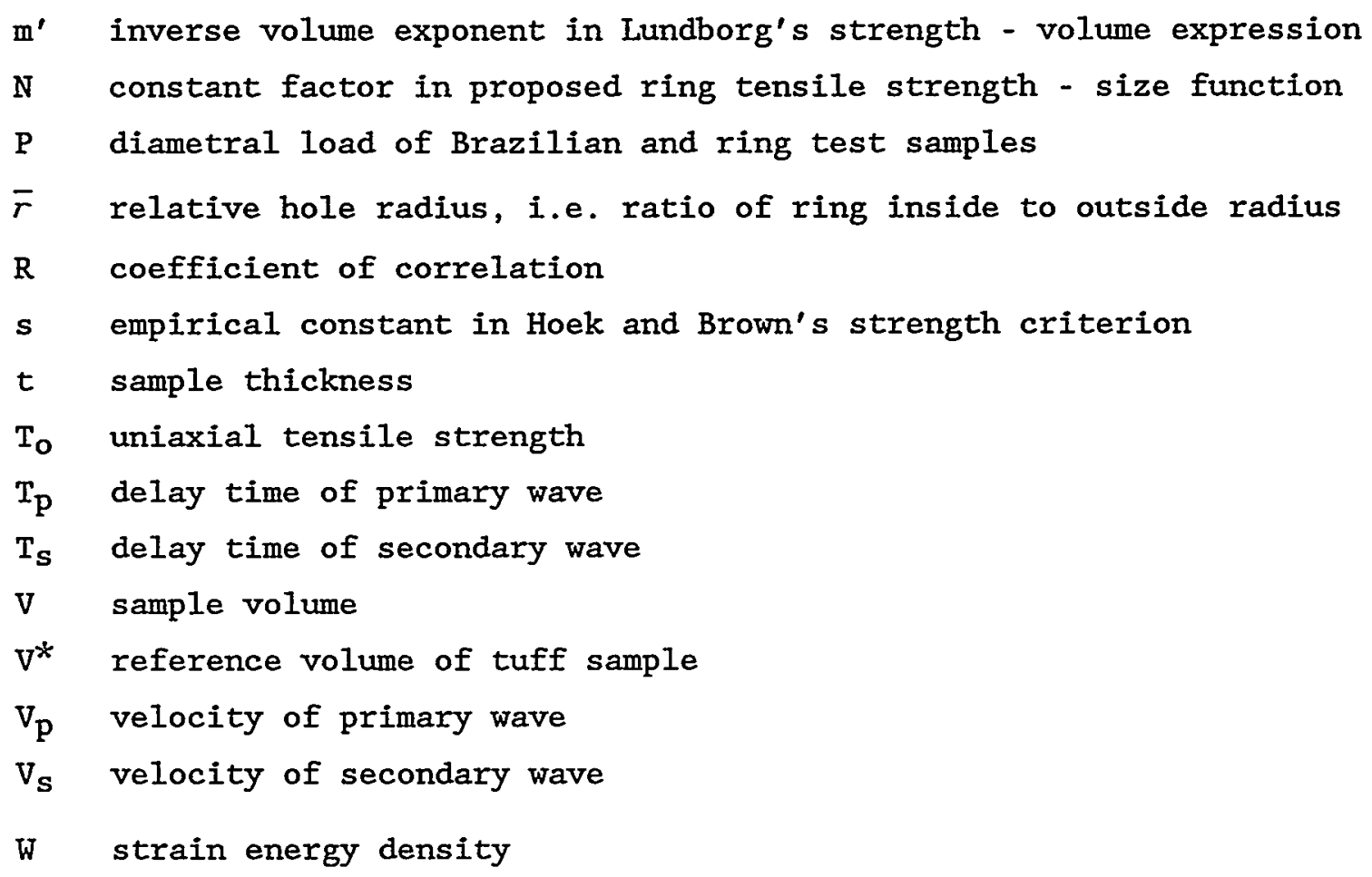

\section{Greek Symbols}

$\alpha \quad$ size exponent in Evans' Brazilian strength equation

B constant factor in strength criterion for heterogeneous rock

$Y$ unit weight of rock

$\epsilon_{r} \quad$ radial strain

$\epsilon_{R} \quad$ axial strain rate in uniaxial compression test

$\epsilon_{R}^{*} \quad$ reference axial strain rate

$\epsilon_{\theta} \quad$ tangential strain

$\lambda$ constant factor for size effect of proposed strength criterion

$\lambda^{-} \quad$ size exponent in proposed ring tensile strength - diameter equation

$v \quad$ Poisson's ratio

$v_{d}$ dynamic Poisson's ratio

$\sigma_{1}, \sigma_{2}, \sigma_{3}$ major, intermediate and minor principal stresses

$\sigma_{B} \quad$ Brazilian tensile strength

$\sigma_{c} \quad$ uniaxial compressive strength

$\sigma_{n} \quad$ normal stress on incipient failure plane 
$\rho$ rock density

$\rho$ * reference rock density

$\tau \quad$ shear stress component

$\phi \quad$ internal friction angle

$x$ constant factor (slope) in proposed $J_{2 D}-I_{1}$ relationship

$\psi$ constant factor (intercept) in proposed $J_{2 D}-I_{1}$ relationship 


\section{EXECUTIVE SUMMARY}

The immediate objective of this work is to determine mechanical properties of the densely welded brown unit of the Apache Leap tuff. A more fundamental, underlying objective is to identify and clarify some of the difficulties associated with mechanical characterization of highly nonuniform rocks such as tuffs. Associated with this more fundamental objective is an evaluation of standard (ASTM) test procedures and of sample preparation procedures. A primary result of the investigation is the development of a semi-empirical failure criterion. By incorporating the effects of size, density, length-to-diameter ratio and loading rate, the proposed criterion considerably improves the predictability of the compressive strength of the densely welded Apache Leap tuff. Some systematic bias remains, and deserves further investigation. It would be desirable to validate the criterion for other heterogeneous rock types, and for a wider range of loading configurations, anisotropic and nonuniform stress fields, sizes, density ranges, moisture contents, and load durations.

The characterization tests include uniaxial and triaxial compressive strength tests, Brazilian tensile strength tests, and seismic velocity measurements. Test procedures, sample specifications and calculation methods follow, as much as possible, the ASTM standard practices. Additional tests have been performed to investigate the effects of loading rate, length-to-diameter ratio, and of cyclic loading on the uniaxial compressive strength, as well as the effects of sample size on the Brazilian tensile strength. All samples have been tested dry and at room temperatures $\left(22 \pm 2^{\circ} \mathrm{C}\right)$. The Apache Leap tuff samples are collected along an old mine road, near Superior, Arizona. Core drilling is performed in the laboratory normal to the flow layers.

Table I summarizes the uniaxial and triaxial compressive strengths, Brazilian tensile strengths, and seismic velocities. The uniaxial compressive strength of the brown unit of the Apache Leap tuff determined using the ASTM (D2938) test method is $73.2 \pm 16.5 \mathrm{MPa}$. The Young's modulus and Poisson's ratio determined using the ASTM (D3184) standard method are $22.6 \pm 5.7 \mathrm{GPa}$ and $0.20 \pm 0.03$. The elastic parameters are the tangent at 508 compressive strength. The uniaxial stress-strain relationship is virtually linear. The strengths obtained from long samples ( $L / D=3$; suggested by the ISRM test method) are more consistent than those from short samples $(\mathrm{L} / \mathrm{D}=2.5$ and 2.0 ; recommended by the ASTM standard method). This is probably because larger L/D ratios minimize end effects which may cause the variation of the results, or because the tuff samples failed in shear yield more consistent failure stresses than the ones failed in tensile splitting. To study the effect of the loading rate, tests have been performed on 95 $\mathrm{mm}$ and $102 \mathrm{~mm}$ diameter samples at a constant strain rate ranging from $10^{-8}$ to $10^{-4}$ per second. The high strain rates tend to induce tensile splitting. The low strain rates induce shear fractures. The effects of 
Table I. Summary of Results of Mechanical Characterization Tests on Apache Leap Tuff, Brown Unit

\begin{tabular}{|c|c|c|}
\hline & & NOTES* \\
\hline \multicolumn{3}{|l|}{ Uniaxial Compression Tests } \\
\hline \multirow{6}{*}{$\begin{array}{l}\text { Uniaxial Compressive } \\
\text { Strength (MPa) }\end{array}$} & $73.2 \pm 16.5$ & $D=50 \mathrm{~mm} ; \mathrm{L} / \mathrm{D}=2.5 ; \mathrm{N}-13$ \\
\hline & $126.2 \pm 13.4$ & $\begin{array}{l}D=95 \& 102 \mathrm{~mm} ; \mathrm{L} / \mathrm{D}=2 \\
\mathrm{~N}=10\end{array}$ \\
\hline & $91.2 \pm 25.1$ & $D=50 \mathrm{~mm} ; \mathrm{L} / \mathrm{D}=2 ; \mathrm{N}=5$ \\
\hline & $99.7 \pm 19.3$ & $D=50 \mathrm{~mm} ; \mathrm{L} / \mathrm{D}=2.5 ; \mathrm{N}=5$ \\
\hline & $107.0 \pm 3.6$ & $D=50 \mathrm{~mm} ; L / D=3 ; N=5$ \\
\hline & 97.45 & All samples \\
\hline Young's Modulus (GPa) \# & $22.6 \pm 5.7$ & $\mathrm{D}=50 \mathrm{~mm} ; \mathrm{L} / \mathrm{D}=2.5 ; \mathrm{N}=5$ \\
\hline Poisson's Ratio & $0.20 \pm 0.03$ & $\mathrm{D}=50 \mathrm{~mm} ; \mathrm{L} / \mathrm{D}=2.5 ; \mathrm{N}=5$ \\
\hline \multicolumn{3}{|l|}{ Brazilian Tension Tests } \\
\hline \multirow{5}{*}{$\begin{array}{l}\text { Brazilian Tensile } \\
\text { Strength (MPa) }\end{array}$} & $5.7 \pm 1.2$ & $D=50 \mathrm{~mm} ; L / D=0.5 ; N=27$ \\
\hline & $8.1 \pm 2.0$ & $\mathrm{D}=25 \mathrm{~mm} ; \mathrm{L} / \mathrm{D}=0.5 ; \mathrm{N}=8$ \\
\hline & $6.5 \pm 1.0$ & $\mathrm{D}=95 \mathrm{~mm} ; \mathrm{L} / \mathrm{D}=0.5 \mathrm{~N}=8$ \\
\hline & $6.8 \pm 1.6$ & $\mathrm{D}=150 \mathrm{~mm} ; \mathrm{L} / \mathrm{D}=0.5 ; \mathrm{N}=8$ \\
\hline & $6.2 \pm 1.4$ & $\mathrm{D}=181 \mathrm{~mm} ; \mathrm{L} / \mathrm{D}=0.5 ; \mathrm{N}=5$ \\
\hline \multirow[t]{2}{*}{ Young's Modulus (GPa)\# } & $127.1 \pm 94.7$ & $D=181 \mathrm{~mm} ; 508$ strength \\
\hline & $112.5 \pm 63.0$ & $D=181 \mathrm{~mm} ; 108$ strength \\
\hline \multicolumn{3}{|c|}{ Seismic Velocity Measurements } \\
\hline P-Wave Velocity $(\mathrm{m} / \mathrm{s})$ & $6420 \pm 1530$ & $\mathrm{D}=100 \mathrm{~mm} ; \mathrm{L} / \mathrm{D}=0.25 ; \mathrm{N}=8$ \\
\hline S-Wave Velocity $(\mathrm{m} / \mathrm{s})$ & $2320 \pm 380$ & $D=100 \mathrm{~mm} ; \mathrm{L} / \mathrm{D}=0.25 ; \mathrm{N}=8$ \\
\hline $\begin{array}{l}\text { Dynamic Young's Modulus } \\
(\mathrm{GPa})\end{array}$ & $35.7 \pm 9.9$ & $D=100 \mathrm{~mm} ; \mathrm{L} / \mathrm{D}=0.25 ; \mathrm{N}=8$ \\
\hline Dynamic Poisson's Ratio & $0.39 \pm 0.10$ & $\mathrm{D}=100 \mathrm{~mm} ; \mathrm{L} / \mathrm{D}=0.25 ; \mathrm{N}=8$ \\
\hline Dry Density $(g / c c)$ & $2.3-2.5$ & Al1 samples \\
\hline
\end{tabular}


Table I. Summary of Results of Mechanical Characterization Tests on Apache Leap Tuff, Brown Unit--Continued

\begin{tabular}{|l|c|c|}
\hline \multicolumn{3}{|c|}{ Triaxial Compression Tests } \\
\hline \multicolumn{2}{|c|}{ NOTES* $^{*}$} \\
\hline $\begin{array}{l}\text { Triaxial Compressive } \\
\text { Strength (MPa) }\end{array}$ & $\begin{array}{c}\tau=15.9+0.094 \sigma_{\mathrm{k}} \text { or } \\
\sigma_{1}=73.4+5.34 \sigma_{3}\end{array}$ & $\begin{array}{c}\text { Coulomb criterion } \\
\mathrm{R}-0.973\end{array}$ \\
\hline Cohesion (MPa) & 16 & \\
\hline $\begin{array}{l}\text { Internal Friction Angle } \\
\text { (degrees) }\end{array}$ & 43 & \\
\hline
\end{tabular}

${ }^{*} \mathrm{D}=$ diameter of sample; $\mathrm{L} / \mathrm{D}=$ length-to-diameter ratio; $\mathrm{N}=$ number of samples; $\mathrm{R}$ = correlation coefficient

\#Results highly uncertain 
the loading rate, $L / D$ ratio, and cyclic loading cannot be clearly determined. This is due to the insufficient number of tests performed and the high intrinsic variability of the tuff.

The ASTM (D3967) test method determines the Brazilian tensile strength of the Apache Leap tuff as $5.7 \pm 1.2 \mathrm{MPa}$. The tensile strength tends to decrease as the sample size increases. Large variation of the strength is observed for all sizes tested.

The dynamic Young's modulus and Poisson's ratio determined from the seismic velocity measurements are $35.7 \pm 9.9 \mathrm{GPa}$ and $0.39 \pm 0.10$. These values are higher than those obtained from the uniaxial compression test. There is no correlation between static and dynamic Young's moduli and rock density.

Triaxial compressive strength tests (ASTM D2664) have been performed on thirteen samples with confining pressures ranging from 3.4 to $62.0 \mathrm{MPa}$. The relationship between the major and the minor principal stresses at failure tends to be linear. Among all strength criteria evaluated, the Coulomb criterion gives the best representation of the failure envelope of the tuff. The criterion gives an internal friction angle of $43^{\circ}$ and a cohesion of $16 \mathrm{MPa}$. The tuff behaves as a brittle material under the confining pressures from 0 to $62 \mathrm{MPa}$.

Smoothness and perpendicularity of all samples tested do not fully satisfy the ASTM standard requirements. This is due to the presence of voids and inclusions on the sample surfaces and due to the methods of sample preparation. Conventional sample preparation (coring, cutting, grinding) may not be adequate for this heterogeneous tuff. A lathe may be required to machine the samples. It would be desirable to investigate whether machining would produce samples that meet ASTM requirements, and at what increase in time and cost required for sample preparation. Complementarily desirable would be an investigation of the extent to which deviations from the ASTM requirements affect test results. Insufficient tests have been conducted here to allow a discriminatory analysis.

An empirical criterion has been derived to describe compressive failure of the Apache Leap tuff. The formulation incorporates the effects of size, L/D ratio, loading rate, and density variations. The proposed criterion gives a better strength prediction for the tuff than does the Coulomb criterion. The derivation method helps in explaining the variation of the strength with rock density and test parameters.

The brown unit of the Apache Leap tuff is highly heterogeneous, as suggested by visual observation and confirmed by large variations of the mechanical properties. The high intrinsic variability of the tuff is probably caused by the presence of flow layers and by nonuniform distributions of the inclusions, voids and degree of welding. Similar variability of the mechanical properties has been found in the Topopah Spring tuff at Yucca Mountain. We believe that the nonuniformity of the Apache Leap tuff occurs on a scale much larger than the size of the samples used in the characterization tests. To improve the understanding of the rock behavior and to increase the 
representativeness of the test results, the minimum size of the samples tested should be $25 \mathrm{~cm}$ diameter and a large number of tests is required. Sampling should be made along and across the flow layers (i.e. horizontal and vertical variations in position) to identify whether the stratigraphy is reflected in the nonhomogeneity. The mechanical characterization tests should be supported by chemical and petrographical analyses. Correlations should be made among degree of welding, chemical composition, porosity, density and mechanical properties of each sample. Probably most helpful would be to try to explain the basic mechanisms responsible for the variability in strength and stiffness. In this investigation, density (and hence, presumably porosity) does not entirely explain the variability. Detailed observations of fracture initiation and propagation during and after failure may assist in identifying the contribution and effects of various components in the rock, e.g. minerals, intergrain contacts, soft and strong inclusions, etc., on the strength of welded tuff. The variability of the raw data for all mechanical properties is large, with standard deviations typically on the order of twenty percent, so that the modeling of such rocks as homogeneous materials may be questionable. On the other hand, after the normalization procedure developed in this report is applied to the data, the results show a good consistency. More biaxial and polyaxial strength results under a wide range of densities are needed to rigorously assess the predictive capability of the proposed empirical strength criterion. 
CHAPTER ONE

INTRODUCTION

\subsection{Objectives}

The immediate objective of this investigation is to determine the mechanical properties of the densely welded brown unit of the Apache Leap tuff. This work is part of a research project on "Sealing of Boreholes and Shafts in Tuff". The mechanical properties of the rock are needed for designing the instrumentation and test procedures of the sealing experiments. The properties are used to analyze the experimental results. The characterization results of the Apache Leap tuff allow comparisons of the sealing test results with results from other locations, particularly at Yucca Mountain.

\subsection{Scope and Iimitations}

This report describes laboratory experiments performed to determine mechanical properties of tuff. The characterization tests include uniaxial and triaxial compressive strength tests, Brazilian tensile strength tests and seismic velocity measurements. All experimental work is performed at nearly isothermal conditions $\left(22 \pm 2^{\circ} \mathrm{C}\right)$. The samples are from the brown unit of the Apache Leap tuff. Tuff blocks are collected along the old mine road, approximately 2.5 miles east of Superior, Arizona. Core specimens are prepared in the laboratory. The core drilling has been performed under unconfined conditions, i.e. simulation of in-situ drilling conditions is not attempted. The core is drilled normal to the flow layers. The sample diameters range from 2.5 to $15 \mathrm{~cm}$ and the lengths from 5 to $30 \mathrm{~cm}$. The number of specimens used in various experiments varies from 5 to 27 . All samples are tested dry. The effects of pore pressure and degree of saturation are not studied.

Test procedures, sample specifications and data reduction follow standard ASTM practices. Deviations therefrom are indicated whenever they have been made. Redundant measurements of deformation, displacement and load are made where possible.

\subsection{Organization}

This first chapter introduces the report by identifying the objectives of this research. The second section briefly states the scope and limitations of the studies. This third section gives a chapter-by-chapter overview of the contents of this report. Source location and general descriptions of the brown unit of the Apache Leap tuff samples are described in the four the section. Comparisons of the chemical composition, mineralogy and hydrological properties between the Apache Leap tuff and the Topopah Spring tuff are made. Similarities and differences are identified. 
Chapter Two describes the test methods used to determine the mechanical properties of the rock. The first section gives results of the uniaxial compression tests, including the strength and elastic parameters. The effects of length-to-diameter ratio, loading rate, cyclic loading, and sample size are determined. Section two gives the indirect splitting (Brazilian tensile strength results, including the influence of sample size. Results of the seismic velocity measurements are given in the third section. The fourth section provides the results of the triaxial compressive strength tests. The conventional strength criterion which best represents the failure envelope of the Apache Leap tuff is determined in section five. A new empirical strength criterion for the tuff is derived in section six. Section seven discusses the effects of the inclusions, flow layers and degree of welding on the characterization results obtained from the ASTM test methods. Comparison of the properties between the Topopah Spring and Apache Leap tuffs is presented.

Chapter Three provides a summary of the work performed, the conclusions drawn therefrom, and an identification of information needs, leading to recommendations for follow-up investigations. The first section summarizes the methods and results of the experiments. Section two identifies remaining knowledge gaps in the determination of the mechanical properties of the tuff. Suggestions are made for experimental work required to improve the understanding of the rock behavior and to increase the representativeness of the test results.

Appendix A gives the mechanical and petrographical properties of the non-welded unit of the A-Mountain tuff. Methods used to measure the seismic velocity of the rock and the dynamic elastic properties are described in Appendix B. Appendix C gives the rock sample designation coding system.

\subsection{Source Location and General Description of Tested Tuff}

Rock samples are from the densely welded brown unit of the Apache Leap tuff. The tuff belongs to a dacitic ash flow sheet exposed approximately from $30^{\circ} 15^{\circ} \mathrm{N}$ to $30^{\circ} 45^{\circ} \mathrm{N}$, and from $110^{\circ} 45^{\circ} \mathrm{W}$ to $111^{\circ} 30^{\circ} \mathrm{W}$. The exposure is in the mid-eastern part of Arizona, near the junctions of Maricopa, Pinal and Gila counties. The easternmost exposure of the tuff is found at Globe. The westernmost exposure is at Apache Junction on Highway 60. Evans (1983) and Vogt (1988) describe the geology of the area and the origin of the rock. Based upon degree of welded (Smith, 1960), this ash flow tuff has been divided into five units (from top to bottom): white unit, grey unit, brown unit, vitrophyre and basal tuff. The brown unit has the highest degree of welding.

The brown unit tuff samples are collected along the old Highway 60 , about 2.5 miles northeast of superior, Arizona (Figure 1.1). Tuff blocks with sizes varying from $0.5 \times 10.5 \times 0.5 \mathrm{~m}$ to $0.5 \times 1.0 \times 1.5 \mathrm{~m}$ are transported to the University of Arizona where the sample preparation is performed. Core drilling is usually perpendicular to flow layers. 


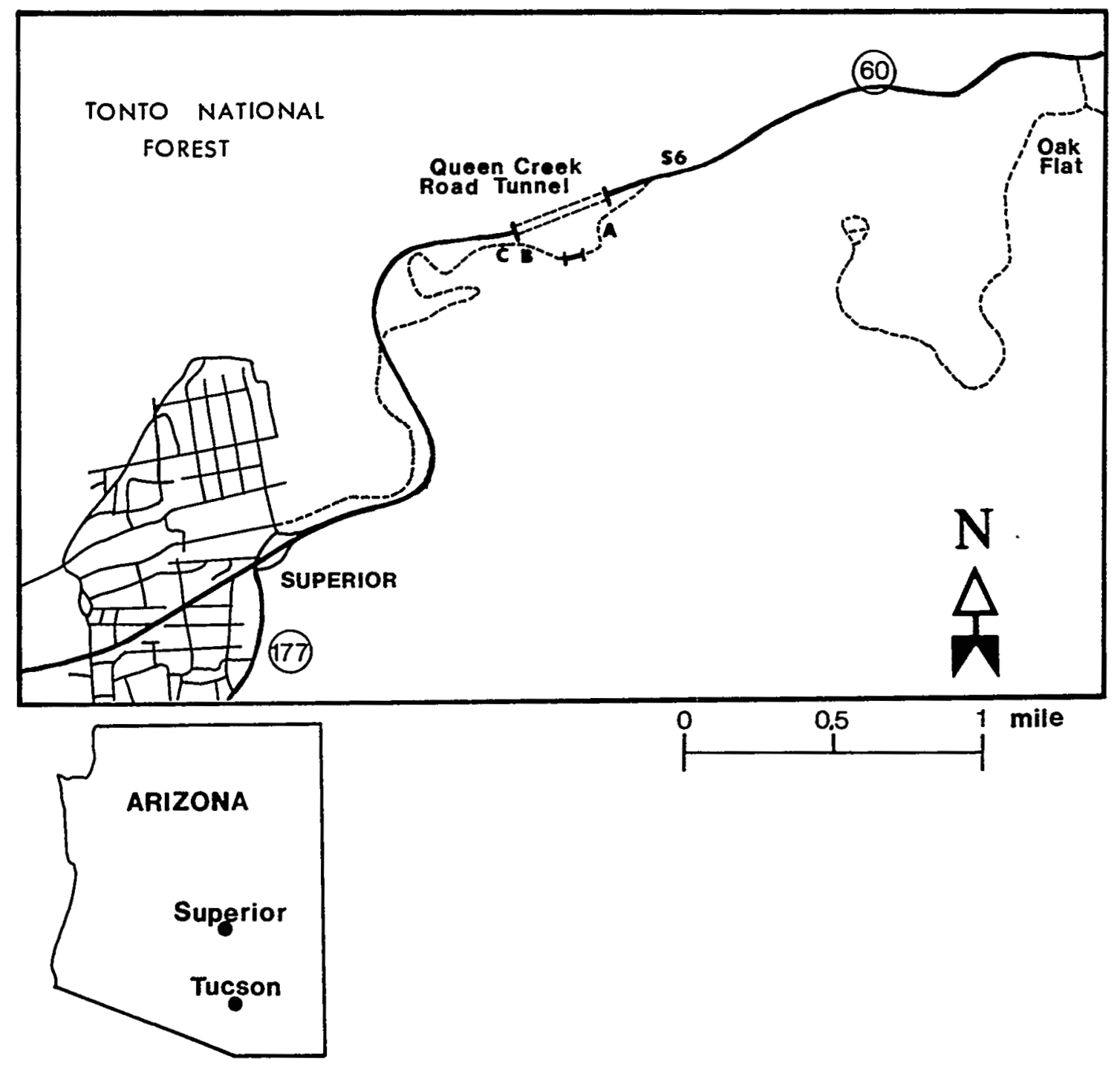

Figure $1.1 \quad A, B$ and $C$ are locations where the Apache Leap tuff specimens have been collected. $S 6=$ shaft no. 6 . 
Table 1.1 gives the chemical composition of the brown unit of the Apache Leap tuff compared with those of Topopah Spring tuff and of the nonwelded unit of the A-Mountain tuff. Appendix A gives a description and properties of the A-Mountain tuff, a rock type which early on in this project had been investigated in terms of similarities with the Topopah Spring tuff. Apache leap tuff contains a higher iron oxide content and lower silica content than Topopah Spring and of A-Mountain tuff. The percentages of calcium, magnesium and aluminum oxides of Apache Leap tuff are slightly higher than those of Topopah Spring and of A-Mountain tuff.

Table 1.2 gives the chemical composition of the matrix, inclusion and fracture-filled material of the Apache Leap tuff. The three phases forming the rock contain comparable amounts of the oxides. Mineral composition of Apache Leap tuff obtained from petrographic microscope studies is given in Table 1.3. The rock consists mainly of quartz and Plagioclase (50-558) in phenocryst and groundmass forms. Hematite probably results from the alteration of Olivine and Magnetite. Apache Leap tuff contains two types of pumic inclusions, which can be distinguished by their color (reddish brown to light grey to white). The reddish brown inclusions contain slightly more iron oxides, are more porous, and are stronger than the rock matrix. The white inclusions are soft and usually appear as pockets of densely compacted powder. They probably are alteration products of feldspars. Distribution for both inclusion types is highly nonuniform. Flow layers in the rock matrix can be recognized by alignments of quartz and feldspar grains, and sometimes by orientation of the lenticular inclusions and vesicles. The flow layers do not appear as a perfect plane. Twisting and curly characteristics are always observed from the scale of $1 \times 1 \mathrm{~mm}$ to $50 \mathrm{x} 50 \mathrm{~cm}$. These petrographic features are widely observed in other volcanic tuffs (Ross and Smith, 1960; Rippa and Vinale, 1983; Zimmerman et al., 1985; Nappi and Otaviani, 1986).

Table 1.4 gives the water hydraulic conductivities of the tuffs. The permeability of the Apache Leap tuff is low and is comparable to that of the Topopah Spring tuff. These two rocks have about two orders of magnitude lower permeability than the A-Mountain tuff. This is probably because the A-Mountian tuff has a higher porosity and lower density (Table 1.5). The density of Apache Leap tuff is slightly higher than that of Topopah Spring tuff. This does not mean that the Apache Leap tuff has a higher degree of welding. The welding does not necessarily decrease the porosity nor increase the density. Welding usually decreases the connectivity of voids, which leads to a decrease in the permeability of the tuff. 
Table 1.1 Chemical Composition of Tuffs

\begin{tabular}{|c|c|c|c|c|}
\hline & $\begin{array}{l}\text { Non-Welded } \\
\text { Unit of } \\
\text { A-Mountain } \\
\text { Tuff } \\
(8)\end{array}$ & $\begin{array}{l}\text { Brown Unit } \\
\text { of } \\
\text { Apache Leap } \\
\text { Tuff } \\
(\&)\end{array}$ & $\begin{array}{c}\text { Topopah } \\
\text { Spring } \\
\text { Tuff } \\
(8)\end{array}$ & $\begin{array}{c}\text { Topopah } \\
\text { Spring } \\
\text { Tuff* } \\
\text { (wt \&) }\end{array}$ \\
\hline $\mathrm{SiO}_{2}$ & 76.9 & 71.7 & 76.8 & 73.2 \\
\hline $\mathrm{Na}_{2} \mathrm{O}$ & 3.7 & 3.8 & 4.1 & 3.65 \\
\hline $\mathrm{K}_{2} \mathrm{O}$ & 3.9 & 2.5 & 3.8 & 4.89 \\
\hline $\mathrm{CaO}$ & 0.4 & 2.5 & 0.3 & 2.10 \\
\hline MgO & 0.21 & 0.85 & 0.11 & 0.25 \\
\hline $\mathrm{Al}_{2} \mathrm{O}_{3}$ & 12.2 & 14.8 & 12.4 & 12.1 \\
\hline $\mathrm{Fe}_{2} \mathrm{O}_{3}$ & 1.0 & 3.3 & 1.0 & 1.10 \\
\hline $\mathrm{FeO}$ & 0.05 & 0.10 & 0.05 & \\
\hline $\mathrm{TiO}_{2}$ & & & & 0.10 \\
\hline Mno & & & & 0.112 \\
\hline $\mathrm{P}_{2} \mathrm{O}_{5}$ & & & & 0.11 \\
\hline $\mathrm{SO}_{3}$ & & & & $<0.1$ \\
\hline
\end{tabular}

*From Malek and Roy (1985). 
Table 1.2 Chemical Composition of Brown Unit of Apache Leap Tuff

\begin{tabular}{|c|c|c|c|}
\hline & $\begin{array}{c}\text { Rock } \\
\text { Matrix } \\
(8)\end{array}$ & $\begin{array}{c}\text { Inclusion } \\
(8)\end{array}$ & $\begin{array}{c}\text { Fracture- } \\
\text { Filling } \\
\text { Material } \\
(8)\end{array}$ \\
\hline $\mathrm{SiO}_{2}$ & 68.9 & 68.1 & 70.7 \\
\hline $\mathrm{Na}_{2} \mathrm{O}$ & 3.7 & 3.4 & 3.2 \\
\hline $\mathrm{K}_{2} \mathrm{O}$ & 3.6 & 2.4 & 3.1 \\
\hline $\mathrm{CaO}$ & 2.8 & 3.4 & 2.5 \\
\hline $\mathrm{MgO}$ & 1.1 & 1.7 & 0.9 \\
\hline $\mathrm{Al}_{2} \mathrm{O}_{3}$ & 15.4 & 15.1 & 14.2 \\
\hline $\mathrm{Fe}_{2} \mathrm{O}_{3}$ & 3.0 & 4.4 & 3.4 \\
\hline $\mathrm{FeO}$ & $<0.1$ & $<0.1$ & $<0.1$ \\
\hline Mno & 0.01 & 0.04 & 0.10 \\
\hline $\mathrm{P}_{2} \mathrm{O}_{5}$ & 0.06 & 0.06 & 0.05 \\
\hline $\mathrm{SO}_{3}$ & $<0.01$ & $<0.01$ & $<0.01$ \\
\hline $\mathrm{TiO}_{2}$ & 0.04 & 0.09 & 0.04 \\
\hline
\end{tabular}


Table 1.3 Mineral Composition of Apache Leap Tuff

\begin{tabular}{|c|c|c|c|c|c|}
\hline & \multirow{2}{*}{$\begin{array}{l}\text { Average } \\
\text { Grain } \\
\text { Size }\end{array}$} & \multicolumn{4}{|c|}{ Sample Number } \\
\hline & & $\begin{array}{l}\text { AP19-1 } \\
-2-M I 1\end{array}$ & $\begin{array}{l}\text { AP19-1 } \\
-2-M I 2\end{array}$ & $\begin{array}{l}\text { AP19-1 } \\
-2-\text { MI3 }\end{array}$ & $\begin{array}{l}\text { AP19-1 } \\
-2-M I 4\end{array}$ \\
\hline Olivine & $1 \times 1 \mu \mathrm{m}$ & $5 \%$ & 108 & 158 & 158 \\
\hline $\begin{array}{l}\text { Plagioclase } \\
+ \text { quartz } \\
\text { phenocryst }\end{array}$ & $3 \times 3 \mathrm{~mm}$ & 508 & 458 & 508 & 508 \\
\hline $\begin{array}{l}\text { Plagioclase } \\
\quad+\text { quartz } \\
\text { groundmass }\end{array}$ & $10 \times 10 \mu \mathrm{m}$ & 58 & 58 & 58 & 58 \\
\hline Magnetite & $0.5 \times 0.5 \mathrm{~mm}$ & 108 & 88 & 58 & 58 \\
\hline Hematite & $0.5 \times 0.5 \mu \mathrm{m}$ & 258 & 308 & 258 & 308 \\
\hline $\begin{array}{l}\text { Vesicles/ } \\
\text { cavities }\end{array}$ & $1 \times 1 \mu \mathrm{m}$ & $<18$ & $<18$ & $<18$ & $<18$ \\
\hline
\end{tabular}

Table 1.4 Water Hydraulic Conductivities of Saturated Tuffs

\begin{tabular}{|c|c|c|c|}
\hline & $\begin{array}{l}\text { Hydraulic } \\
\text { Conductivity } \\
(\mathrm{cm} / \mathrm{s})\end{array}$ & $\begin{array}{l}\text { Test } \\
\text { Method }\end{array}$ & Source \\
\hline $\begin{array}{l}\text { Apache Leap tuff, } \\
\text { densely welded } \\
\text { brown unit }\end{array}$ & $<10^{-11}-10^{-9}$ & $\begin{array}{c}\text { Radial } \\
\text { Permeameter } \\
\text { Test }\end{array}$ & $\begin{array}{l}\text { Fuenkajorn and } \\
\text { Daemen }\end{array}$ \\
\hline $\begin{array}{l}\text { Topopah Spring } \\
\text { Tuff }\end{array}$ & $<10^{-10}-10^{-8}$ & - & $\begin{array}{l}\text { Zimmerman et al. } \\
(1985) \text { and } \\
\text { Anderson (1981) }\end{array}$ \\
\hline $\begin{array}{l}\text { A-Mountain tuff, } \\
\text { nonwelded unit }\end{array}$ & $<10^{-8}-10^{-7}$ & $\begin{array}{c}\text { Falling Head } \\
\text { Test }\end{array}$ & $\begin{array}{l}\text { Fuenkajorn and } \\
\text { Daemen }\end{array}$ \\
\hline
\end{tabular}

*Fuenkajorn, K. and J.J.K. Daemen, 1991, "Borehole Stability in Densely Welded Tuffs," Technical Report NUREG/CR-5687, U.S. Nuclear Regulatory Commission. (In preparation) 
Table 1.5 Porosity and Density of Tuffs

\begin{tabular}{|c|c|c|c|c|}
\hline $\begin{array}{l}\text { Rock } \\
\text { Type }\end{array}$ & $\begin{array}{c}\text { Porosity } \\
(8)\end{array}$ & $\begin{array}{c}\text { Measurement } \\
\text { Methods } \\
\end{array}$ & $\begin{array}{l}\text { Dry Density } \\
(\mathrm{g} / \mathrm{cc})\end{array}$ & Sources \\
\hline $\begin{array}{l}\text { Apache Leap } \\
\text { Tuff (Brown } \\
\text { Unit) }\end{array}$ & 1 & Petrographical study & $2.37 \pm 0.42$ & Table 1.3 (Section 2.1) \\
\hline$n$ & 10 & $\begin{array}{l}\text { Bulk and solid density } \\
\text { measurements }\end{array}$ & & Ouyang and Daemen* \\
\hline$"$ & $6.1-6.7$ & $\begin{array}{c}\text { Bulk and solid density } \\
\text { measurements }\end{array}$ & 2.4 & Evans (1983) \\
\hline$n$ & $5.91 \bullet 0.07$ & Mercury porosimetry & 2.45 & Vogt (1988) \\
\hline $\begin{array}{l}\text { A-Mountain } \\
\text { Tuff }\end{array}$ & $15-20$ & Petrographic study & $1.92 \pm .30$ & Table A.3 (Appendix A) \\
\hline $\begin{array}{c}\text { Topopah } \\
\text { Spring Tuff }\end{array}$ & $6-20$ & & $2.0-2.3$ & Anderson (1981) \\
\hline
\end{tabular}

*Ouyang, S. and J.J.K. Daemen, 1991, "Sealing Performance of Bentonite and Bentonite/Crushed Rock Borehole Plugs," Technical Report NUREG/CR-5685, U.S. Nuclear Regulatory Commission. (In preparation) 


\section{CHARAGTERIZATION TESTING}

This chapter describes methods and results of the characterization experiments of the brown unit of the Apache Leap tuff. The effort is divided into four tasks: uniaxial compression, Brazilian tension, seismic velocity, and triaxial compression tests. The uniaxial test measures the uniaxial compressive strength and elastic properties. The effects of length-to-diameter ratio, of loading rate and of cyclic loading are investigated. The Brazilian test gives the indirect splitting tensile strength of the rock, including its size effect. Dynamic Young's modulus and Poisson's ratio are determined from the seismic velocity measurements. The triaxial compression test measures the failure stresses under confining pressures up to $62 \mathrm{MPa}$. Strength criteria that give the best representation of the failure envelope are determined. A new empirical criterion has been derived to describe compressive failure of the tuff. Discussion of the test results and comparisons of the mechanical properties of Apache Leap tuff with those of Topopah Spring tuff (at Yucca Mountain) are given at the end of the chapter.

\subsection{Uniaxial Compression Test}

The prime objective of the uniaxial compression test is to determine the Young's modulus, Poisson's ratio and the uniaxial compressive strength using ASTM D2938 and D3184 standard practices. Additional tests are performed to study the effects of length-to-diameter ratio, loading rate, cyclic loading, and sample size. Sample diameters range from 50 $\mathrm{mm}$ to $102 \mathrm{~mm}$, the $\mathrm{L} / \mathrm{D}$ ratios from 2 to 3 , and the constant strain rates from $10^{-8}$ to $10^{-4}$ per second. The number of samples used for each set of test parameters varies from 5 to 13 .

\subsubsection{Uniaxial Compressive Strength and Elastic Properties.}

Uniaxial compression tests have been performed on thirteen Apache Leap tuff specimens. Sample preparation, test procedure and method of calculation follow the ASTM standard practice (ASTM D2938), which is similar to the ISRM suggested method (Bieniawski et al., 1978). The cylindrical specimens are prepared from tuff blocks no. AP11, AP13, AP14 and AP19. The nominal diameter and length are $50 \mathrm{~mm}$ and $128 \mathrm{~mm}$, respectively. All samples, except AP11-2-2-UN2, meet the ASTM side smoothness requirements. Fifty percent of the samples meet the end perpendicularity requirement (Table 2.1). The lack of compliance of many samples is due to the presence of voids on the sample surfaces. The loading rate used in the test is $390 \mathrm{kPa} /$ second. 
Table 2.1 Perpendicularity and Smoothness of Apache Leap Tuff Samples Used in Uniaxial Compression Test, Compared with ASTM Requirements (ASTM D2938, Section 4)

\begin{tabular}{|l|c|c|c|}
\hline $\begin{array}{c}\text { Sample } \\
\text { Number }\end{array}$ & $\begin{array}{c}\text { Side Smoothness } \\
(<0.02 \text { in })\end{array}$ & \multicolumn{2}{c|}{$\begin{array}{c}\text { Perpendicularity } \\
(<0.005 \text { in })\end{array}$} \\
\hline AP11-1-2-UN1 & $0.013 *$ & 0.007 & $0.004 *$ \\
\hline AP11-2-2-UN2 & 0.028 & $0.004 *$ & 0.007 \\
\hline AP11-3-2-UN1 & $0.020 *$ & $0.004 *$ & 0.006 \\
\hline AP11-4-2-UN2 & $0.014 *$ & $0.004 *$ & $0.005 *$ \\
\hline AP13-1-2-UN5 & $0.018 *$ & 0.006 & $0.003 *$ \\
\hline AP13-2-2-UN6 & $0.018 *$ & $0.002 *$ & $0.005 *$ \\
\hline AP13-4-2-UN7 & $0.011 *$ & $0.004 *$ & $0.003 *$ \\
\hline AP14-1-2-UN8 & $0.017 *$ & 0.006 & $0.005 *$ \\
\hline AP14-3-2-UN9 & $0.004 *$ & $0.004 *$ & $0.004 *$ \\
\hline AP19-1-2-UN10 & $0.010 *$ & $0.004 *$ & 0.006 \\
\hline AP19-2-2-UN11 & $0.012 *$ & - & - \\
\hline AP19-3-2-UN12 & $0.009 *$ & $0.003 *$ & $0.003 *$ \\
\hline AP19-5-2-UN13 & $0.009 *$ & $0.004 *$ & $0.003 *$ \\
\hline
\end{tabular}

* indicates that the measurement meets ASTM requirements 
Table 2.2 gives the results of the uniaxial compression tests. Mean and standard deviation of the uniaxial compressive strength are 73.2 and $16.5 \mathrm{MPa}$, respectively. The failure planes usually make an angle of approximately 30 degrees with the core axis. Figure 2.1 shows some of the tested specimens.

Electrical resistance strain gages have been installed on five uniaxial compression test specimens. The gages measure the circumferential and axial strains. Gage installation, method of measurement and test procedure follow the ASTM D3184 standard practice, which is similar to the ISRM suggested method (Bieniawski et al., 1978). The elastic modulus and Poisson's ratio are given in Table 2.3. The circumferential strain is plotted as a function of the axial strain in Figure 2.2. Figure 2.3 gives the axial stress-strain curves. Mean and standard deviation of the elastic modulus are 22.6 and $5.7 \mathrm{GPa}$, respectively. The lateral strain strongly suggests that the Apache Lap tuff is not a linearly elastic rock, and hence that a description of the stiffness in terms of single elastic parameters $E$ and $v$ is not fully satisfactory. The (tangent) Poisson's ratio at 508 of the compressive strength is $0.20 \pm 0.03$.

\subsubsection{Effect of Length to Diameter Ratio on Uniaxial Compressive Strength}

The purpose of this study is to determine the effect of the length-todiameter ratio of specimens on the uniaxial compressive strength of Apache Leap tuff. The L/D ratio used here covers the range suggested by the ISRM (Bieniawski, 1978) test method (i.e. L/D $=2.5$ to 3.0 ), as well as the range recommended by ASTM $D 2938(\mathrm{~L} / \mathrm{D}=2.0$ to 2.5 ).

\subsubsection{Rock Sample and Test Method}

Fifteen cylindrical specimens with a diameter of $50.2 \mathrm{~mm}$ are cut from core drilled normal to flow layers from an Apache Leap tuff block (no. AP40). The specimens have nominal length-to-diameter ratios of $2.0,2.5$ and 3.0 (five samples for each ratio). Both end surfaces of the cylinders are ground flat and parallel. Smoothness and perpendicularity of each sample are measured in accordance with the ASTM (D2938) standard practice. Table 2.4 gives the results of these measurements. Only four samples satisfy both perpendicularity and smoothness requirements. Most samples do not satisfy the ASTM requirements due to the presence of voids, vesicles and inclusions on the rock surfaces. Density of the samples averages $2.45 \pm 0.01 \mathrm{~g} / \mathrm{cc}$.

All rock cylinders are loaded to failure at an axial strain rate of 100 microstrains per second in an SBEL (CT 500) load frame with servocontroller. Failure load, test duration and failure mode are recorded. The compressive strength is calculated by assuming that the cross-sectional area remains constant during loading.

\subsubsection{Test Results}

Table 2.5 summarizes the results. The uniaxial compressive strengths of rock cylinders having $L / D$ ratios of $2.0,2.5$ and 3.0 are $91.18 \pm 25.08$, $99.70 \pm 19.30$ and $107.04 \pm 3.56$, respectively. Figure 2.4 gives the 
Table 2.2 Results of the Uniaxial Compressive Strength Tests on Apache Leap Tuff

\begin{tabular}{|l|c|c|c|}
\hline $\begin{array}{c}\text { Sample } \\
\text { Number }\end{array}$ & $\begin{array}{c}\text { Average } \\
\text { Diameter } \\
\text { (mm) }\end{array}$ & $\begin{array}{c}\text { Average } \\
\text { Length } \\
\text { (mm) }\end{array}$ & $\begin{array}{c}\text { Uniaxial } \\
\text { Compressive Strength } \\
\text { (MPa) }\end{array}$ \\
\hline AP11-1-2-UN1 & 50.5 & 127.2 & 83.0 \\
\hline AP11-2-2-UN2 & 50.5 & 127.5 & 87.9 \\
\hline AP11-3-2-UN3 & 50.5 & 127.7 & 69.0 \\
\hline AP11-4-2-UN4 & 50.4 & 127.5 & 70.9 \\
\hline AP13-2-2-UN6 & 50.5 & 127.9 & 78.6 \\
\hline AP13-4-2-UN7 & 50.5 & 127.7 & 84.3 \\
\hline AP14-1-2-UN8 & 50.6 & 128.2 & 63.9 \\
\hline AP14-3-2-UN9 & 50.6 & 127.9 & 59.8 \\
\hline AP19-1-2-UN10 & 50.6 & 127.6 & 96.1 \\
\hline AP19-2-2-UN11 & 50.6 & 127.7 & 98.2 \\
\hline AP19-3-2-UN12 & 50.6 & 127.0 & 64.6 \\
\hline AP19-5-2-UN13 & 50.6 & 127.6 & 228 \\
\hline \\
$\begin{array}{l}\text { Mean - Standard Deviation: } \\
\text { Coefficient of Variation: }\end{array}$ & & & $73.24 \pm 16.5$ \\
\hline
\end{tabular}

NOTE: Loading rate is $390 \mathrm{kPa} / \mathrm{s}$. 


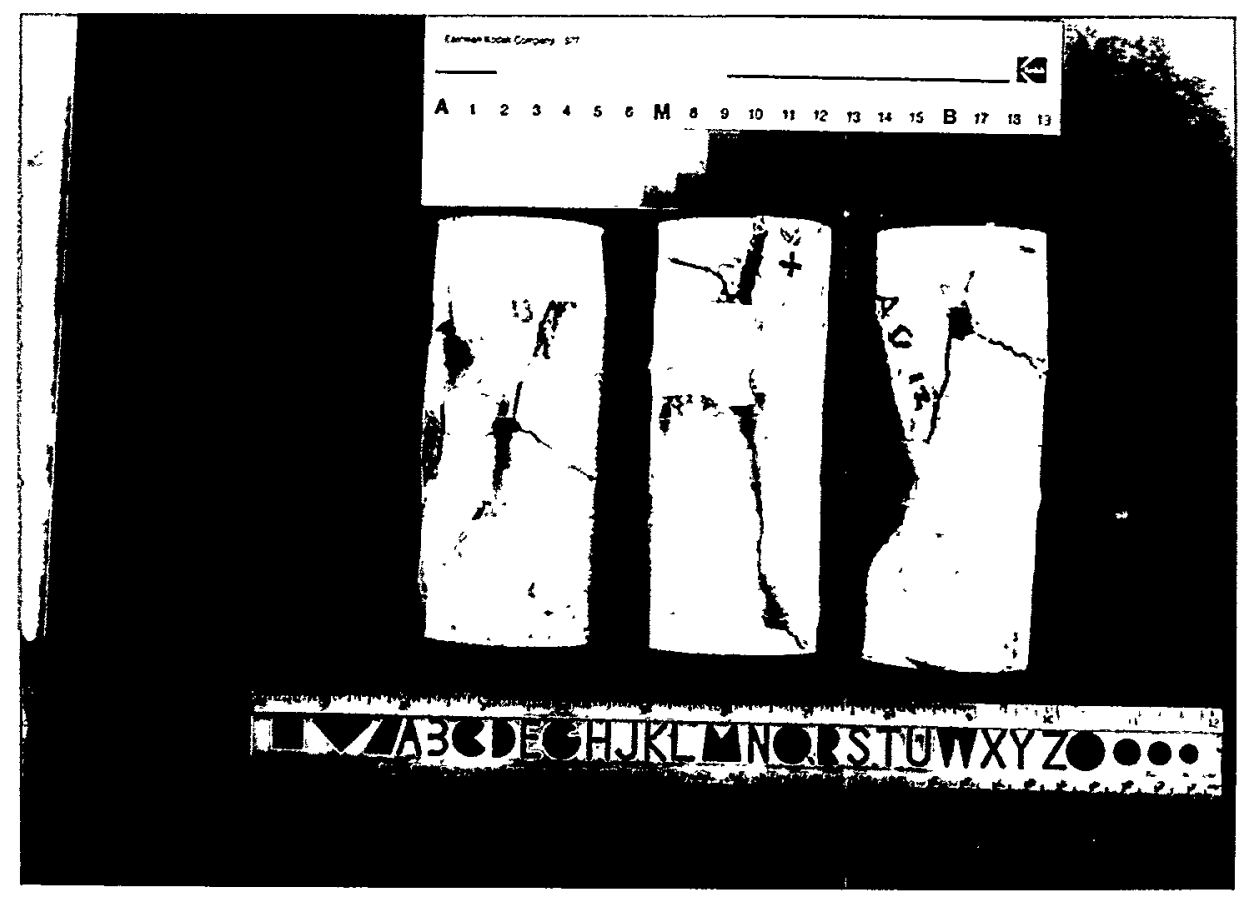

Figure 2.1 Apache Leap tuff specimens tested in uniaxial compression. The shear failure planes make an angle of approximately $30^{\circ}$ with the core axis. 
Table 2.3 Elastic Modulus and Poisson's Ratio of Apache Leap Tuff Obtained from Uniaxial Compression Tests: Measured at $50 \%$ Peak Stress

\begin{tabular}{|c|c|c|}
\hline Sample Number & $\begin{array}{l}\text { Elastic Modulus } \\
\text { (GPa) }\end{array}$ & Poisson's Ratio \\
\hline AP11-1-2-UN1 & 27.7 & 0.22 \\
\hline AP13-4-2-UN7 & 17.3 & 0.16 \\
\hline AP14-3-2-UN9 & 19.6 & 0.20 \\
\hline AP19-2-2-UN11 & 29.8 & 0.24 \\
\hline AP19-5-2-UN13 & 18.5 & 0.19 \\
\hline \multicolumn{2}{|c|}{$\begin{array}{l}\text { Means } \pm \text { Standard Deviation: } \\
\text { Coefficient of Variation }\end{array}$} & $\begin{array}{c}0.20 \pm 0.03 \\
158\end{array}$ \\
\hline
\end{tabular}




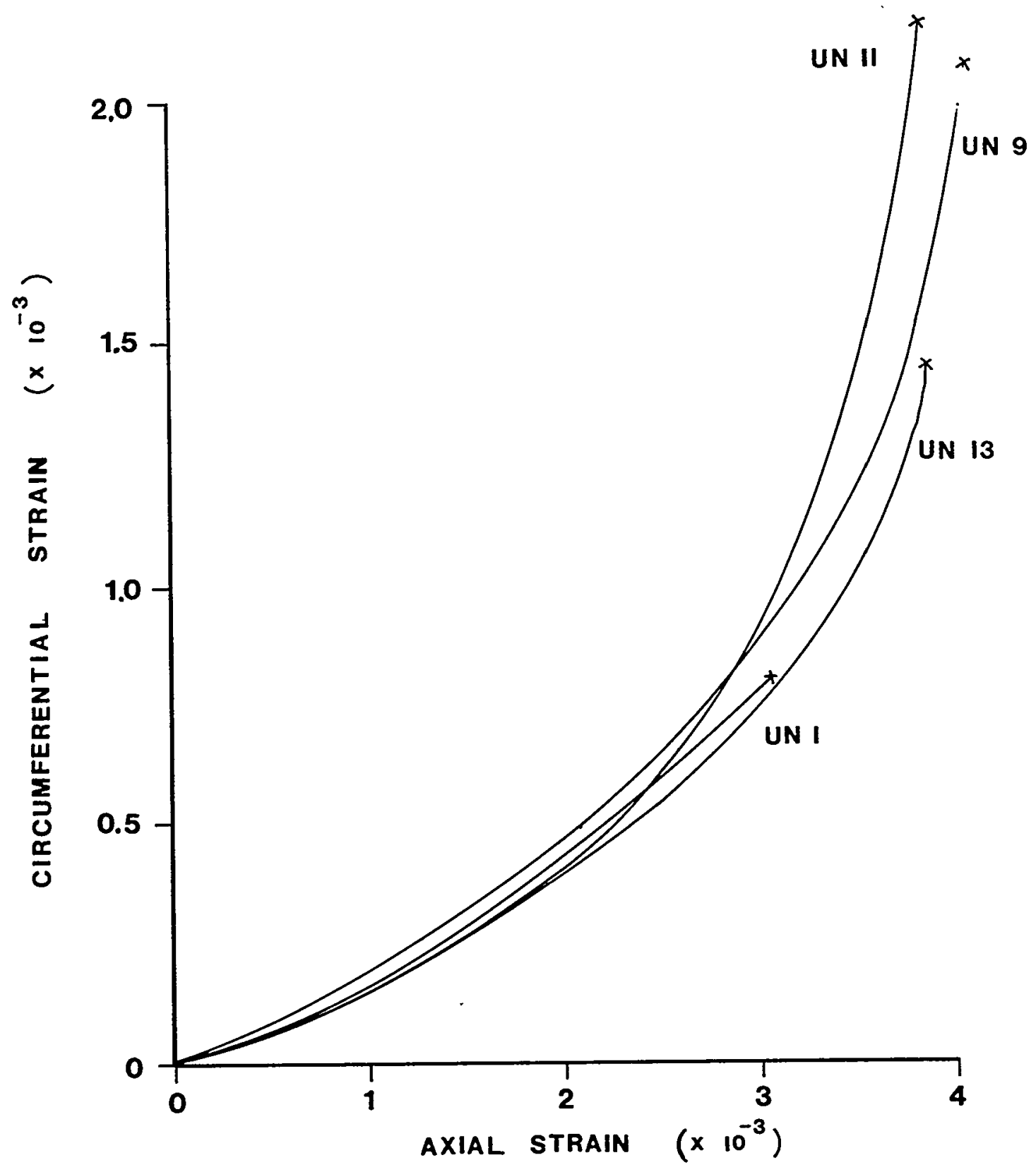

Figure 2.2 Circumferential strain as a function of axial strain. The strains are measured from uniaxial compression tests specimens AP11-1-2-UN1, AP14-3-2-UN9, AP19-2-2-UN11 and AP19-52-UN3 (Apache Leap tuff). The samples are loaded to failure $(X)$. The vertical scale is exaggerated. 


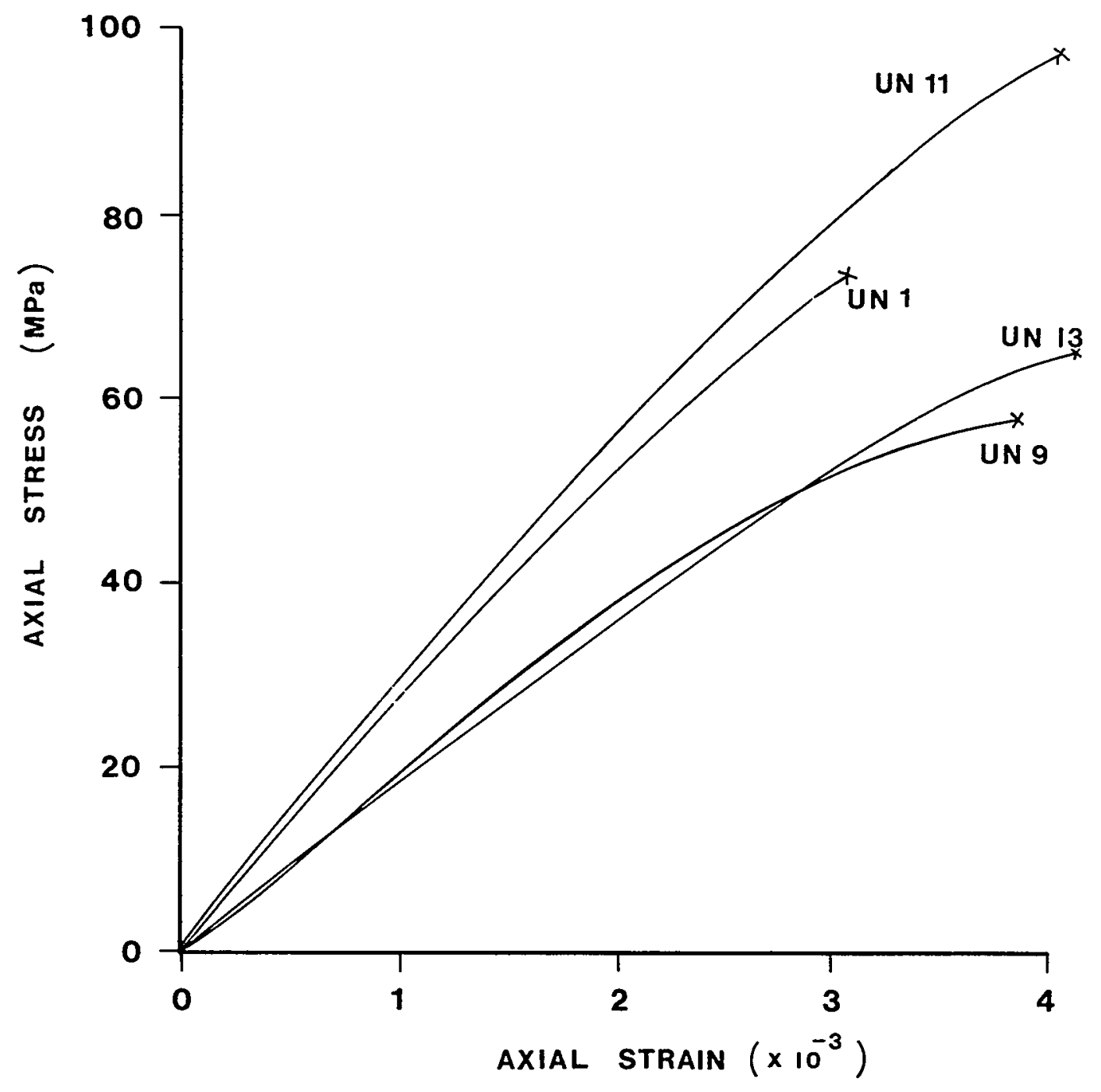

Figure 2.3 Axial stress-strain of Apache Leap tuff obtained from uniaxial compression test specimens AP11-1-2-UN1, AP14-3-2UN9, AP19-2-2-UN11 and AP19-5-2-UN3. 
Table 2.4 Perpendicularity and Smoothness of Apache Leap Tuff Cylinders Compared with ASTM Requirements

\begin{tabular}{|c|c|c|c|c|}
\hline \multirow[b]{2}{*}{ Sample Number } & \multirow{2}{*}{$\begin{array}{c}\text { Side } \\
\text { Smoothness } \\
(<0.02 \text { in })\end{array}$} & \multicolumn{2}{|c|}{$\begin{array}{l}\text { Perpendicularity } \\
(<0.005 \text { in })\end{array}$} & \multirow{2}{*}{$\begin{array}{c}\text { End } \\
\text { Smoothness } \\
\text { (degree) }\end{array}$} \\
\hline & & Top & Bottom & \\
\hline AP40-10b-2-UN1 & $0.012 *$ & 0.006 & 0.025 & $0.17 *$ \\
\hline AP40-4-2-UN2 & $0.020 *$ & 0.023 & 0.010 & 0.67 \\
\hline AP40-8 - 2-UN3 & $0.007 *$ & $0.003 *$ & $0.005 *$ & $0.14 *$ \\
\hline AP40-6a-2-UN4 & $0.019 *$ & $0.003 *$ & $0.004 *$ & $0.12 *$ \\
\hline$A P 40-9 a-2-U N 5$ & $0.010 *$ & $0.004 *$ & 0.007 & $0.20 *$ \\
\hline AP40-10a-2.5-UN6 & 0.022 & 0.011 & $0.002 *$ & 0.32 \\
\hline AP40-9a-2.5-UN7 & $0.009 *$ & $0.003 *$ & 0.006 & $0.17 *$ \\
\hline AP40-9b-2.5-UN8 & 0.039 & $0.004 *$ & 0.023 & 0.67 \\
\hline $\mathrm{AP} 40-10-2.5-\mathrm{UN} 10$ & $0.019 *$ & 0.016 & $0.003 *$ & 0.46 \\
\hline AP40-5-2.5-UN11 & 0.036 & 0.008 & 0.007 & $0.23 *$ \\
\hline AP40-7a-3-UN9 & $0.009 *$ & $0.005 *$ & $0.004 *$ & $0.14 *$ \\
\hline AP40-7b-3-UN12 & 0.039 & 0.008 & 0.007 & $0.23 *$ \\
\hline AP40-3b-3-UN13 & $0.010 *$ & $0.005 *$ & $0.004 *$ & $0.14 *$ \\
\hline AP40-4a-3-UN14 & $0.013 *$ & 0.008 & 0.012 & 0.38 \\
\hline AP40-4b-3-UN15 & 0.028 & 0.038 & 0.012 & 1.10 \\
\hline
\end{tabular}

* indicates that the measurement meets ASTM Standard D2938 requirements 
Table 2.5 Results of Uniaxial Compression Test of Apache Leap Tuff Cylinders with Different L/D Ratios

\begin{tabular}{|c|c|c|c|c|c|c|}
\hline $\begin{array}{l}\text { Sample } \\
\text { Number }\end{array}$ & $\begin{array}{l}\text { Length } \\
(\mathrm{mm})\end{array}$ & $\begin{array}{l}\text { Diameter } \\
(\mathrm{mm})\end{array}$ & $\begin{array}{l}\text { Density } \\
(g / c c)\end{array}$ & $\begin{array}{c}\mathrm{L} / \mathrm{D} \\
\text { Ratio }\end{array}$ & $\begin{array}{l}\text { Test } \\
\text { Duration } \\
\text { (min:s) }\end{array}$ & $\begin{array}{c}\text { Failure } \\
\text { Stress } \\
(\mathrm{MPa})\end{array}$ \\
\hline$A P 40-10 b-2-U N 1$ & 101.4 & 50.2 & 2.45 & 2.02 & $3: 10$ & 65.08 \\
\hline $\mathrm{AP} 40-4-2-\mathrm{UN} 2$ & 98.9 & 50.2 & 2.43 & 1.97 & $3: 15$ & 67.33 \\
\hline AP40-8-2-UN3 & 101.0 & 50.2 & 2.44 & 2.01 & $3: 18$ & 92.11 \\
\hline AP40-6a-2-UN4 & 100.0 & 50.2 & 2.46 & 1.99 & $3: 33$ & 121.31 \\
\hline AP40-9a-2-UN5 & 99.9 & 50.2 & 2.45 & 1.99 & $4: 09$ & 110.08 \\
\hline \multicolumn{4}{|c|}{ Mean \pm Standard Deviation } & $\begin{array}{l}2.00 \\
\pm 0.02\end{array}$ & & $\begin{array}{r}91.18 \\
+25.08\end{array}$ \\
\hline \multicolumn{4}{|c|}{ Coefficient of Variation } & 18 & & 288 \\
\hline AP40-10a-2.5-UN6 & 128.1 & 50.2 & 2.44 & 2.55 & $4: 26$ & 114.35 \\
\hline AP40-9a-2.5-UN7 & 124.1 & 50.2 & 2.46 & 2.47 & $4: 18$ & 112.32 \\
\hline AP40-9a-2.5-UN8 & 124.4 & 50.2 & 2.46 & 2.48 & $3: 51$ & 114.68 \\
\hline AP40-10-2.5-UN10 & 125.9 & 50.2 & 2.45 & 2.51 & $5: 38$ & 78.70 \\
\hline AP40-5-2.5-UN11 & 127.2 & 50.2 & 2.45 & 2.53 & $3: 26$ & 78.47 \\
\hline \multicolumn{4}{|c|}{ Mean \pm Standard Deviation } & $\begin{array}{l}2.51 \\
\pm 0.03\end{array}$ & & $\begin{array}{r}99.70 \\
\pm 19.30\end{array}$ \\
\hline \multicolumn{4}{|c|}{ Coefficient of Variation } & 18 & & 198 \\
\hline AP40-7a-3-UN9 & 152.5 & 50.3 & 2.46 & 3.03 & $4: 14$ & 109.65 \\
\hline AP40-7b-3-UN12 & 154.6 & 50.2 & 2.46 & 3.08 & $4: 49$ & 100.99 \\
\hline AP40-3b-3-UN13 & 150.9 & 50.2 & 2.46 & 3.00 & $4: 22$ & 107.73 \\
\hline AP40-4a-3-UN14 & 152.8 & 50.3 & 2.47 & 3.04 & 4.23 & 109.65 \\
\hline AP40-4b-3-UN15 & 150.2 & 50.3 & 2.46 & 2.98 & $4: 01$ & 107.20 \\
\hline \multicolumn{4}{|c|}{ Mean \pm Standard Deviation } & 3.03 & & 107.04 \\
\hline \multicolumn{4}{|c|}{ Coefficient of Variation } & 18 & & 38 \\
\hline
\end{tabular}




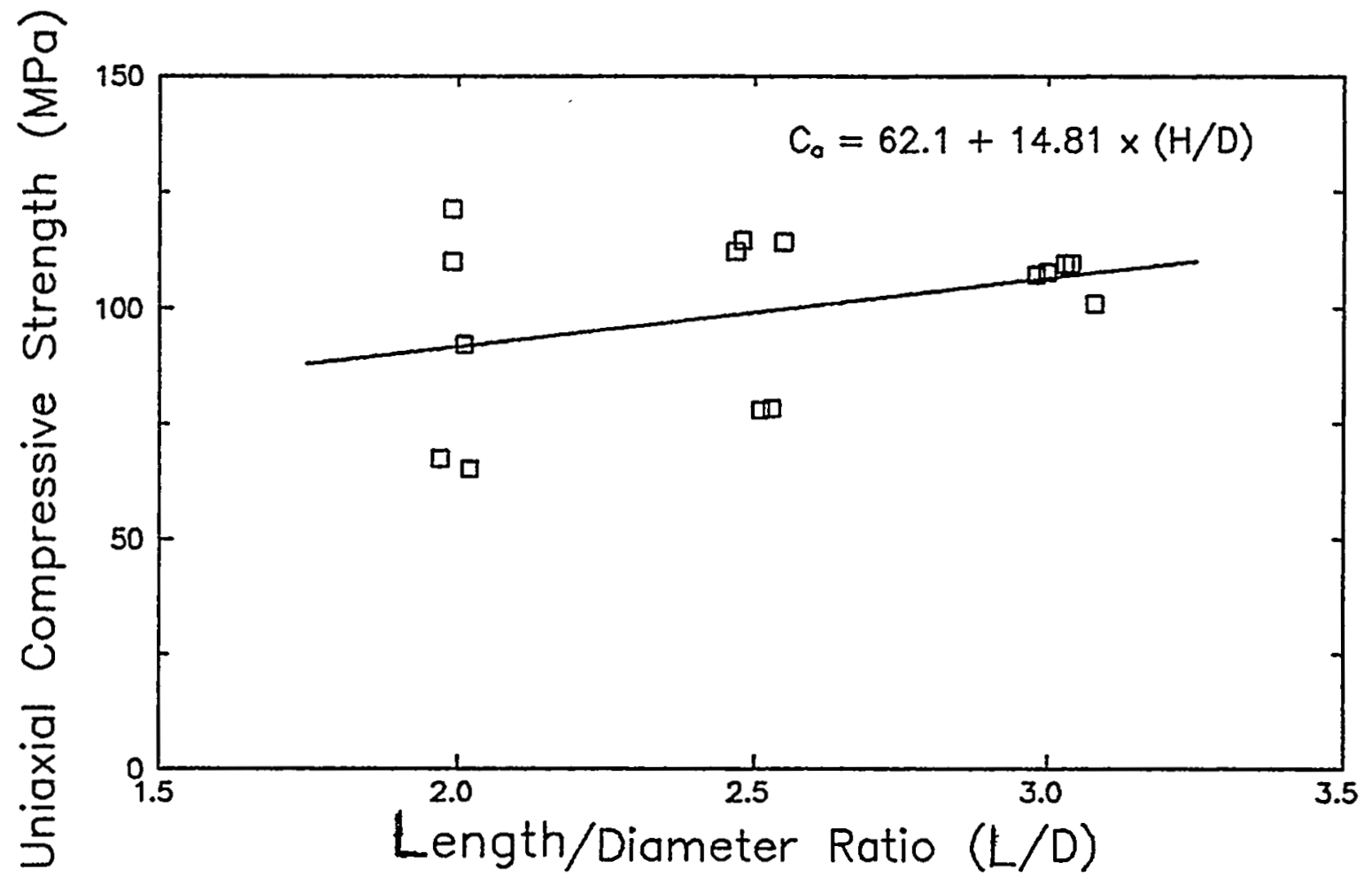

Figure 2.4 Uniaxial compressive strength as a function of length-todiameter ratio. Test data (points) and linear regression results (line). 
compressive strengths as a function of $\mathrm{L} / \mathrm{D}$ ratio. Linear regression analysis suggests that the strength $\left(C_{0}\right)$ increases as the $L / D$ ratio increases: $C_{o}=62.1+14.81(\mathrm{~L} / \mathrm{D})$, for $2 \leq \mathrm{L} / \mathrm{D} \leq 3$, but this relation is statistically very uncertain. This strength increase is in conflict with the usual observation that the uniaxial compressive strength decreases with increasing L/D ratio (e.g. Jaeger and Cook, 1979, Section 6.2). Coefficients of variation of the strength (Table 2.2) tend to decrease with increasing $L / D$ ratio. This implies that more consistent strength results are obtained by testing samples with large L/D ratios (about 3). This might be explained by the fact that large L/D ratios minimize the end effect (i.e. friction between loading platens and sample end surfaces) which may cause the variation of test results, or that the tuff samples failed in shear (observed from long specimens) yield more consistent failure stresses than do the ones failed in tensile splitting (observed from short specimens). These conclusions and implications suggest that the L/D ratio of 2.5 to 3.0 recommended by the ISRM (Bieniawski et al., 1978) may be more appropriate for tuff testing than the ASTM-recommended L/D ratio of 2.0 to 2.5. More specimens need to be tested to confirm this conclusion, as well as to establish relations, if any, between strength and cylinder length. The shear failure planes have an angle of approximately $30^{\circ}$ with the core axis.

\subsubsection{Effect of Strain Rate on Compressive Strength}

The purpose of this testing is to determine the effect of the axial strain rate on the uniaxial compressive strength of Apache Leap tuff. The strain rate ranges from $0.022 \times 10^{-6}$ to $96 \times 10^{-6}$ second $^{-1}$.

\subsubsection{Rock Samples and Test Method}

Ten cylindrical samples with L/D ratios of 2 have been prepared from Apache Leap tuff. Five samples have been cut from $95 \mathrm{~mm}$ diameter core drilled from tuff block no. AP21. Five samples having a diameter of 101 $\mathrm{mm}$ have been obtained from tuff block no. APSHFT6. The sample axis is perpendicular to the flow layers. Smoothness and perpendicularity of the samples are measured in accordance with the ASTM (D2938) standard practice. Table 2.6 summarizes the results. Only four samples satisfy the side smoothness requirement. None satisfies the end perpendicularity requirement. This is due to the presence of voids on the rock surfaces. This lack of compliance implies that application of the smoothness and perpendiculariy requirements for $50 \mathrm{~mm}$ diameter samples may not be appropriate for $101 \mathrm{~mm}$ diameter samples or that the sample preparation method is not adequate. Density of the samples averages $2.47 \mathrm{~g} / \mathrm{cc}$.

An SBEL (CT 500) load frame with servocontroller is used to apply axial load to the samples at constant strain rates. The axial strain rates range from $0.022 \times 10^{-6}$ to $96 \times 10^{-6}$ second $^{-1}$. The axial and lateral strains are measured by means of electrical strain gages installed at the midsection of the cylinder. All samples are loaded to failure. The axial load-displacement curve and axial-lateral displacement curve are plotted using an $X-Y-Y$ plotter. 
Table 2.6 Dimensions of Apache Leap Tuff Specimens Used in Strain Rate Effect Study

\begin{tabular}{lccccc}
$\begin{array}{c}\text { Sample } \\
\text { Number }\end{array}$ & $\begin{array}{c}\text { Diameter } \\
(\mathrm{mm})\end{array}$ & $\begin{array}{c}\text { Length } \\
(\mathrm{mm})\end{array}$ & $\begin{array}{c}\text { Density } \\
(\mathrm{g} / \mathrm{cc})\end{array}$ & $\begin{array}{c}\text { ASTM D2938 } \\
\text { Side } \\
\text { Smooth- } \\
\text { ness }\end{array}$ & $\begin{array}{c}\text { Specification } \\
\text { End } \\
\text { Perpendic- } \\
\text { ularity }\end{array}$ \\
\hline & & & & & \\
-5-SNUN1 & 95.3 & 192.7 & 2.42 & $*$ & $\mathrm{X}$ \\
-3-SNUN2 & 95.4 & 190.3 & 2.42 & $*$ & $\mathrm{X}$ \\
-4-SNUN3 & 95.4 & 187.5 & 2.42 & $\mathrm{X}$ & $\mathrm{X}$ \\
-6-SNUN5 & 95.3 & 190.1 & 2.42 & $\mathrm{X}$ & $\mathrm{X}$ \\
-7-SNUN4 & 95.3 & 191.8 & 2.42 & $\mathrm{X}$ & $\mathrm{X}$ \\
HFT6-5-SNUN6 & 102.1 & 200.7 & 2.53 & $\mathrm{X}$ & $\mathrm{X}$ \\
HFT6-4-SNUN7 & 102.0 & 197.0 & 2.53 & $\mathrm{X}$ & $\mathrm{X}$ \\
\hline HFT6-3-SNUN8 & 101.9 & 197.1 & 2.53 & $*$ & $*$ \\
\hline HFT6-1-SNUN10 & 102.0 & 197.2 & 2.53 & $*$ & $\mathrm{X}$ \\
\hline
\end{tabular}

*: complies with the ASTM standard

$\mathrm{X}$ : does not comply with the ASTM standard 


\subsubsection{Test Results}

Table 2.7 summarizes the results of the uniaxial compression tests. For each sample size, the strength tends to increase with increasing strain rate. Figure 2.5 gives the compressive strength as a function of axial strain rate. The average uniaxial compressive strength, elastic modulus, and Poisson's ratio are $126.19 \pm 13.42 \mathrm{MPa}, 34.3 \pm 1.5 \mathrm{GPa}$, and $0.21 \pm 0.02$, respectively. Linear regression analyses have been performed on the three parameters for both sample sizes. Table 2.8 gives the results. Figures 2.6 and 2.7 give the elastic modulus and Poisson's ratio as a function of strain rate. For all parameters, the coefficient of correlation $(R)$ is low. The number of tests is not statistically significant; therefore, no firm conclusions can be drawn. Observation on the post-test specimens shows that the high strain rates tend to induce splitting tensile fractures, whereas the low strain rates tend to induce shear failure, at an angle of about $30^{\circ}$ to the core axis.

\subsubsection{Effect of Cyclic Loading on Compressive Strength}

The purpose of this study is to determine the effect of cyclic loading on the uniaxial compressive strength of Apache Leap tuff. The test is performed by rapid axial loading and unloading of the rock sample until failure.

\subsubsection{Rock Samples and Test Method}

Five cylinders with a nominal diameter of $102 \mathrm{~mm}$ and length-to-diameter ratio of 2 have been prepared from Apache Leap tuff. The flow layers are perpendicular to the core axis. Four samples have been cored from tuff block no. AP44 and have a density of $2.31 \mathrm{~g} / \mathrm{cc}$. One sample, prepared from block no. AP47, has a density of $2.50 \mathrm{~g} / \mathrm{cc}$. Table 2.9 gives sample dimensions and loading parameters. Table 2.10 gives the perpendicularity and smoothness of the rock cylinders and compares them with the ASTM D2938 standard requirements. No sample satisfies all perpendicularity and end smoothness requirements. Three samples satisfy the side smoothness requirements. The difficulty encountered in preparing samples is probably due to the presence of inclusions and vesicles along the rock surfaces.

Cycles of loading and unloading are applied using an SBEL (CT 500) load frame with a servocontroller. Three samples have been tested to failure. Failure loads, number of loading cycles and mode of failure are recorded.

\subsubsection{Test Results}

Table 2.11 gives the results of cyclic loading tests. The average uniaxial compressive strength of $102 \mathrm{~mm}$ diameter samples of Apache Leap tuff is $126 \pm 13 \mathrm{MPa}$. It had been planned to cyclically load Sample AP44-1-4-CL1 at $63 \mathrm{MPa}$ ( 508 of the average compressive strength). The sample failed at $53.76 \mathrm{MPa}$ due to the presence of a previously undetected crack. It had been planned to cycle Sample AP44-2-4-CL2 to 95 $\mathrm{MPa}$ ( 758 compressive strength). The sample failed at $44.55 \mathrm{MPa}$. 
Table 2.7 Uniaxial Compressive Strength of Apache Leap Tuff Determined at Various Axial Strain Rates

\begin{tabular}{lcccc} 
Number & $\begin{array}{c}\text { Axial } \\
\text { Strain } \\
\text { Rate } \\
\left(\mathrm{x} 10^{-6} \mathrm{~s}^{-1}\right)\end{array}$ & $\begin{array}{c}\text { Uniaxial } \\
\text { Compressive } \\
\text { Strength } \\
\text { (MPa) }\end{array}$ & $\begin{array}{c}\text { Elastic } \\
\text { Modulus } \\
\text { (GPa) }\end{array}$ & $\begin{array}{c}\text { Poisson's } \\
\text { Ratio }\end{array}$ \\
\hline AP21-5-SNUN1 & 1.1 & 130.8 & 33.7 & 0.24 \\
AP21-3-SNUN2 & 18 & 124.6 & 34.0 & 0.19 \\
AP21-4-SNUN3 & 96 & 131.9 & 32.5 & 0.21 \\
AP21-6-SNUN5 & 2.6 & 125.4 & 33.6 & 0.24 \\
AP21-7-SNUN4 & 0.55 & 109.1 & 32.1 & 0.17 \\
APSHFT6-5-SNUN6 & 4.9 & 137.9 & 35.9 & 0.21 \\
APSHFT6-4-SNUN7 & 0.098 & 142.5 & 33.8 & 0.19 \\
APSHFT6-3-SNUN8 & 0.045 & 124.3 & 37.2 & 0.22 \\
APSHFT6-2-SNUN9 & 0.022 & 98.7 & 34.7 & 0.21 \\
APSHFT6-1-SNUN10 & 0.022 & 136.7 & 35.3 & 0.22 \\
& & 126.19 & 34.3 & 0.21 \\
Mean \pm Standard Deviation & \pm 13.42 & \pm 1.5 & \pm 0.02 \\
\multicolumn{2}{c}{ Coefficient of Variation } & 118 & 48 & 118 \\
\hline
\end{tabular}

NOTE: The elastic modulus and Poisson's ratio are determined at 508 failure stress. 


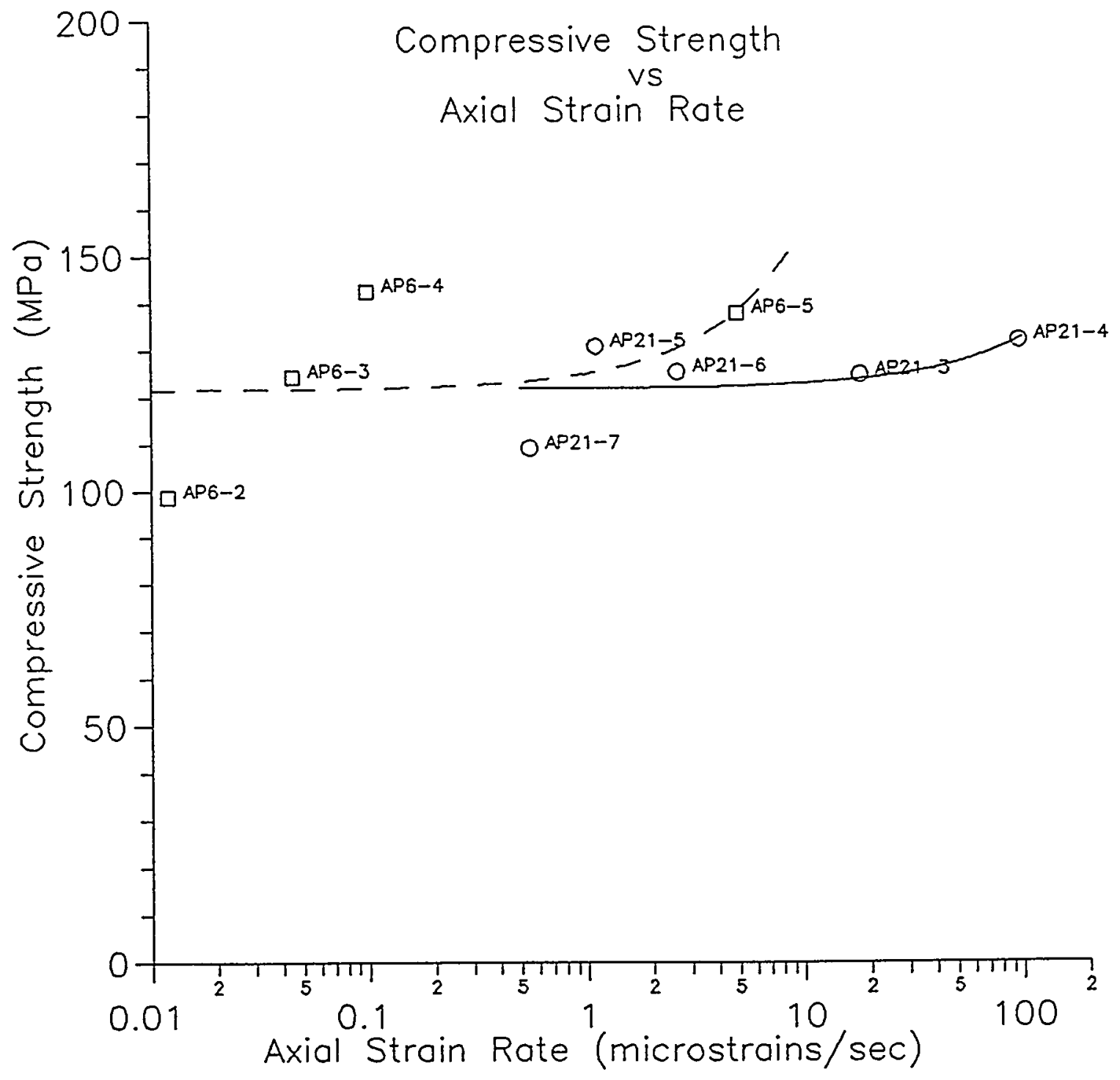

Figure 2.5 Uniaxial compressive strength as a function of axial strain rate. A linear fit applied to each data set indicates an increase in strength with increasing strain rate.

circles $=95 \mathrm{~mm}$ diameter samples

squares $=101 \mathrm{~mm}$ diameter samples. 
Table 2.8 Results of Linear Regression Analysis; Uniaxial Test on Apache Leap Tuff

Uniaxial Compressive Strength: $C_{0}=\alpha \epsilon_{R}+b$

For $95 \mathrm{~mm}$ samples:

$C_{0}=0.108 \epsilon_{R}+120.3 M P \alpha ; \quad R^{2}=0.237$

For $101 \mathrm{~mm}$ samples:

$C_{0}=3.149 \epsilon_{R}+121.5 M P a ; R^{2}=0.177$

Elastic Modulus:

$E=d \epsilon_{R}+l$

For $95 \mathrm{~mm}$ samples:

$E=-0.007 \epsilon_{R}+33.3 G P \alpha ; \quad R^{2}=0.119$

For $101 \mathrm{~mm}$ samples:

$E=0.056 \epsilon_{R}+36.6 G P \alpha ; \quad R^{2}=0.014$

Poisson's Ratio:

$v=i \epsilon_{R}+j$

For $95 \mathrm{~mm}$ samples

$v=0.21 ; R^{2}=0.003$

For $101 \mathrm{~mm}$ samples

$v=-0.003 \epsilon_{R}+0.18 ; \quad R^{2}=0.102$

where $\epsilon_{R}=$ strain rate in microstrains per second

$a, d, i=$ slope of the curve

$b, l, j=$ intercept. 


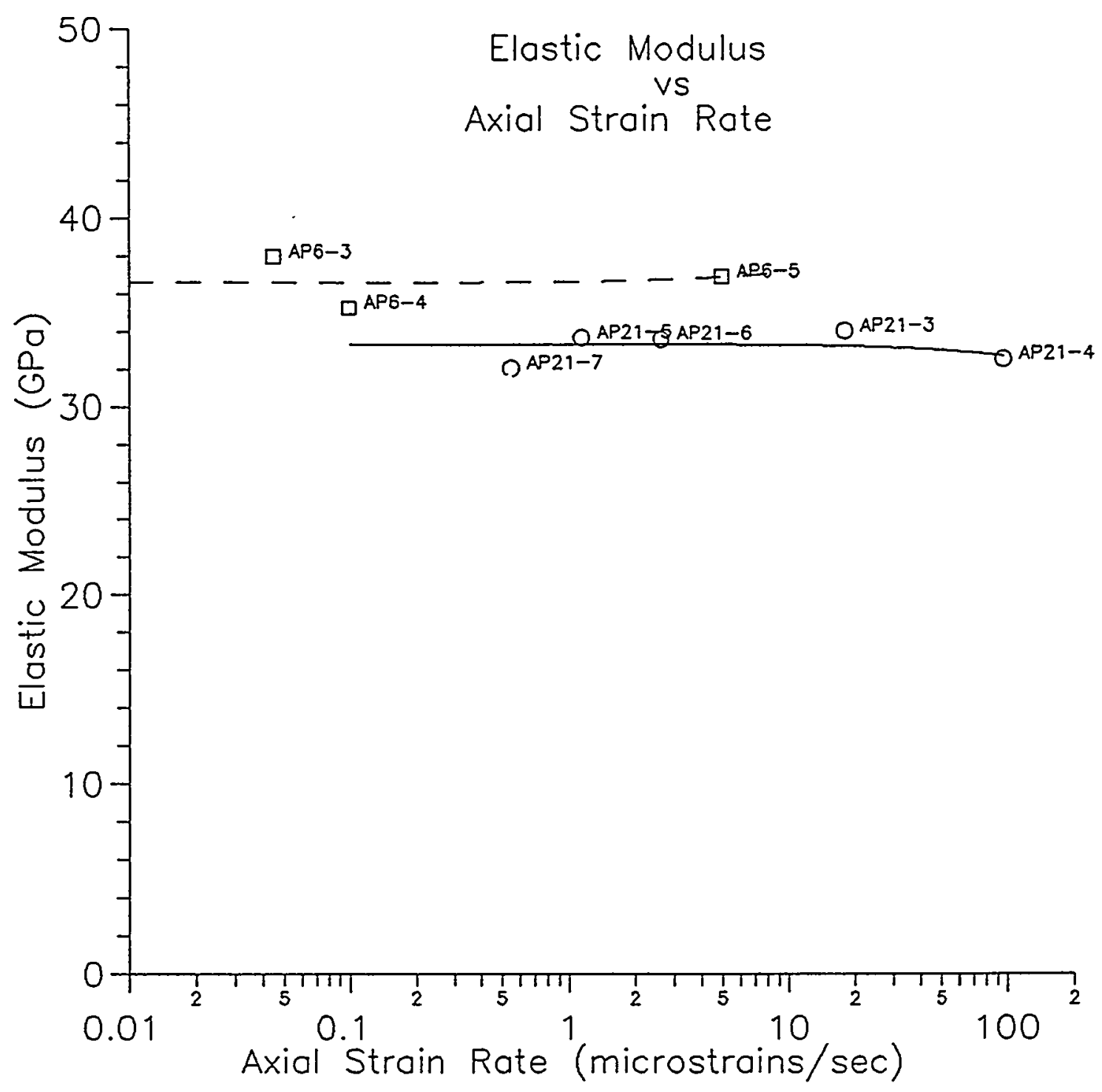

Figure 2.6 Elastic modulus as a function of axial strain rate. A linear fit applied to both data sets.

circles $=95 \mathrm{~mm}$ diameter samples

squares $=101 \mathrm{~mm}$ diameter samples. 


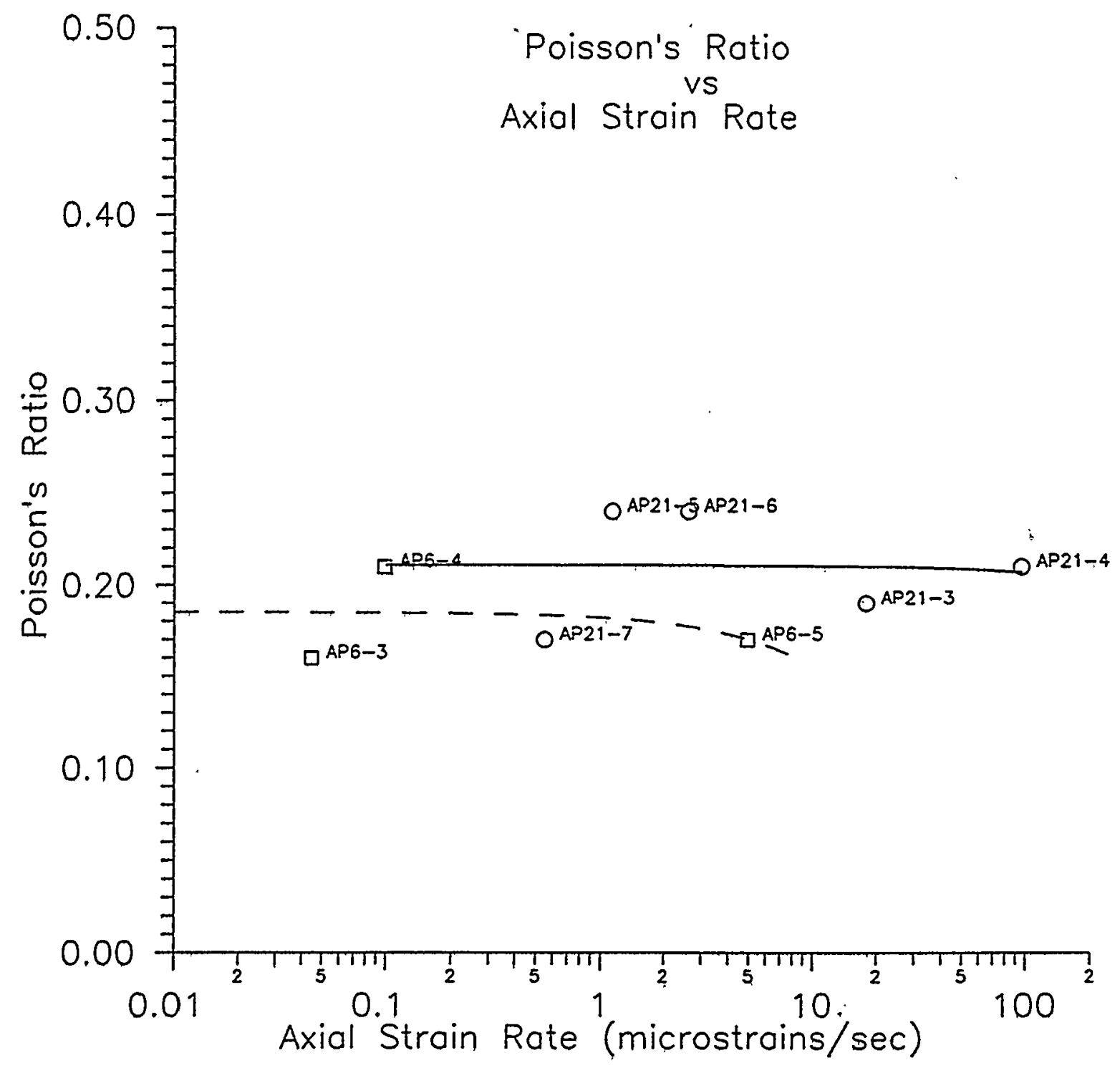

Figure 2.7 Poisson's ratio as a function of axial strain rate. A linear fit applied to both data sets.

circles $=95 \mathrm{~mm}$ diameter samples squares $\Rightarrow 101 \mathrm{~mm}$ diameter samples. 
Table 2.9 Dimensions and Density of Apache Leap Samples (Brown Unit) Used in Cyclic Loading Test

\begin{tabular}{|l|l|l|l|l|}
\hline Sample & Length & Diameter & Density & \multicolumn{1}{|c|}{ Cyclic Loading } \\
\hline No. & $(\mathrm{mm})$ & $(\mathrm{mm})$ & $(\mathrm{g} / \mathrm{cc})$ & \multicolumn{1}{|c|}{ Parameters } \\
\hline AP44-1-4-CL1 & 198.6 & 101.6 & 2.31 & $\begin{array}{l}508 \text { compressive } \\
\text { strength }\end{array}$ \\
\hline AP44-2-4-CL2 & 199.1 & 101.5 & 2.31 & $\begin{array}{l}758 \text { compressive } \\
\text { strength }\end{array}$ \\
\hline AP44-3-4-CL3 & 195.6 & 101.5 & 2.32 & Progressively increases \\
\hline AP44-4-4-CL4 & 198.1 & 101.4 & 2.50 & $\begin{array}{l}758 \text { revised failure } \\
\text { load }\end{array}$ \\
\hline AP47-4-4-CL5 & 198.1 & 101.4 & 2.50 & Progressively increases \\
\hline
\end{tabular}

NOTES: Compressive strength of $101 \mathrm{~mm}$ diameter samples of Apache Leap tuff is $126.2 \pm 13.4 \mathrm{MPa}$

Table 2.10 Perpendicularity and Smoothness of Apache Leap Tuff Samples (Brown Unit) used in Cyclic Loading Test, Compared with ASTM Standard D2938 Requirements

\begin{tabular}{|c|c|c|c|c|}
\hline $\begin{array}{l}\text { Sample } \\
\text { Number }\end{array}$ & $\begin{array}{c}\text { Side } \\
\text { Smoothness } \\
(>0.02 \text { in })\end{array}$ & $\begin{array}{l}\text { Perpendic } \\
\quad(<0.0 \\
\text { Top }\end{array}$ & $\begin{array}{l}\text { irity } \\
\text { in) } \\
\text { Bottom }\end{array}$ & $\begin{array}{c}\text { End } \\
\text { Smoothness } \\
\text { (Degrees) }\end{array}$ \\
\hline AP44-1-4-CL1 & 0.032 & 0.031 & 0.023 & 0.64 \\
\hline AP44-2-4-CL2 & $0.017 *$ & 0.014 & 0.021 & 0.50 \\
\hline AP44-3-4-CL3 & $0.014 *$ & 0.014 & 0.006 & 0.69 \\
\hline AP44-4-4-CL4 & $0.007 *$ & $0.005 *$ & 0.009 & 1.01 \\
\hline AP47-4-4-CL5 & 0.034 & 0.059 & $0.003 *$ & 0.83 \\
\hline
\end{tabular}

* indicates that the measurement meets ASTM standard D2938 requirements 
Table 2.11 Results of Cyclic Loading Tests on Apache Leap Tuff (Brown Unit)

\begin{tabular}{|c|c|c|c|}
\hline $\begin{array}{l}\text { Sample } \\
\text { Number }\end{array}$ & $\begin{array}{l}\text { Peak Load } \\
\text { of Each Cycle } \\
\text { (MPa) }\end{array}$ & $\begin{array}{l}\text { Number of } \\
\text { Cycles Before } \\
\text { Failure }\end{array}$ & $\begin{array}{l}\text { Failure } \\
\text { Load } \\
\text { (MPa) }\end{array}$ \\
\hline AP44-1-4-CL1 & 63 & 1 & 53.76 \\
\hline AP44-2-4-CL2 & 95 & 1 & 45.55 \\
\hline AP44-3-4-CL3 & $33 \rightarrow$ failure* & 29 & 84.10 \\
\hline AP44-4-4-CL4 & 62.02 & 10 & 62.02 \\
\hline AP47-4-4-CL5 & $42 \rightarrow$ failure* & 57 & 126.50 \\
\hline
\end{tabular}

NOTE: Samples CL1 and CL2 failed before the desired peak load had been reached.

*Peak load increased by $1.2 \mathrm{MPa}$ during each cycle. 
Cyclic loading was applied to sample AP44-3-4-CL3 while progressively increasing the peak load of each cycle by approximately $1.2 \mathrm{MPa}$. The peak of the first cycle was $33 \mathrm{MPa}$. The sample failed at $84.10 \mathrm{MPa}$. The number of loading cycles was 29.

Sample AP44-4-4-CL4 failed after 10 cycles. The peak of each cycle was $62.02 \mathrm{MPa}$. Figure 2.8 shows a decrease of the secant Young's modulus with increasing number of cycles. The Young's modulus decreases from $31.8 \mathrm{GPa}$ for the first cycle to $24.8 \mathrm{GPa}$ for the last cycle. Loaddisplacement curves obtained from loading and unloading can not be differentiated. The secant Young's modulus is calculated at the peak of each load cycle.

Cyclic loading was applied to sample AP47-4-4-CL5 by progressively increasing the peak load of each cycle by $1.2 \mathrm{MPa}$. The peak of the first cycle was $42 \mathrm{MPa}$. The sample failed at $126.5 \mathrm{MPa}$, after 57 cycles.

All samples show shear failure planes with angles between 25 and $30^{\circ}$ with the core axis.

The test results are not conclusive. The relationship between the number of loading cycles and the compressive strength can not be determined. Due to the strong heterogeneity of tuff, a large number of tests is required to obtain statistically meaningful results. The property variability (e.g. compressive strength) of tuff can be seen by comparing the results of samples CL3 and CL5. The difference in the failure loads between these two samples is about $40 \mathrm{MPa}$. Sample CL3, obtained from tuff block AP44, has a density of $2.31 \mathrm{~g} / \mathrm{cc}$. Sample CL5, obtained from tuff block AP47, has a density of $2.50 \mathrm{~g} / \mathrm{cc}$.

\subsubsection{Size Effect on Uniaxial Compression Strength}

The purpose of this testing is to determine the effect of sample size on the strength, Young's modulus and Poisson's ratio obtained from uniaxial compression tests. This effort includes performing uniaxial compressive strength tests on large size specimens and comparing the results with those obtained from smaller samples (Sections 2.1.1-2.1.4).

\subsubsection{Rock Samples and Test Methods}

Seven cylindrical samples with $L / D$ ratio of 2 have been prepared from Apache Leap tuff. Three samples have a nominal diameter of $144 \mathrm{~mm}$; four samples have a nominal diameter of $101 \mathrm{~mm}$. Sample preparation is similar to that used for the $50 \mathrm{~mm}$ diameter samples (Section 2.1.1). Except for the sample size, the test is performed in accordance with the ASTM D2938 standard method. An SBEL CT-500 load frame with servocontroller is used to apply an axial load at a constant rate of 100 microstrains per second. The axial and lateral strains are measured by means of strain gages installed at the midsection of the cylinder. All samples are loaded to failure. The axial load-displacement curve and axiallateral displacement curve are used to determine the Young's modulus and Poisson's ratio. 


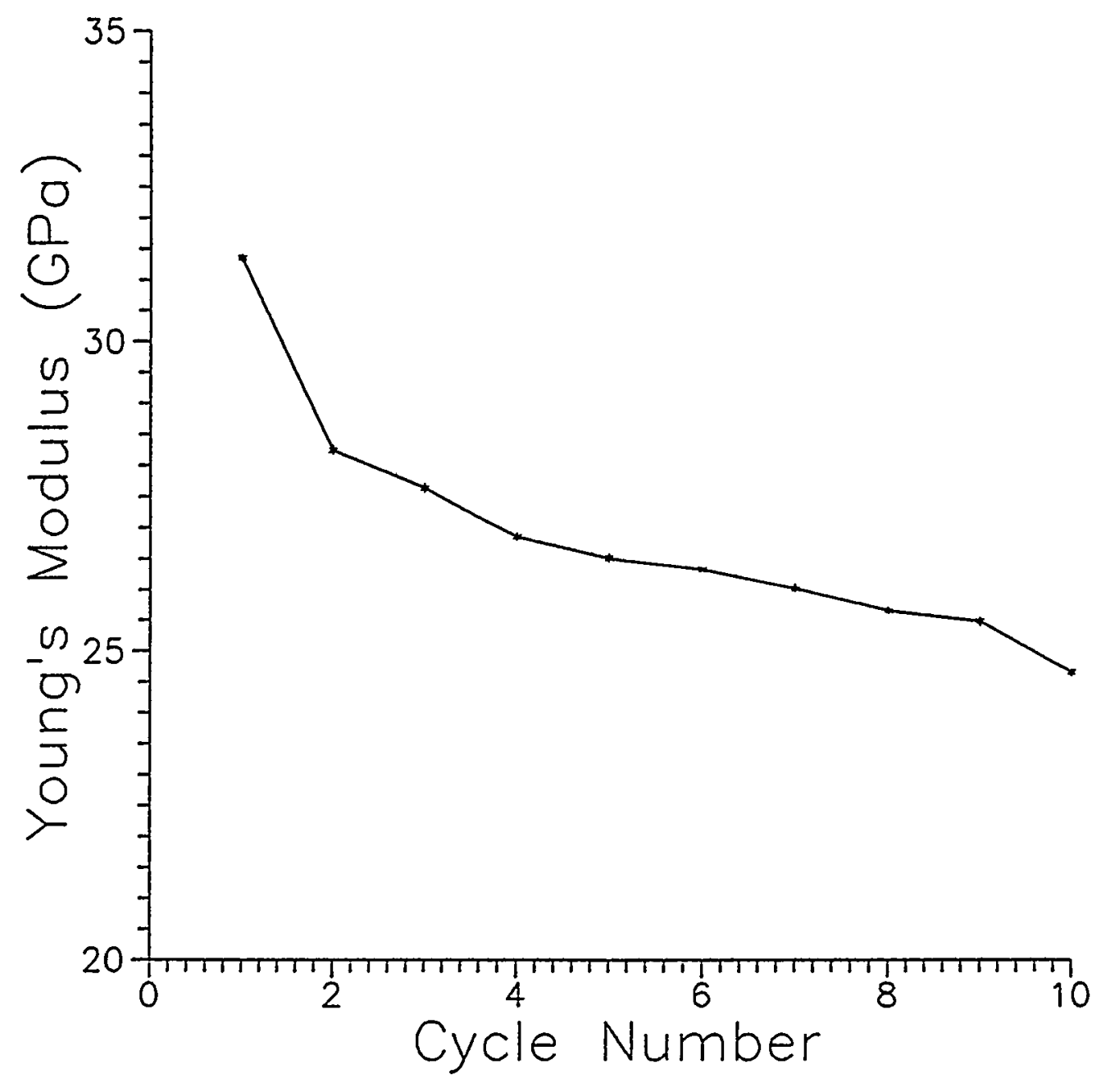

Figure 2.8 Young's modulus as a function of loading cycle number.

Results from cyclic loading tests of samples AP44-4-4-CI4. 


\subsubsection{Test Results}

The results are combined with those of smaller samples as a function of sample diameter in Figures 2.9 through 2.11. The uniaxial compressive strength for $101 \mathrm{~mm}$ diameter samples ranges from 101 to $137 \mathrm{MPa}$, and for $144 \mathrm{~mm}$ diameter samples from 86 to $88 \mathrm{MPa}$. The tangent Young's modulus and Poisson's ratio are calculated at 508 failure stress. No relationship between the mechanical properties (compressive strength, Young's modulus, and Poisson's ratio) and the sample diameter can be determined. There is no obvious trend of change of the properties with the sample size. This is probably because the Apache Leap tuff has high intrinsic variability of the properties. A clear correlation appears to exist between rock stiffness (E, Fig. 2.10) and rock strength (Fig. 2.9). The $100 \mathrm{~mm}$ and the $50 \mathrm{~mm}$ diameter samples have been cored from different blocks; hence, the difference in average strength may be associated with differences in position within the tuff horizon.

\subsection{Brazilian Tension Test}

\subsubsection{Brazilian Tensile Strength}

Brazilian tension tests are performed to determine the splitting tensile strength of Apache Leap tuff. Sample preparation, test procedure and method of calculation are performed in accordance with ASTM standard practice (ASTM D3967), which is similar to the ISRM suggested method (Bieniawski and Hawkes, 1978).

Twenty-seven tuff specimens are prepared from tuff blocks no. AP11, AP12, AP13 and AP14. The samples have a nominal diameter of $5 \mathrm{~cm}$ with a length to diameter ratio of 0.5 . The flow layers are perpendicular to the core axis. A Soiltest Versatester compression machine with loading rate controller (Soiltest CT-5000) is used for testing. Each specimen is loaded to failure at a rate of $3.5 \mathrm{MPa} /$ minute. Cardboard is placed at each contact between loading platen and tuff specimen. Failure loads are recorded to the nearest $10 \mathrm{~N}$.

Table 2.12 gives the results. None of the samples meet the ASTM perpendicularity requirement $\left(0.5^{\circ}\right)$. All samples satisfy the side and end smoothness specifications (less than $0.50 \mathrm{~mm}$ ). Figure 2.12 shows some post-failure specimens. All samples failed in tension along the loading diameter. The average Brazilian tensile strength, standard deviation, and coefficient of variation are $5.12 \mathrm{MPa}, 1.20 \mathrm{MPa}$ and 238 , respectively. The maximum and minimum strengths are $7.06 \mathrm{MPa}$ and $2.07 \mathrm{MPa}$.

\subsubsection{Size Effect on Brazilian Tensile Strength}

The Brazilian tensile strength of Apache Leap tuff has been determined for four sample sizes $(24.8,95.4,150.0$, and $180 \mathrm{~mm}$ diameters). The primary purpose is to investigate the size effect. Except for the 


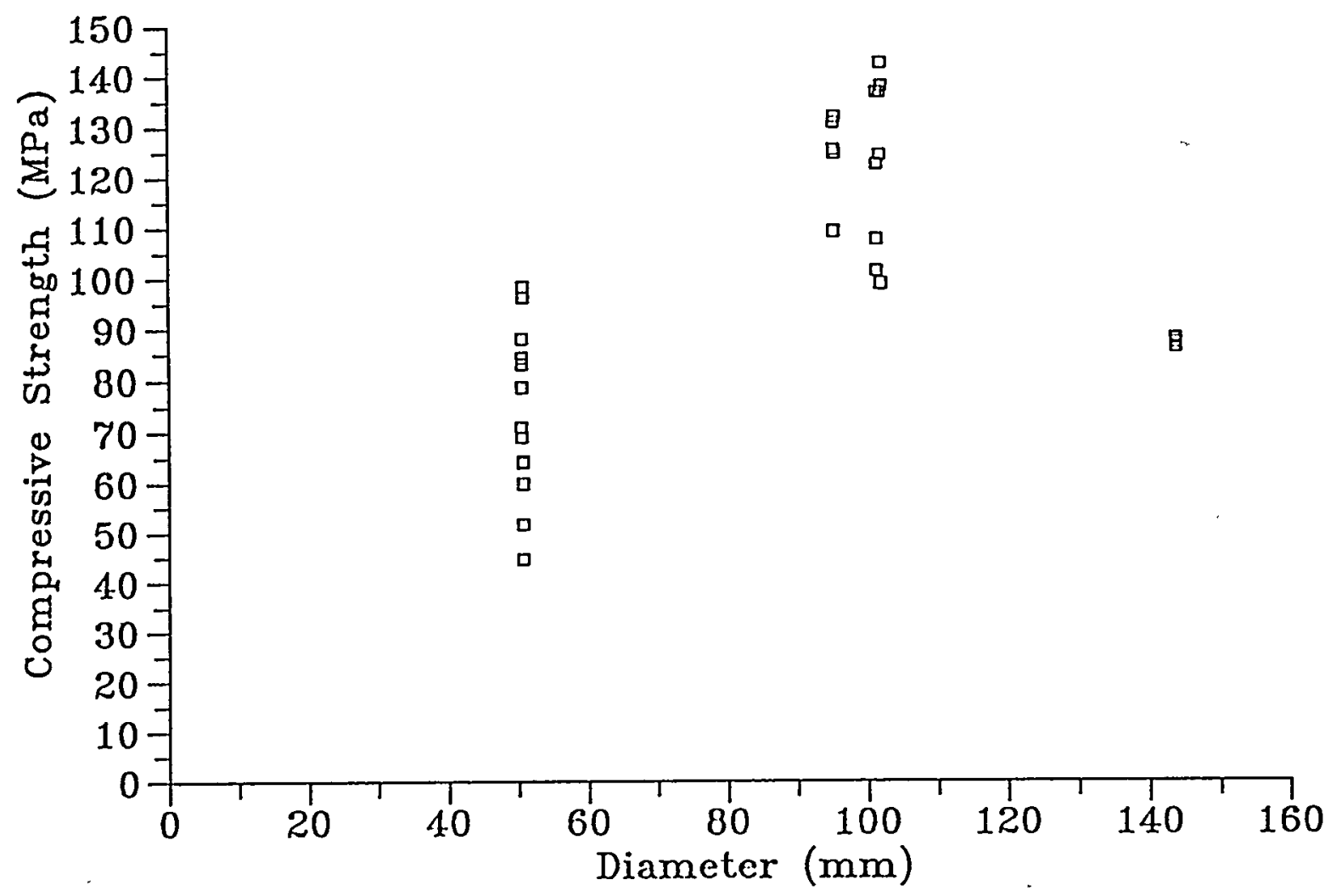

Figure 2.9 Uniaxial compressive strength as a function of sample diameter. 


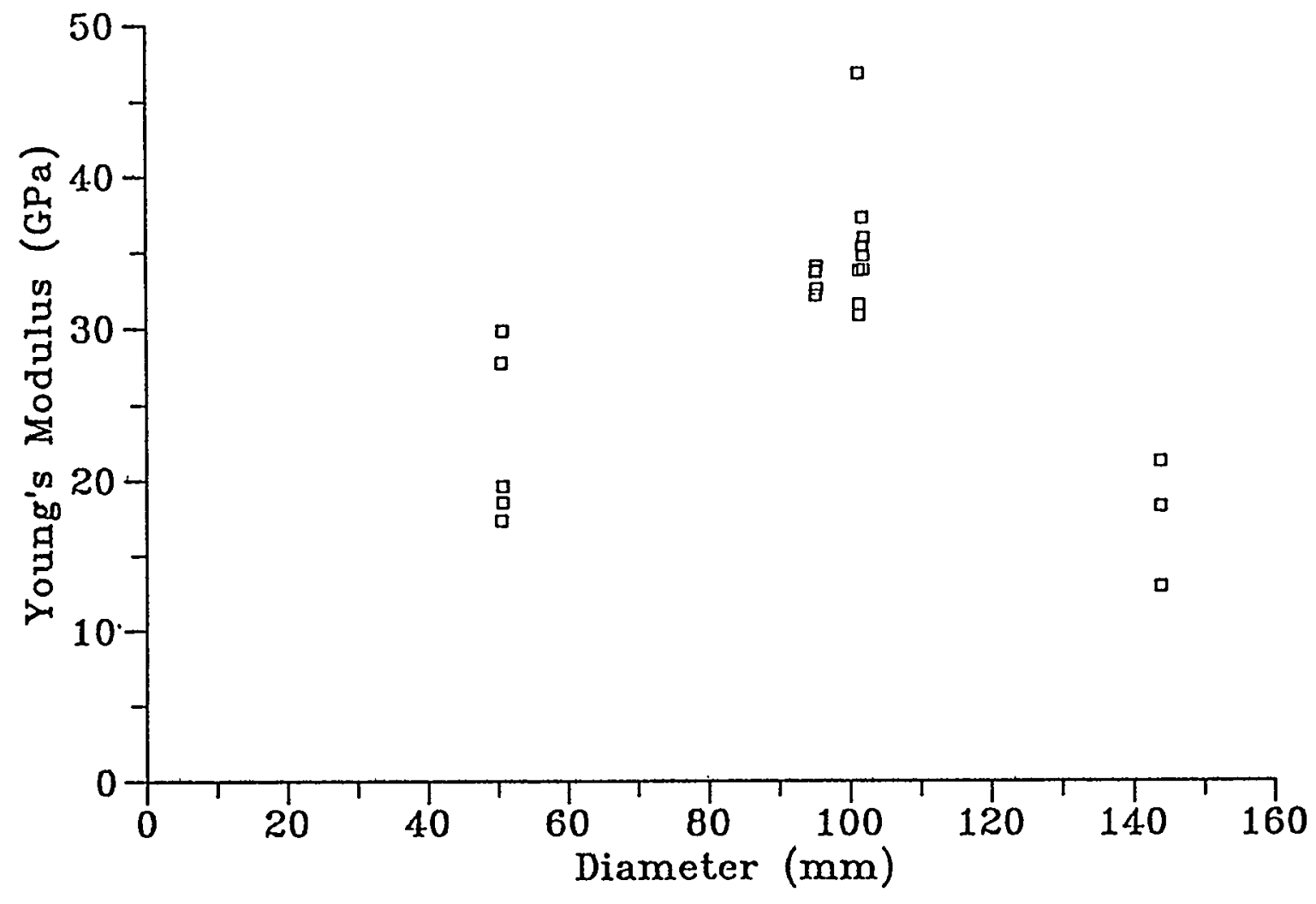

Figure 2.10 Young's modulus as a function of sample diameter for densely welded Apache Leap tuff, tangent modulus measured at $50 \%$ failure stress. 

Table 2.12 Results of Brazilian Tensile Strength Tests on Apache Leap Tuff

\begin{tabular}{|c|c|c|c|c|}
\hline $\begin{array}{l}\text { Sample } \\
\text { Number }\end{array}$ & $\begin{array}{c}\text { Diameter } \\
(\mathrm{mm})\end{array}$ & $\begin{array}{c}\text { Thickness } \\
\text { (mm) }\end{array}$ & $\begin{array}{l}\text { Failure } \\
\text { Load } \\
\left(\times 10^{3} \mathrm{~N}\right)\end{array}$ & $\begin{array}{c}\text { Brazilian } \\
\text { Tensile } \\
\text { Strength } \\
\text { (MPa) }\end{array}$ \\
\hline AP11-1-2-BZ1 & 50.50 & 26.09 & 15.61 & 4.37 \\
\hline AP11-2-2-BZ2 & 50.47 & 25.88 & 12.01 & 5.84 \\
\hline AP11-2-2-BZ3 & 50.52 & 26.59 & 14.01 & 6.63 \\
\hline $\mathrm{AP} 11-3-2-\mathrm{BZ4}$ & 50.44 & 26.24 & 11.12 & 5.35 \\
\hline AP11-4-2-BZ5 & 50.34 & 26.01 & 10.40 & 5.10 \\
\hline AP11-4-2-BZ6 & 50.39 & 26.09 & 4.27 & 2.07 (minimum) \\
\hline$A P 11-5-2-B Z 7$ & 50.50 & 26.39 & 11.25 & 5.37 \\
\hline AP11-5-2-BZ8 & 50.55 & 25.40 & 12.99 & 6.44 \\
\hline AP12-1-2-BZ9 & 50.42 & 25.81 & 8.50 & 4.15 \\
\hline AP12-2-2-BZ10 & 50.52 & 25.70 & 7.47 & 3.66 \\
\hline AP12-3-2-BZ11 & 50.47 & 25.78 & 10.94 & 5.35 \\
\hline AP12-7-2-BZ12 & 50.55 & 26.52 & 12.68 & 6.01 \\
\hline AP13-1-2-B213 & 50.50 & 26.59 & 13.43 & 6.79 \\
\hline $\mathrm{AP} 13-1-2-\mathrm{BZ14}$ & 50.52 & 25.86 & 7.92 & 3.86 \\
\hline AP13-2-2-BZ15 & 50.52 & 26.24 & 10.68 & 5.37 \\
\hline AP13-2-2-BZ16 & 50.50 & 25.50 & 6.32 & 2.98 \\
\hline AP13-3-2-BZ17 & 50.47 & 25.73 & 13.03 & 6.39 \\
\hline AP13-3-2-BZ18 & 50.60 & 25.65 & 11.03 & 5.84 \\
\hline AP13-3-2-BZ19 & 50.47 & 26.01 & 12.45 & 6.03 \\
\hline $\mathrm{AP} 13-4-2-\mathrm{BZ20}$ & 50.55 & 26.04 & 14.59 & 7.06 (maximum) \\
\hline AP13-4-2-BZ21 & 50.50 & 26.09 & 11.57 & 5.59 \\
\hline $\mathrm{AP} 13-5-2-\mathrm{BZ22}$ & 50.52 & 26.42 & 9.43 & 4.50 \\
\hline $\mathrm{AP} 13-6-2-\mathrm{BZ} 23$ & 50.47 & 26.29 & 11.74 & 5.63 \\
\hline AP13-6-2-BZ24 & 50.52 & 25.83 & 9.21 & 4.49 \\
\hline AP14-1-2-BZ25 & 50.52 & 26.06 & 8.72 & 4.21 \\
\hline AP14-3-2-BZ26 & 50.50 & 26.49 & 10.59 & 5.04 \\
\hline $\mathrm{AP} 14-3-2-\mathrm{BZ27}$ & 50.55 & 25.81 & 8.45 & 4.12 \\
\hline \multicolumn{4}{|c|}{$\begin{array}{l}\text { Mean } \pm \text { Standard Deviation } \\
\text { Coefficient of Variation: }\end{array}$} & $5.12 \pm 1.20$ \\
\hline
\end{tabular}




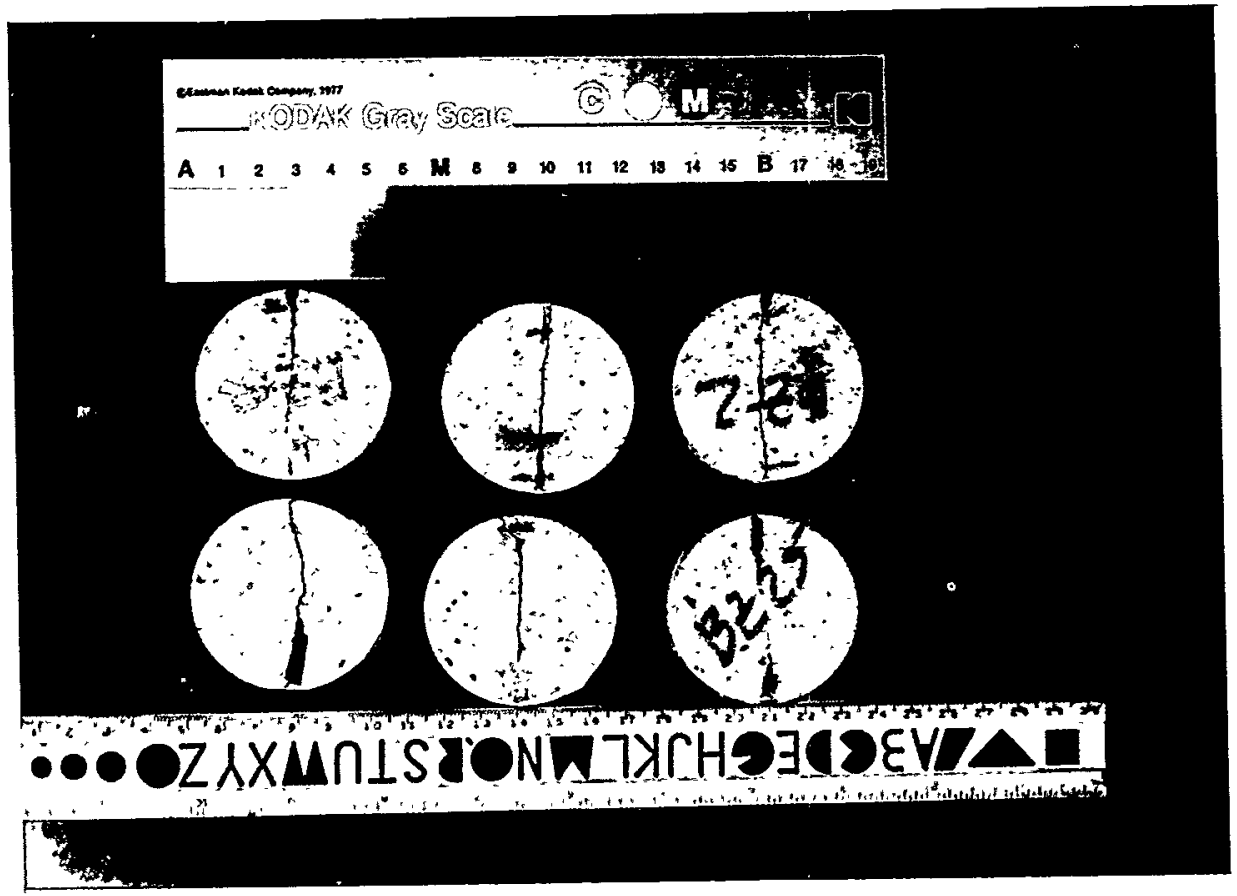

Figure 2.12 Brazilian test specimens of Apache Leap tuff after failure. Some representative $50 \mathrm{~mm}$ diameter tuff disks loaded to failure in diametrical compression. Tensile crack is induced along the loading diameter. 
sample size, the test method follows the ASTM standard D3967. Flow layers are perpendicular to the sample axis. All samples are loaded at $390 \mathrm{kPa} / \mathrm{min}$.

Tables 2.13 through 2.16 give results for the $24.8,95.4,150.0$, and $181.5 \mathrm{~mm}$ diameter specimens, respectively. All samples fail along the loaded diameter. For each sample size, the tensile strength shows a high coefficient of variation. The tensile strength does not seem to decrease consistently as the sample size increases. This does not mean that the size of the specimen has no influence on the tensile strength nor that the distribution of the pore spaces within the rock is uniform. Large variation of the tensile strengths observed from each sample size suggests a strong effect of inclusion content.

Table 2.17 summarizes the results of the Brazilian tests on different sizes of specimens. The number of specimens tested for most sizes is less than ASTM D3967 specifies. The ASTM standard requires that at least 10 specimens be tested. The number of specimens can be less than 10 if the coefficient of variation is less than 58. For the Apache Leap tuff, a large coefficient of variation is observed for all specimen sizes. This strength variation may not be reduced by increasing the number of the tested specimens as indicated by testing 27 disks of $50 \mathrm{~mm}$ diameter.

The inclusions in tuff may cause large variations of the mechanical properties as demonstrated here. ASTM standard D3967 specifies that the sample should have a diameter of $49 \mathrm{~mm}$ or that the diameter should be 10 times larger than the average grain size. Even though the average grain size of the Apache Leap tuff is less than $2 \times 2 \mathrm{~mm}$, the sample diameter (49 $\mathrm{mm}$ ) specified by ASTM might be too small due to the inclusion effect. We believe that in order to obtain a representative value of the tuff mechanical properties, the sample diameter should be at least $250 \mathrm{~mm}$. This suggested diameter is ten times larger than the size of the inclusions (average size of $10 \times 25 \mathrm{~mm}$ ).

Electrical resistance strain gages are installed at the center of the disks to measure the strains normal to and along the loading diameter. The strain gages are connected to a strain indicator and a switch-andbalance unit. During loading, the strain gages are read every minute until failure. The strains are used to calculate the elastic modulus and Poisson's ratio of the rock. Hondros (1959) gives solutions to calculate the elastic parameters (E,v) from a Brazilian test specimen as:

$$
\begin{gathered}
v=-\left(\frac{3 \epsilon_{\theta}+\epsilon_{r}}{3 \epsilon_{r}+\epsilon_{\theta}}\right) \\
E=\frac{6 P\left(1-v^{2}\right)}{\pi D t\left(\epsilon_{\theta}+v \epsilon_{r}\right)}
\end{gathered}
$$


Table 2.13 Brazilian Tensile Strengths of Apache Leap Tuff Samples with Nominal Diameters of $25 \mathrm{~mm}$

\begin{tabular}{lcccc}
$\begin{array}{c}\text { Sample } \\
\text { Number }\end{array}$ & $\begin{array}{c}\text { Diameter } \\
(\mathrm{mm})\end{array}$ & $\begin{array}{c}\text { Thickness } \\
(\mathrm{mm})\end{array}$ & $\begin{array}{c}\text { Failure } \\
\text { Load } \\
(\mathrm{kN})\end{array}$ & $\begin{array}{c}\text { Brazilian } \\
\text { Tensile } \\
\text { Strength } \\
\text { (MPa) }\end{array}$ \\
\hline AP35-12A-1-BZ1 & 24.7 & 13.7 & 3.70 & 7.02 \\
AP35-12B-1-BZ2 & 24.8 & 12.8 & 4.93 & 9.88 \\
AP35-12C-1-BZ3 & 24.7 & 12.6 & 4.93 & 10.08 \\
AP35-12D-1-BZ4 & 24.8 & 14.0 & 3.87 & 7.10 \\
AP35-12E-1-BZ5 & 24.8 & 12.9 & 4.84 & 9.63 \\
AP35-12F-1-BZ6 & 24.8 & 13.3 & 4.31 & 8.32 \\
AP35-11A-1-BZ7 & 24.7 & 13.6 & 4.66 & 8.84 \\
AP35-11B-1-BZ8 & 24.9 & 13.5 & 2.24 & 4.25 \\
\hline & & & & $8.14 \pm 1.96$ \\
Mean \pm Standard Deviation & & & \\
Coefficient of Variation & & & & \\
\hline
\end{tabular}

Table 2.14 Brazilian Tensile Strengths of Apache Leap Tuff Samples with Nominal Diameters of $95 \mathrm{~mm}$

\begin{tabular}{lcccc}
$\begin{array}{c}\text { Sample } \\
\text { Number }\end{array}$ & $\begin{array}{c}\text { Diameter } \\
(\mathrm{mm})\end{array}$ & $\begin{array}{c}\text { Thickness } \\
(\mathrm{mm})\end{array}$ & $\begin{array}{c}\text { Failure } \\
\text { Load } \\
(\mathrm{kN})\end{array}$ & $\begin{array}{c}\text { Brazilian } \\
\text { Tensile } \\
\text { Strength } \\
(\mathrm{MPa})\end{array}$ \\
\hline AP35-3A-4-BZ1 & 95.4 & 51.8 & 59.84 & 7.71 \\
AP35-3B-4-BZ2 & 95.4 & 53.0 & 39.47 & 4.97 \\
AP35-3C-4-BZ3 & 95.4 & 50.8 & 46.86 & 6.16 \\
AP35-3D-4-BZ4 & 95.4 & 51.5 & 48.53 & 6.29 \\
AP35-4A-4-BZ6 & 95.4 & 50.7 & 54.56 & 7.18 \\
AP35-4B-4-BZ7 & 95.4 & 52.0 & 43.56 & 5.59 \\
AP35-4C-4-BZ8 & 95.4 & 51.6 & 50.95 & 6.59 \\
AP35-4D-4-BZ9 & 95.4 & 53.7 & 60.72 & 7.55 \\
\hline \\
Mean \pm Standard Deviation
\end{tabular}


Table 2.15 Brazilian Tensile Strengths of Apache Leap Tuff Samples with Nominal Diameters of $150 \mathrm{~mm}$

\begin{tabular}{lcccc}
$\begin{array}{c}\text { Sample } \\
\text { Number }\end{array}$ & $\begin{array}{c}\text { Diameter } \\
(\mathrm{mm})\end{array}$ & $\begin{array}{c}\text { Thickness } \\
(\mathrm{mm})\end{array}$ & $\begin{array}{c}\text { Failure } \\
\text { Load } \\
(\mathrm{kN})\end{array}$ & $\begin{array}{c}\text { Brazilian } \\
\text { Tensile } \\
\text { Strength } \\
(\mathrm{MPa})\end{array}$ \\
\hline AP2-2-6-BZ1 & 150.3 & 81.1 & 94.60 & 4.94 \\
AP30-3A-6-BZ2 & 150.6 & 76.9 & 103.84 & 5.71 \\
AP30-3B-6-BZ3 & 150.5 & 76.8 & 170.28 & 9.38 \\
AP35-1A-6-BZ4 & 150.0 & 76.5 & 122.76 & 6.81 \\
AP35-1B-6-BZ5 & 149.9 & 78.0 & 146.08 & 7.95 \\
AP35-1C-6-BZ6 & 149.9 & 78.1 & 153.12 & 8.33 \\
AP35-2B-6-BZ7 & 150.5 & 78.2 & 91.08 & 4.93 \\
AP35-3A-6-BZ8 & 149.9 & 77.6 & 117.48 & 6.43 \\
\hline & & & & $6.81 \pm 1.63$ \\
Mean \pm Standard Deviation & & & \\
Coefficient of Variation & & &
\end{tabular}

Table 2.16 Brazilian Tensile Strengths of Apache Leap Tuff Samples with Nominal Diameters of $181.5 \mathrm{~mm}$

\begin{tabular}{lccc}
$\begin{array}{c}\text { Sample } \\
\text { Number }\end{array}$ & $\begin{array}{c}\text { Average } \\
\text { Diameter } \\
(\mathrm{mm})\end{array}$ & $\begin{array}{c}\text { Average } \\
\text { Length } \\
(\mathrm{mm})\end{array}$ & $\begin{array}{c}\text { Brazilian } \\
\text { Tensile } \\
\text { Strength } \\
\text { (MPa) }\end{array}$ \\
\hline AP42-2A-7-BZ1 & 181.5 & 86.3 & 5.06 \\
AP42-2A-7-BZ2 & 181.4 & 93.1 & 5.36 \\
AP42-2A-7-BZ3 & 181.2 & 86.5 & 5.60 \\
AP42-2A-7-BZ4 & 181.5 & 86.3 & 6.33 \\
AP42-2A-7-BZ5 & 181.7 & 94.3 & 8.43 \\
Mean \pm Standard Deviation & & $6.16 \pm 1.36$ \\
Coefficient of Variation & & 228 \\
\hline
\end{tabular}


Table 2.17 Brazilian Tensile Strength of Apache Leap Tuff Obtained from Different Sample sizes

\begin{tabular}{ccccc}
$\begin{array}{c}\text { Nominal } \\
\text { Diameter } \\
\text { (mm) }\end{array}$ & $\begin{array}{c}\text { Length } \\
\text { to } \\
\text { Diameter } \\
\text { Ratio }\end{array}$ & $\begin{array}{c}\text { Brazilian } \\
\text { Tensile } \\
\text { Strength } \\
\text { (MPa) }\end{array}$ & $\begin{array}{c}\text { Coefficient } \\
\text { of } \\
\text { Variation } \\
(\%)\end{array}$ & $\begin{array}{c}\text { Number } \\
\text { of } \\
\text { Samples }\end{array}$ \\
\hline 25.0 & 0.5 & $8.14 \pm 1.96$ & 24 & 8 \\
50.5 & 0.5 & $5.12 \pm 1.20$ & 23 & 27 \\
95.4 & 0.5 & $6.51 \pm 0.95$ & 15 & 8 \\
150.0 & 0.5 & $6.81 \pm 1.63$ & 24 & 8 \\
7181.5 & 0.5 & $6.16 \pm 1.36$ & 22 & 5 \\
\hline
\end{tabular}


where E, $v=$ elastic modulus and Poisson's ratio of the rock disk

$P=$ diametrical load

D = disk diameter

$t=$ disk thickness

$\epsilon_{\theta}=$ strain normal to loaded diameter

$E_{r}=$ strain along the loaded diameter.

Table 2.18 gives the tangent elastic modulus and Poisson's ratio calculated from the strains at the disk center. The elastic parameters are calculated at 108 and at 508 of the tensile strengths. The Poisson's ratio calculation gives meaningless values, except for samples AP41-2A7-B23 and AP42-2A-7-B25. The Young's moduli appear equally questionable. This is probably caused by heterogeneity of the rock due to the presence of flow layers, vesicles (voids) and inclusions, which induces a complex strainfield. Mechanical strain gages with a larger base length may be preferable to electrical resistance strain gages, especially short ones, for monitoring strains on welded tuff.

Figure 2.13 gives the Brazilian tensile strength of Apache Leap tuff as a function of sample size (disk diameter).

In order to determine a mathematical relationship between strength and size, Evans' power law and Lundborg's logarithmic expression (Jaeger and Cook, 1979, pp. 196-199) are used in linear regression analysis. Table 2.19 gives the results of the regression. Figures 2.14 and 2.15 give curve fits and experimental data. Both criteria show a low coefficient of correlation ( $R$ ). Mathematically, the strength decreases as sample size increases. The size effect criteria (Evans' law and Lundborg's expression) do not fit the experimental data. A large coefficient of variation is obtained from all sample sizes. To extrapolate the tensile strength to a larger scale (i.e. toward in-situ conditions), samples with larger diameters should be tested.

\subsection{Seismic Velocity Measurements}

Seismic velocity measurements have been performed to determine the dynamic Young's modulus and dynamic Poisson's ratio of Apache Leap tuff. The tests are performed on disks with a diameter of approximately $10 \mathrm{~cm}$ and a thickness to diameter ratio of 0.25 . The test procedure (Appendix B) follows a method given by Structural Behavior Engineering Laboratories, Inc. A seismic analyzer (SBEL 2007H) is used to send signals (primary and secondary waves) via transducers through the rock sample. The signal is displayed by an oscilloscope (Tektronix T912). Delay times are shown by the digital display of the seismic analyzer. A minimum of four delay time readings are obtained for each sample and each wave type. The average delay time is used to calculate the primary and secondary wave velocities. The dynamic Young's modulus $\left(E_{\alpha}\right)$ and Poisson's ratio $\left(v_{d}\right)$ are calculated from:

$$
E_{d}=\frac{\gamma V_{s}^{2}\left(3 V_{p}^{2}-4 V_{s}^{2}\right)}{g\left(V_{p}^{2}-V_{s}^{2}\right)}
$$


Table 2.18 Elastic Modulus and Poisson's Ratio of Apache Leap Tuff, Obtained from Brazilian Tests

\begin{tabular}{|c|c|c|c|c|}
\hline \multirow[b]{2}{*}{$\begin{array}{l}\text { Sample } \\
\text { Number }\end{array}$} & \multicolumn{2}{|c|}{ Poisson's Ratio } & \multicolumn{2}{|c|}{ Elastic Modulus (GPa) } \\
\hline & $\begin{array}{l}\text { Measured } \\
\text { at } 108 \\
\text { Strength }\end{array}$ & $\begin{array}{l}\text { Measured } \\
\text { at } 508 \\
\text { Strength }\end{array}$ & $\begin{array}{l}\text { Measured } \\
\text { at } 108 \\
\text { Strength }\end{array}$ & $\begin{array}{l}\text { Measured } \\
\text { at 508 } \\
\text { Strength }\end{array}$ \\
\hline $\begin{array}{l}42-2 A-7-B Z 1 \\
42-2 A-7-B Z 2 \\
42-2 A-7-B Z 3 \\
42-2 A-7-B Z 4 \\
42-2 A-7-B Z 5\end{array}$ & $\begin{array}{r}1.304 \\
-0.106 \\
0.418 \\
0.662 \\
0.186\end{array}$ & $\begin{array}{r}1.661 \\
-0.062 \\
0.418 \\
0.874 \\
0.081\end{array}$ & $\begin{array}{r}142.08 \\
29.30 \\
63.25 \\
151.10 \\
176.83\end{array}$ & $\begin{array}{r}173.06 \\
41.63 \\
55.03 \\
269.54 \\
96.15\end{array}$ \\
\hline
\end{tabular}

Table 2.19 Results of Size Effect Calculation of Brazilian Tensile Strength of Apache Leap Tuff

Evans' Power Law:

$$
\sigma_{B}=k^{\cdot} D^{-\infty}
$$

Apache Leap Tuff:

$\sigma_{B}=8.521 D^{-0.0627} ; \quad R^{2}=0.305$

Lundborg's Expression:

$\ln \sigma_{B}=A^{\prime}-\left(1 / m^{\circ}\right) \ln V$

Apache Leap Tuff:

$\ln \sigma_{B}=1.979-(1 / 47.79) \ln V ; \quad R^{2}=0.303$

where $\sigma_{B}=$ Brazilian tensile strength in $\mathrm{MPa}$

$D$ - sample diameter in $\mathrm{mm}$

$k^{\circ}, \infty, A^{\circ}, m^{\circ}=$ empirical constants

$V=$ sample volume in cc

$R=$ coefficient of correlation 


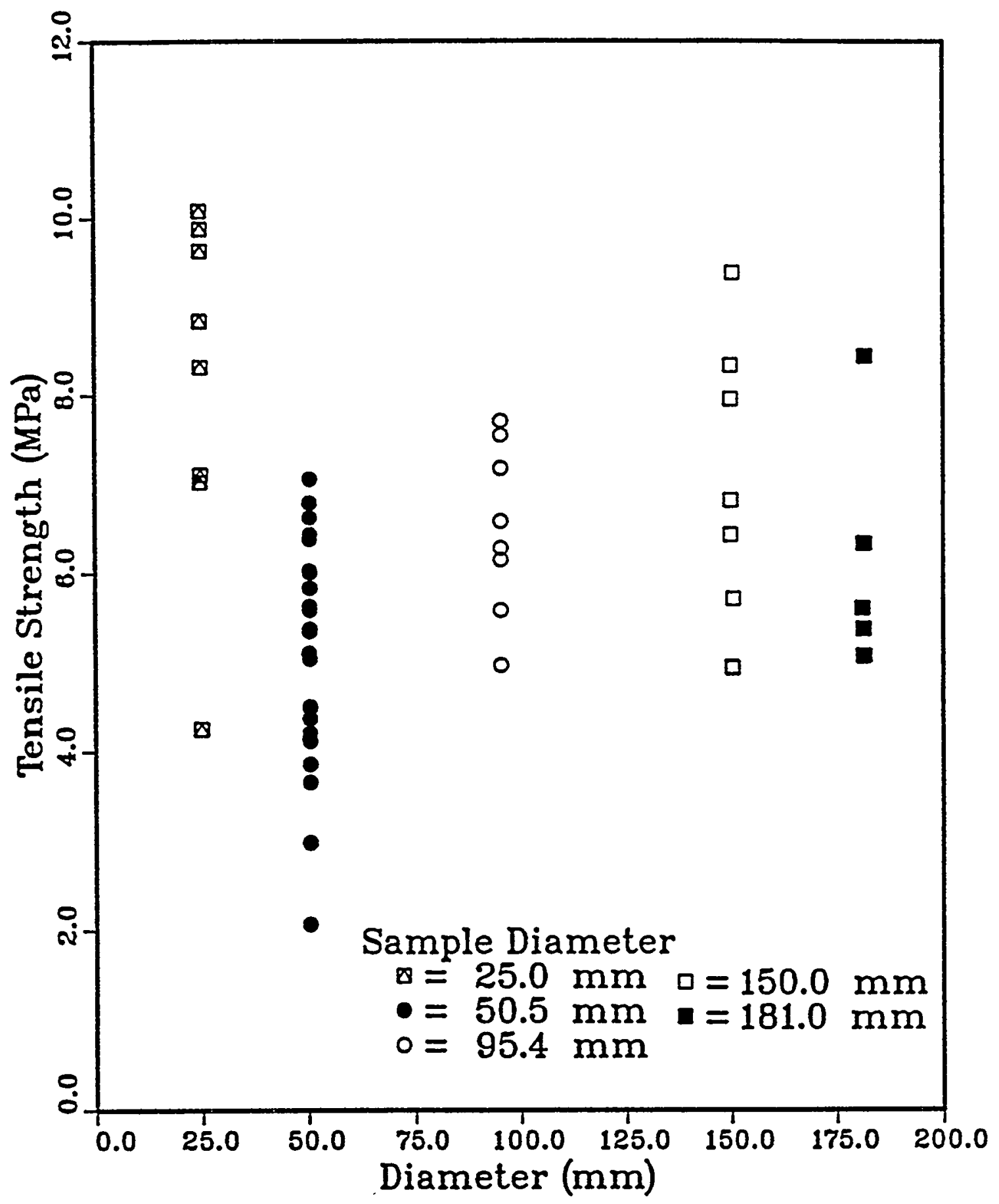

Figure 2.13 Brazilian tensile strength of Apache Leap tuff, obtained from different sample sizes. 


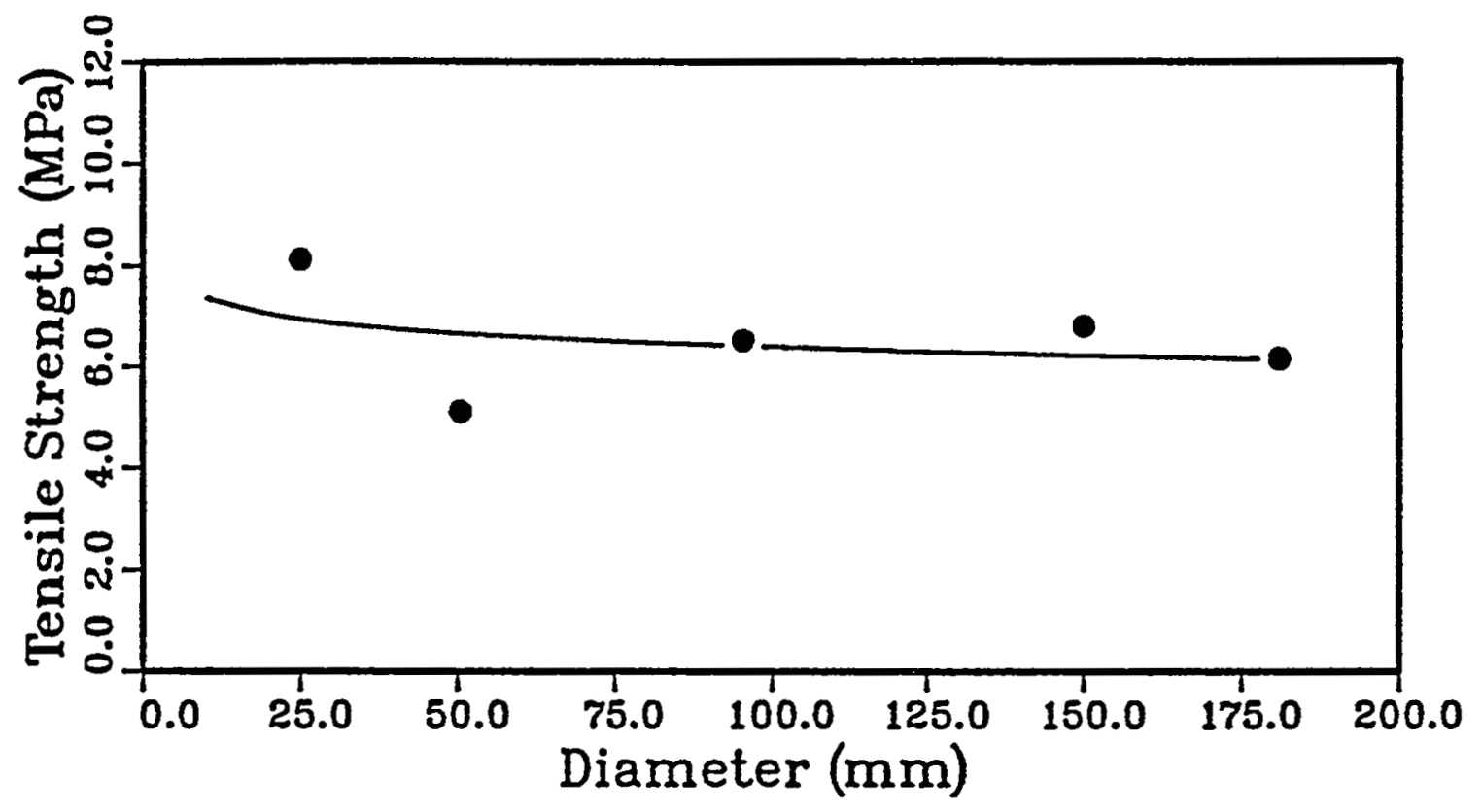

Figure 2.14 Evans' power law fit to Brazilian tensile strength data as a function of disk diameter. Each data point represents an average tensile strength of 5 to 20 tests. 


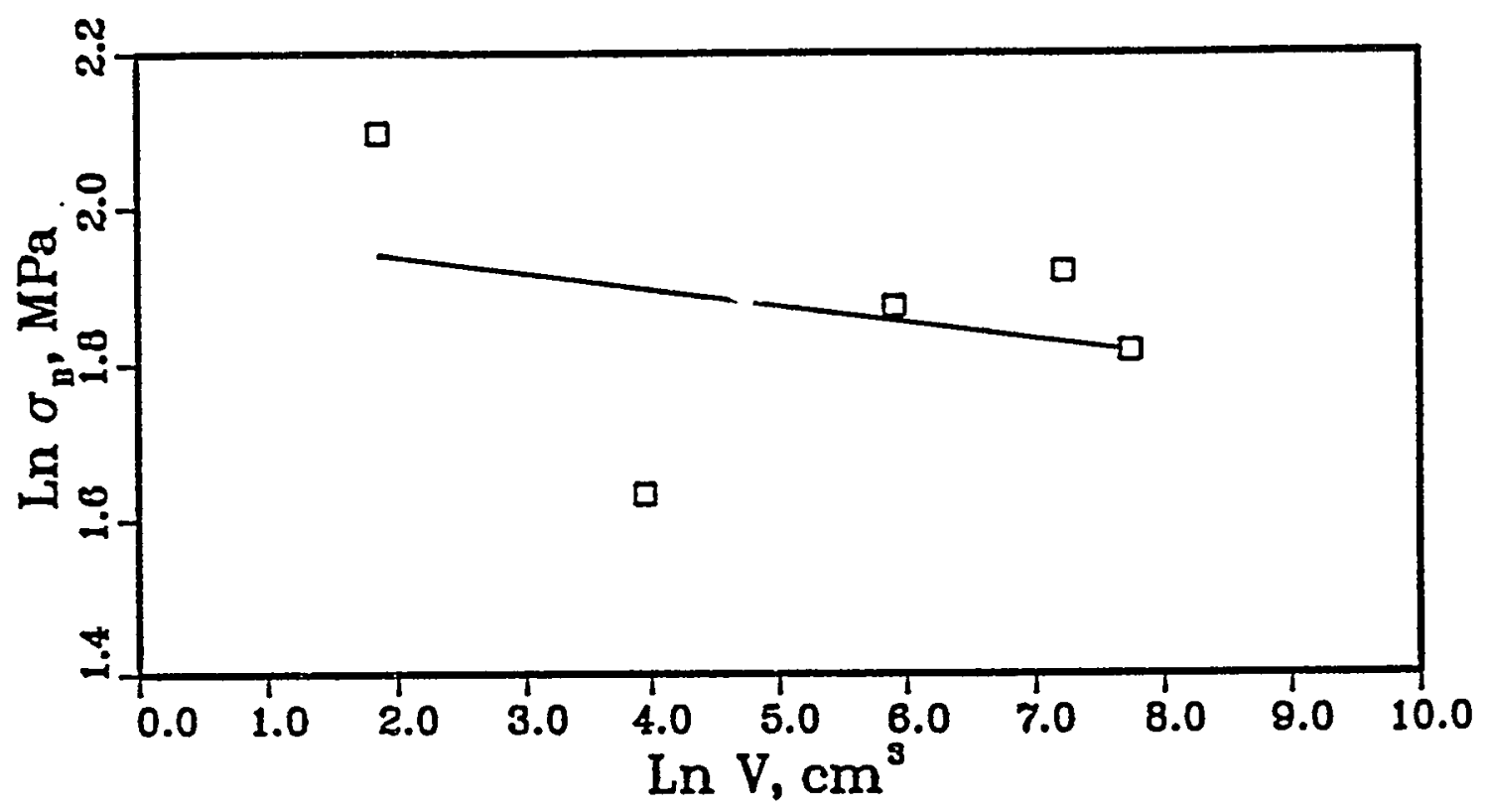

Figure 2.15 Lundborg's logarithmic expression fit to Brazilian tensile strength data as a function of disk diameter. Each data point represents an average tensile strength of 5 to 20 tests. 


$$
\begin{gathered}
v_{d}=\frac{V_{p}^{2}-2 V_{s}^{2}}{2\left(V_{p}^{2}-V_{s}^{2}\right)} \\
V_{p}=\frac{t^{\circ}}{T_{p}} \\
V_{s}=\frac{t^{\circ}}{T_{s}}
\end{gathered}
$$

where $\quad v_{p}=$ primary wave velocity (m/s)

$\mathrm{v}_{\mathrm{s}}=$ secondary wave velocity $(\mathrm{m} / \mathrm{s})$

$t^{\prime}$ - sample thickness (m)

$\mathrm{T}_{\mathrm{p}}$ = delay time for primary wave ( $s$ )

$T_{S}=$ delay time for secondary wave $(s)$

$Y$ = unit weight of the sample $\left(\mathrm{kg} / \mathrm{m}^{3}\right)$

$g=$ acceleration of gravity $\left(9.81 \mathrm{~m} / \mathrm{s}^{2}\right)$.

Table 2.20 gives the seismic velocities. Densities vary from $2.31 \mathrm{~g} / \mathrm{cc}$ to $2.42 \mathrm{~g} / \mathrm{cc}$, and average $2.37 \pm 0.42 \mathrm{~g} / \mathrm{cc}$. Velocities of primary waves vary from 4212 to $7930 \mathrm{~m} / \mathrm{s}$. Velocities of secondary waves vary from 1723 to $2851 \mathrm{~m} / \mathrm{s}$. Dynamic Young's moduli average $35.69 \pm 9.94 \mathrm{GPa}$, with the maximum and minimum values at 46.66 and $20.00 \mathrm{GPa}$, respectively. The average dynamic Poisson's ratio is $0.39 \cdot 0.10$.

\subsection{Triaxial Compressive Strength Test}

Triaxial compression tests have been performed on thirteen Apache Leap tuff specimens. Sample preparation, test procedure, and method of calculation follow the ASTM standard practice D2664. The specimens are prepared from blocks AP12, AP13, AP14, AP19, and AP24. Flow layers are normal to the cylinder axis. The applied confining pressures range from 3.4 to $62.0 \mathrm{MPa}$. The samples are axially loaded at constant strain rates of $2.0 \times 10^{-5}$ per second or $12.0 \times 10^{-5}$ per second. Table 2.21 gives the results.

\subsection{Strength Criteria of Apache Leap Tuff}

The purpose of this study is to determine the strength criterion that best represents the failure of tuff. This involves selection of the strength criteria and determination of the material constants (fitting parameters) of these criteria by means of regression analyses. Data used are the uniaxial and triaxial compressive strengths and Brazilian tensile strengths (Tables 2.2, 2.12, 2.21). For the Brazilian test data, the minor principal stress, $\sigma_{3}$, equals the tensile strength of the rock and the major principal stress, $\sigma_{1}$, is compressive and equals three times the tensile strength calculated at the center of the disk sample where failure is initiated (Jaeger and Cook, 1979, pp. 169-173). The analysis assumes that the tuff samples are isotropic, or that all strengths are measured normal to the flow layers. 
Table 2.20 Results of Seismic Velocity Heasurements of Apache Leap Tuff

\begin{tabular}{|c|c|c|c|c|c|}
\hline \multirow{2}{*}{$\begin{array}{l}\text { Sample } \\
\text { Number }\end{array}$} & \multirow{2}{*}{$\begin{array}{r}\text { Density } \\
(g / c c)\end{array}$} & \multicolumn{2}{|c|}{$\begin{array}{l}\text { Wave Velocities } \\
(\mathrm{m} / \mathrm{s})\end{array}$} & \multirow{2}{*}{$\begin{array}{c}{ }_{\mathrm{d}} \\
(\mathrm{GPa})\end{array}$} & \multirow[b]{2}{*}{${ }^{v} \mathrm{~d}$} \\
\hline & & P-Wave & S-Wave & & \\
\hline AP18-1a-4-DY1 & 2.35 & 7930 & 2657 & 46.66 & 0.44 \\
\hline AP18-2-4-DY2 & 2.31 & 6722 & 1723 & 20.00 & 0.46 \\
\hline AP18-2b-4-DY3 & 2.33 & 4432 & 2851 & 43.48 & 0.15 \\
\hline AP18-3a-4-DY4 & 2.35 & 7519 & 2192 & 32.82 & 0.45 \\
\hline AP19-6a-4-DY5 & 2.40 & 7409 & 2400 & 39.85 & 0.44 \\
\hline AP19-6b-4-DY6 & 2.41 & 7808 & 2557 & 45.21 & 0.44 \\
\hline AP19-6c-4-DY7 & 2.42 & 4212 & 1894 & 23.65 & 0.37 \\
\hline AP19-6d-4-DY8 & 2.41 & 5342 & 2251 & 33.86 & 0.39 \\
\hline $\begin{array}{l}\text { Mean } \pm \text { Standard } \\
\text { Deviation: } \\
\text { Coefficient of } \\
\text { Variation: }\end{array}$ & $\begin{array}{l}2.37 \\
\pm 0.042 \\
1.8 \%\end{array}$ & $\begin{array}{l}6422 \\
\pm 1534 \\
24 \%\end{array}$ & $\begin{array}{l}2317 \\
\pm 379 \\
16 \%\end{array}$ & $\begin{array}{l}35.69 \\
\pm 9.94 \\
28 \%\end{array}$ & $\begin{array}{l}0.39 \\
\pm 0.10 \\
26 \%\end{array}$ \\
\hline
\end{tabular}


Table 2.21 Results of Triaxial Compressive Strength Tests on Apache Leap Tuff Specimens

\begin{tabular}{lcccrc}
$\begin{array}{l}\text { Sample } \\
\text { Number }\end{array}$ & $\begin{array}{c}\text { Diameter } \\
(\mathrm{mm})\end{array}$ & $\begin{array}{c}\text { Length } \\
(\mathrm{mm})\end{array}$ & $\begin{array}{c}\text { Strain Rate } \\
\left(\times 10^{-5 / s}\right)\end{array}$ & $\begin{array}{c}\sigma \\
(\mathrm{MPa})\end{array}$ & $\begin{array}{c}\sigma_{1} \\
(\mathrm{MPa})\end{array}$ \\
\hline AP12-1-2-TX1 & 50.4 & 127.5 & 2.0 & 12.4 & 145.7 \\
AP12-3-2-TX2 & 50.3 & 128.6 & 2.0 & 6.9 & 107.6 \\
AP12-6-2-TX3 & 50.5 & 127.6 & 2.0 & 34.5 & 186.1 \\
AP12-7-2-TX4 & 50.5 & 126.7 & 2.0 & 10.3 & 139.0 \\
AP13-3-2-TX5 & 50.5 & 127.9 & 2.0 & 13.8 & 107.6 \\
AP13-6-2-TX6 & 50.5 & 128.4 & 2.0 & 3.4 & 94.2 \\
AP14-2-2-TX7 & 50.6 & 127.6 & 2.0 & 3.4 & 123.3 \\
AP19-4-2-TX8 & 50.8 & 126.5 & 2.0 & 13.8 & 150.2 \\
AP24-3-2-TX9 & 50.3 & 127.3 & 12.0 & 55.1 & 358.7 \\
AP24-4-2-TX10 & 50.2 & 127.1 & 12.0 & 55.1 & 421.5 \\
AP24-5-2-TX11 & 50.2 & 127.5 & 12.0 & 48.2 & 361.0 \\
AP24-6-2-TX12 & 50.3 & 127.3 & 12.0 & 62.0 & 361.0 \\
AP24-7-2-TX13 & 50.3 & 127.0 & 12.0 & 48.2 & 361.0 \\
\hline
\end{tabular}




\subsubsection{Coulomb Criterion}

The Coulomb criterion is the simplest and best-known criterion of failure for rock (Goodman, 1980, pp. 75-79; Brady and Brown, 1985, pp. 106-108). The criterion can be expressed in terms of major and minor principal stresses at failure as:

$$
\sigma_{1}=\sigma_{c}+\sigma_{3} \tan \psi
$$

where $\sigma_{1}, \sigma_{3}=$ major and minor principal stresses

$\sigma_{c}=$ uniaxial compressive strength

$$
\begin{aligned}
\tan \psi & =(1+\sin \phi) /(1-\sin \phi) \\
\phi & =\text { internal friction angle. }
\end{aligned}
$$

The criterion can be expressed in terms of shear and normal stress at failure, as:

$$
\tau=c+\sigma_{n} \tan \phi
$$

where $\tau, \sigma_{n}=$ shear and normal stresses on the incipient failure plane $c=$ cohesion.

The uniaxial compressive strength is related to $c$ and $\phi$ by:

$$
\sigma_{c}=\frac{2 c \cos \phi}{1-\sin \phi}
$$

Regression analysis on Eq. (2.7a) gives a uniaxial compressive strength $\sigma_{c}$ of $73.4 \mathrm{MPa}$ and $\tan \psi$ of 5.341. The internal friction angle $\phi$ calculated from (Eq. 2.7b) is $43^{\circ}$. The cohesion calculated from Eq. (2.7d) is $15.9 \mathrm{MPa}$. The regression gives the coefficient of correlation $R$ as 0.973. Figure 2.16 gives the normalized major principal stress $\left(\sigma_{1} / \sigma_{c}\right)$ as a function of the normalized minor principal stress $\left(\sigma_{3} / \sigma_{c}\right)$. The line represents the best curve fit and the points represent experimental data.

\subsubsection{Bieniawski Criterion}

Bieniawski (1974) gives the following empirical power law strength criterion:

$$
\frac{\sigma_{1}}{\sigma_{c}}=1+A\left(\frac{\sigma_{3}}{\sigma_{c}}\right)^{k}
$$

or 


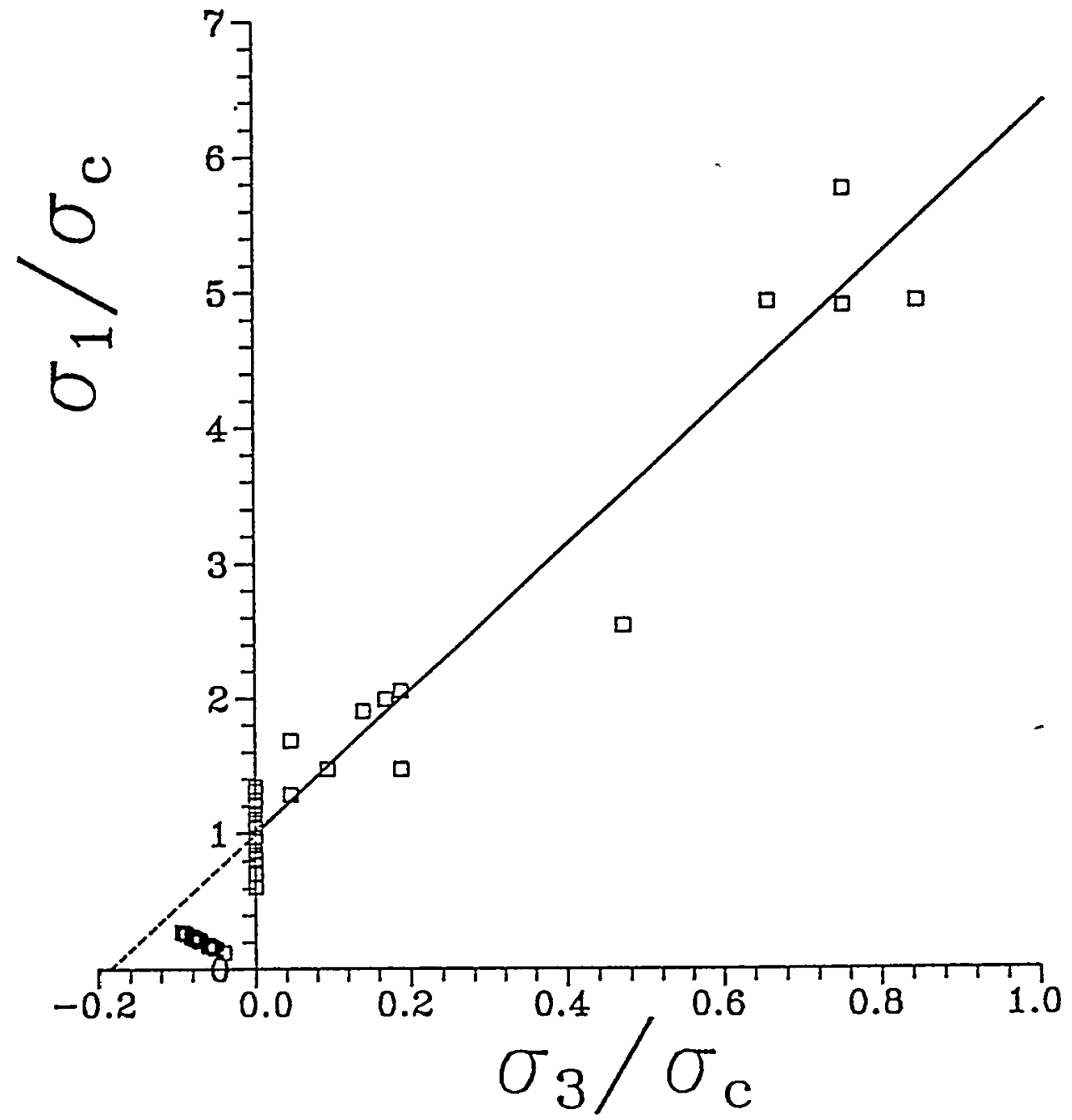

Figure 2.16 Coulomb criterion: curve fit and experimental data. Major principal stress as a function of minor principal stress at failure. Uniaxial compressive strength $\sigma_{c}=73.38 \mathrm{MPa}$. Cohesion $c=15.9 \mathrm{MPa}$. Internal friction angle $\phi=43^{\circ}$. Coefficient of correlation $R=0.973$.

Curve fit: $\quad \sigma_{1} / \sigma_{c}=1+5.341\left(\sigma_{3} / \sigma_{c}\right)$ 


$$
\frac{\tau_{m}}{\sigma_{c}}=0.1+B\left(\frac{\sigma_{m}}{\sigma_{c}}\right)^{c}
$$

where

$$
\begin{aligned}
& \tau_{m}=\frac{1}{2}\left(\sigma_{1}-\sigma_{3}\right) \\
& \sigma_{m}=\frac{1}{2}\left(\sigma_{1}+\sigma_{3}\right)
\end{aligned}
$$

$A, k, B, C$ are empirical constants.

The regression of the strength data of Apache Leap tuff on Eq. (2.8a) gives constants $A$ and $k$ as 4.497 and 0.853 . The uniaxial compressive strength $\sigma_{c}$ is predefined to be $73.2 \mathrm{MPa}$ (averaged from the uniaxial compression test results). The coefficient of correlation is 0.923 . Figure 2.17 gives the major principal stress as a function of the minor principal stress for both experimental data and the curve fit.

\subsubsection{Hoek and Brown Criterion}

Hoek and Brown (1980, pp. 137-140) present an empirical relationship between the major and minor principal stresses associated with the failure of rock:

$$
\sigma_{1}=\sigma_{3}+\left(m \sigma_{c} \sigma_{3}+s \sigma_{c}^{2}\right)^{(1 / 2)}
$$

where $\sigma_{1}, \sigma_{3}=$ major and minor principal stresses at failure

$\sigma_{c}=$ uniaxial compressive strength

$\mathrm{m}, \mathrm{s}=$ empirical constants $(\mathrm{s}=1$ for intact rock).

Hoek and Brown (1980, App. 5, pp. 513-516) give methods to calculate $\sigma_{c}$, $m$ and $s$. For the brown unit of the Apache Leap tuff, the uniaxial compressive strength $\sigma_{c}$ and parameters $m$ and $s$ are $80.5 \mathrm{MPa}, 19.9$ and 1.0 , respectively. The coefficient of correlation is 0.948 . Figure 2.18 gives the normalized major principal stress as a function of the normalized minor principal stress. The normal and shear stress at failure can be calculated using the following equation:

$$
\begin{aligned}
& \sigma=\sigma_{3}+\tau_{m}^{2} /\left(\tau_{m}+m \sigma_{c} / 8\right) \\
& \tau=\left(\sigma-\sigma_{3}\right) \sqrt{1+m \sigma_{\theta} / 4 \tau_{m}}
\end{aligned}
$$

where $\sigma, \tau=$ normal and shear stresses at failure

$$
\tau_{m}=\frac{1}{2}\left(\sigma_{1}-\sigma_{3}\right) \text {. }
$$




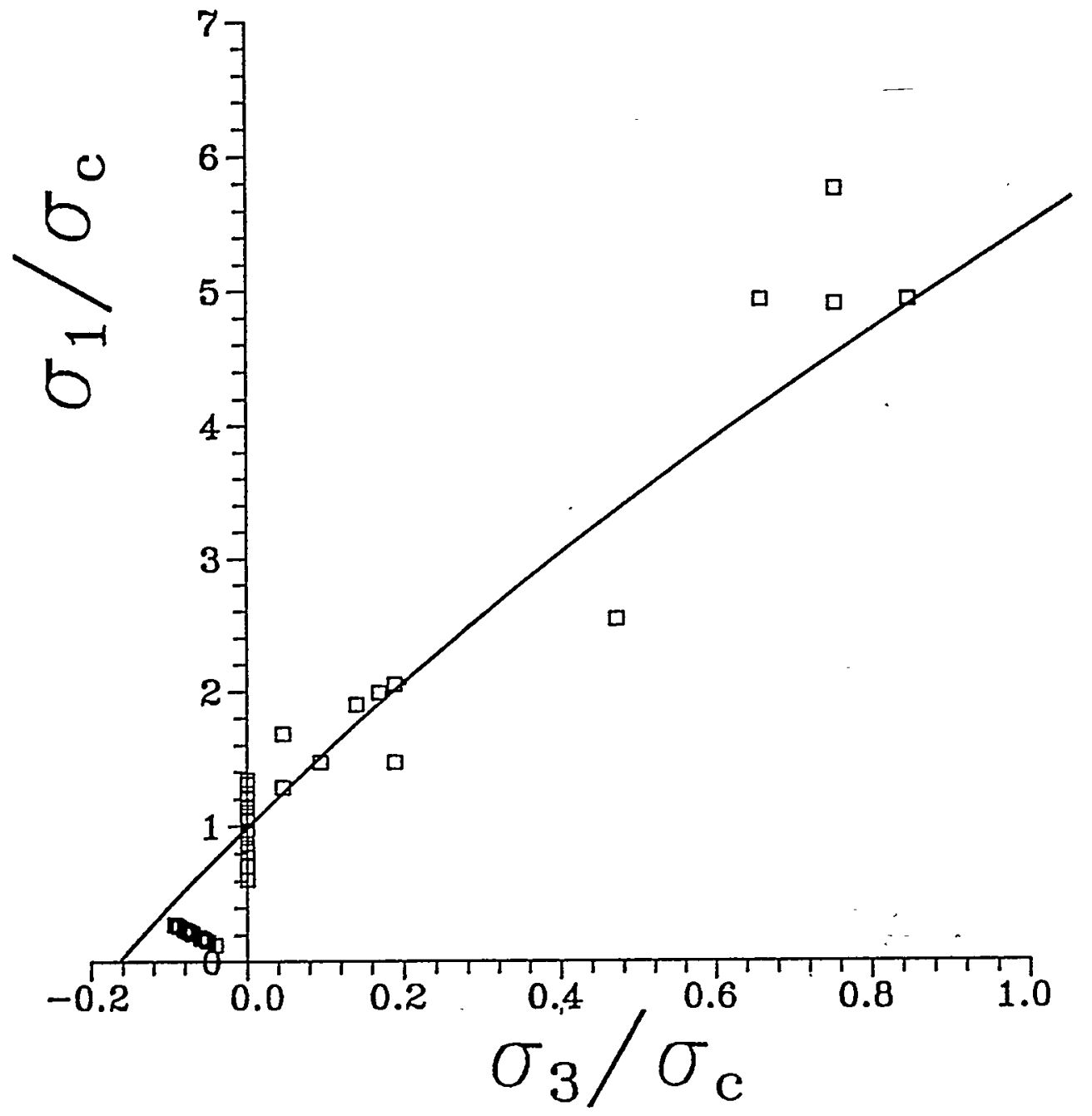

Figure 2.17 Bieniawski criterion: curve fit and experimental data. Major principal stress as a function of minor principal stress at failure. Uniaxial compressive strength $\sigma_{c}=73.2$ $\mathrm{MPa}$. Coefficient of correlation $\mathrm{R}=0.923$.

Curve fit: $\quad \sigma_{1} / \sigma_{c}=1+4.497\left(\sigma_{3} / \sigma_{c}\right)^{0.853}$ 


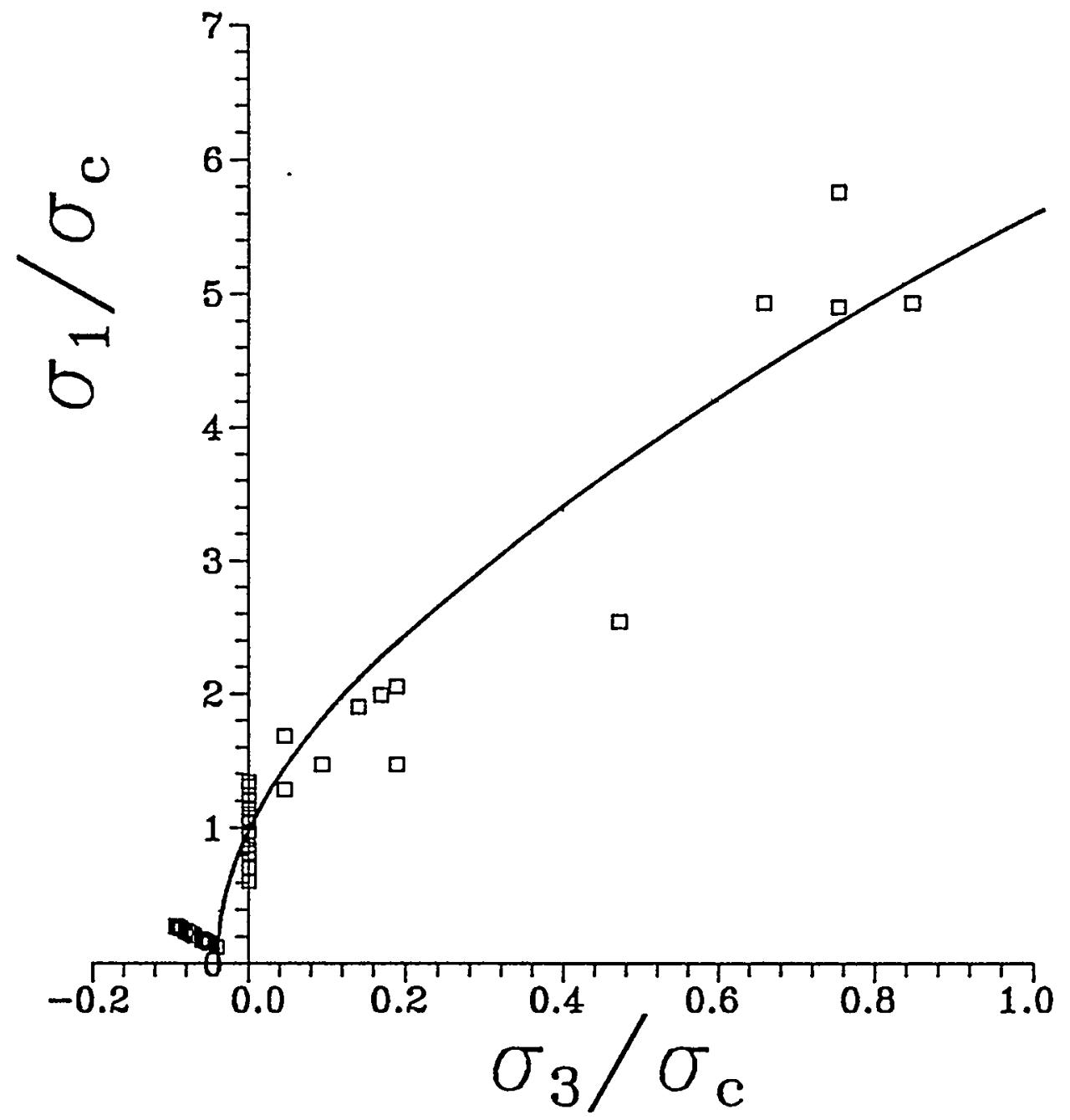

Figure 2.18 Hoek and Brown criterion: curve fit and experimental data. Major principal stress as a function of minor principal stress at failure, $m=19.9, s=1.0$. Uniaxial compressive strength $\sigma_{c}=80.5 \mathrm{MPa}$. Coefficient of correlation R 0.948 .

Curve fit: $\quad \sigma_{1} / \sigma_{c}=\sigma_{3} / \sigma_{c}+\left[19.9 \sigma_{3} / \sigma_{c}+1\right]^{1 / 2}$ 
The uniaxial tensile strength $\sigma_{1}$ can also be calculated from Hoek and Brown's empirical relations:

$$
\sigma_{t}=\frac{-1}{2} \sigma_{c}\left(m-\sqrt{m^{2}+4 s}\right)
$$

The uniaxial tensile strength of Apache Leap tuff calculated from Eq. (2.9d) is $4.0 \mathrm{MPa}$.

\subsubsection{Yudhbir Criterion}

Yudhbir et al. (1983) present an empirical non-linear relation between the major and the minor principal stresses at failure:

$$
\frac{\sigma_{1}}{\sigma_{c}}=D^{\prime}+E^{\prime}\left(\frac{\sigma_{3}}{\sigma_{c}}\right)^{f}
$$

where $D^{\prime}, E^{\prime}$ and $f$ are empirical constants.

The criterion is derived specifically to describe the rock failure under high confining pressure in the ductile range. The parameter $f$ usually ranges from 0.65 to 0.75 . When $f=1$, the Yudhbir criterion and Coulomb criterion are identical. For this condition the parameter $D^{\prime}=1$, and $E^{\prime}=\tan \psi$.

Regression analyses are made on Eq. 2.10 by predefining the parameter $f$ to be $0.6,0.70,0.75,0.90$ and 1.0 , and calculating $\mathrm{D}$ and $\mathrm{E}$. Table 2.22 gives the regression results. The correlation coefficient increases with increasing $f$. Figure 2.19 compares the curve fits and the experimental results of the $\sigma_{1}-\sigma_{3}$ relationship. The best fit is obtained when $f=1.0$, which results in $D^{\prime}=0.998 . E^{\prime}=5.341$, and correlation coefficient $=0.9730$.

\subsubsection{Griffith Criterion}

Griffith (1924) proposes a failure criterion based upon the concept that fracture of brittle materials initiates tensile stress concentrations at the tips of microcracks distributed throughout the material. The criterion relates to stresses when the microcrack begins to propagate, and does not necessarily relate to rupture on a large scale (Franklin and Dusseault, 1989, pp. 262-263). The criterion is expressed as:

$$
\begin{gathered}
\left(\sigma_{1}-\sigma_{3}\right)^{2}-8 T_{0}\left(\sigma_{1}+\sigma_{3}\right)=0 \quad \text { if } \sigma_{1}+3 \sigma_{3}>0 \\
\sigma_{3}+T_{0}=0 \quad \text { if } \sigma_{1}+3 \sigma_{3}<0
\end{gathered}
$$

where $\mathrm{T}_{\mathrm{o}}$ - uniaxial tensile strength (positive number). 
Table 2.22 Summary of Strength Analyses of the Brown Unit of Apache Leap Tuff

\begin{tabular}{|c|c|c|}
\hline Criteria & Regression Results & $\begin{array}{c}\text { Correlation Coefficient } \\
\text { R }\end{array}$ \\
\hline Coulomb (Eq. 2.1) & $\begin{array}{l}\sigma_{1}=73.38+5.341 \sigma_{3} \\
\sigma_{c}=73.38 \mathrm{MPa}, \psi=79.4^{\circ}, \phi=43.2^{\circ}, c=15.9 \mathrm{MPa}\end{array}$ & 0.973 \\
\hline Bieniawski (Eq. 2.2) & $\begin{array}{l}\sigma_{1} / \sigma_{c}=1+4.497\left(\sigma_{3} / \sigma_{c}\right)^{0.853} \\
\sigma_{c}=73.24 M P a, A=4.497, k=0.853\end{array}$ & 0.923 \\
\hline Hoek \& Brown (Eq. 2.3) & $\begin{array}{l}\sigma_{1}=\sigma_{3}+\left(19.94 \sigma_{c} \sigma_{3}+\sigma_{c}^{2}\right)^{1 / 2} \\
m=19.94, s=1.0, \sigma_{c}=80.5 \mathrm{MPa}, \sigma_{1}=4.0 \mathrm{MPa}\end{array}$ & 0.948 \\
\hline Yudhbir (Eq. 2.4) & $\begin{array}{l}\sigma_{1} / \sigma_{c}=D+E\left(\sigma_{3} / \sigma_{c}\right)^{f} ; \sigma_{c}=73.24 M P a \\
f=0.65 \rightarrow D^{\prime}=0.8630, E^{\prime}=4.710 \\
f=0.70 \rightarrow D^{\prime}=0.8843, E^{\prime}=4.817 \\
f=0.75 \rightarrow D^{\prime}=0.9051, E^{\prime}=4.929 \\
f=0.90 \rightarrow D^{\prime}=0.9663, E^{\prime}=5.179 \\
f=1.00 \rightarrow D^{\prime}=0.9980, E^{\prime}=5.341\end{array}$ & $\begin{array}{l}0.957 \\
0.962 \\
0.965 \\
0.972 \\
0.973\end{array}$ \\
\hline Griffith (Eq. 2.5) & $\left\{\begin{aligned}\left(\sigma_{1}-\sigma_{3}\right)^{2}-8 T_{0}\left(\sigma_{1}+\sigma_{2}\right)=0 & \text { if } \sigma_{1}+3 \sigma_{3}>0 \\
\sigma_{3}+T_{0}=0 & \text { if } \sigma_{1}+3 \sigma_{3}<0 \\
T_{0}=10.02 \pm 8.25 \mathrm{MPa} & \end{aligned}\right.$ & \\
\hline
\end{tabular}




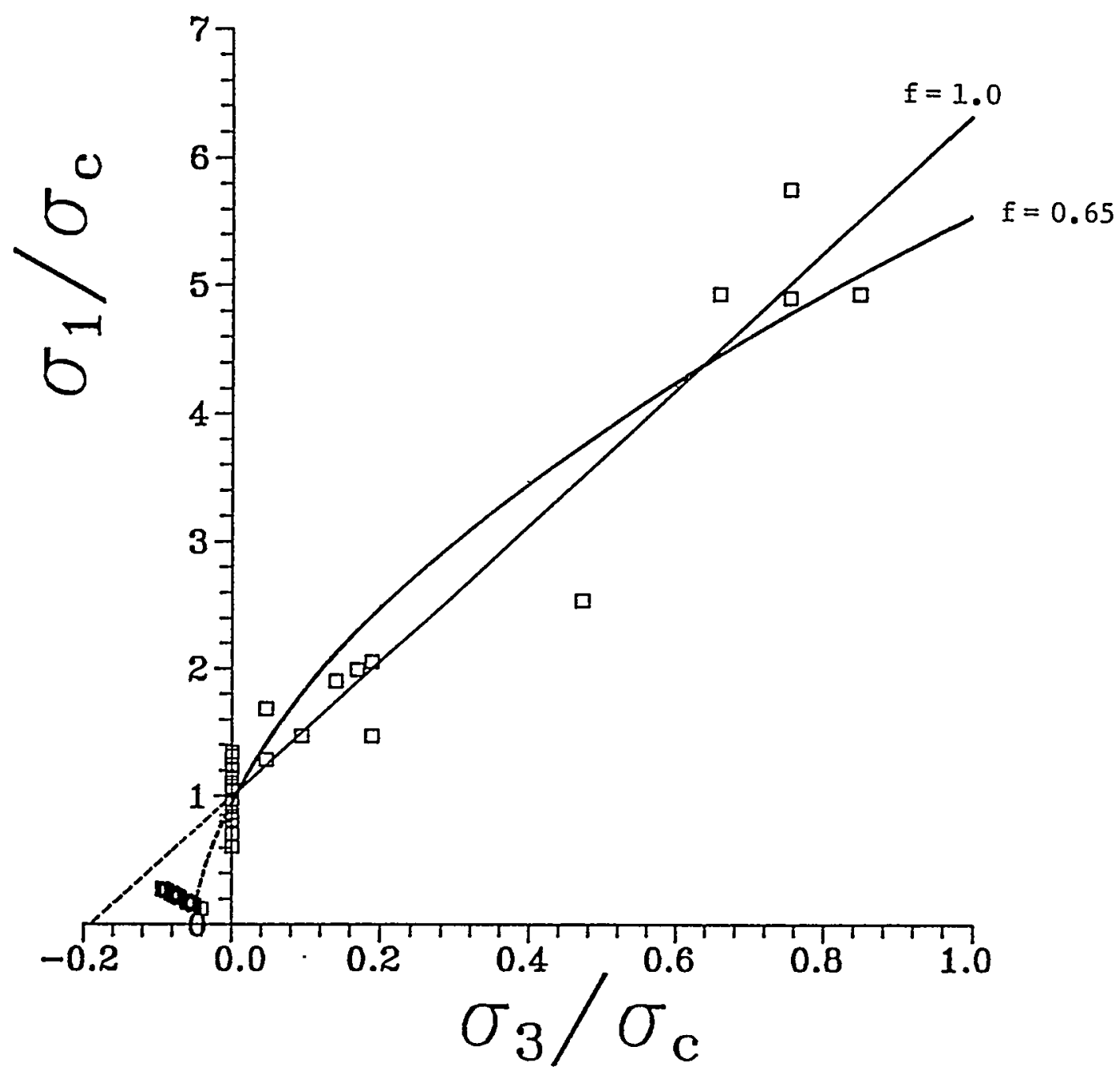

Figure 2.19 Yudhbir criterion: curve fit and experimental data. Major principal stress as a function of minor principal stress at failure. Uniaxial compressive strength $\sigma_{c}=73.2 \mathrm{MPa}$.

Curve fit: $f=0.65$; coeff. corr. $=0.957$

$\sigma_{1} / \sigma_{c}=0.863+4.710\left(\sigma_{3} / \sigma_{c}\right)^{0.65}$

Curve fit: $f=1.0$; coeff. corr. $=0.973$

$\sigma_{1} / \sigma_{c}=0.998+5.341\left(\sigma_{3} / \sigma_{c}\right)$ 
The criterion can be expressed in terms of the shear stress, $\tau$, and the normal stress, $\sigma$, acting on a plane containing the major axis of the crack:

$$
\tau^{2}=4 T_{0}\left(\sigma+T_{0}\right)
$$

The uniaxial tensile strength of the brown unit of Apache Leap tuff has not been determined experimentally. The regression results of Eq. (2.11a) give a uniaxial tensile strength of $10.02 \mathrm{MPa}$. The coefficient of variation is 828 . This calculated tensile strength exceeds the Brazilian tensile strength of the rock $\left(\sigma_{B}=5.72 \mathrm{MPa}\right)$. For the Hoek and Brown criterion (Section 2.5.3), the calculated uniaxial tensile strength of the Apache Leap tuff is $4.0 \mathrm{MPa}$. Figure 2.20 compares the experimental data with the calculated results for both $\mathrm{T}_{0}=10.02 \mathrm{MPa}$ and $\mathrm{T}_{\mathrm{o}}=4.0 \mathrm{MPa}$.

\subsubsection{Discussion of the Strength Criteria of Tuff}

Al1 criteria except the Griffith criterion adequately describe the strength of Apache Leap tuff. The Coulomb criterion gives the best representation.

The linear relationship between the major and the minor principal stresses at failure is confirmed by the regression results of the Yudhbir criterion. The coefficient of correlation increases as the stress exponent, $f$, approaches 1 (Table 2.22). When the stress exponent $f=1$, the Coulomb and Yudhbir criteria are identical.

The tuff behaves as a brittle material. The maximum confining pressure used here ( $62 \mathrm{MPa}$ ) is insufficient to induce ductile behavior. The brittle-to-ductile transition confining pressure of the Apache Leap tuff is higher than $62 \mathrm{MPa}$.

The strength analysis of the Apache Leap tuff performed here assumes that the rock samples are isotropic. The rock samples have the cylinder axis perpendicular to the flow layers. The flow layers could cause anisotropic behavior. The effect of the flow layers on the mechanical properties of the rock has not been determined.

The data used in the analysis is obtained from tuff samples tested dry. Prior to testing, the samples are oven dried for at least 24 hours.

Price (1983) uses the Coulomb criterion to describe the strength of Topopah Spring tuff. His analysis gives an internal friction angle of $67^{\circ}$ and cohesion of $17.5 \mathrm{MPa}$ for dry conditions. Under saturated and drained tests conditions, the friction angle and cohesion are $23.5^{\circ}$ and $34.5 \mathrm{MPa}$. Under dry conditions, the friction angle and cohesion of Apache Leap tuff are substantially lower than those of Topopah Spring tuff. 


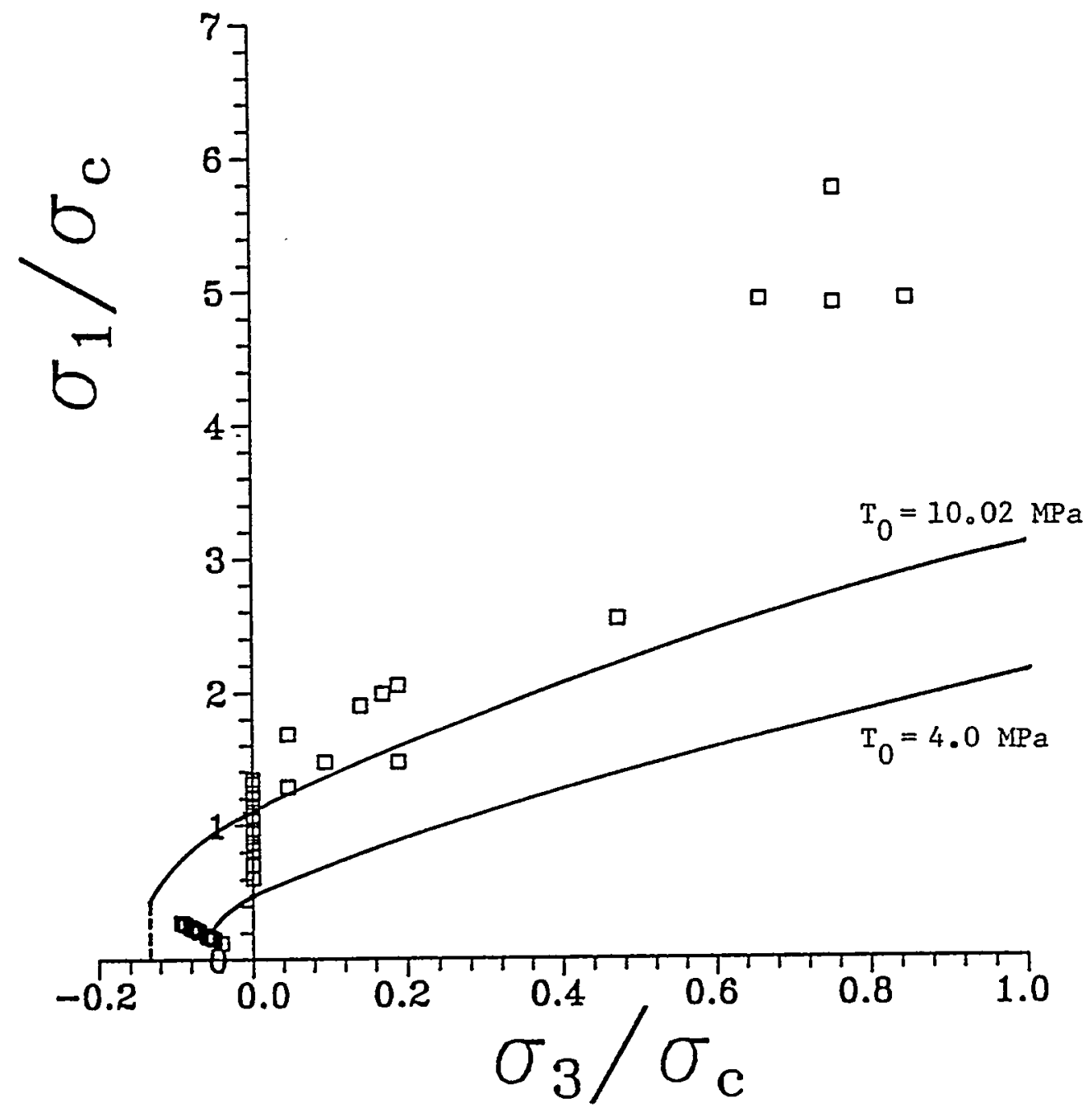

Figure 2.20 Griffith criterion, curve fit and experimental data. Major principal stress as a function of minor principal stress at failure. Uniaxial compressive strength $\sigma_{c}=73.2 \mathrm{MPa}$. $T_{0}=$ $10.02 \mathrm{MPa}$ (regression result) $=4.0 \mathrm{MPa}$ (from Hoek and Brown criterion).

Curve Fits: $\left[\frac{\sigma_{1}}{\sigma_{c}}-\frac{\sigma_{3}}{\sigma_{c}}\right]^{2}=0.4372\left[\frac{\sigma_{1}}{\sigma_{c}}+\frac{\sigma_{3}}{\sigma_{c}}\right]$ for $T_{0}=4.0 \mathrm{MPa}$

$\left[\frac{\sigma_{1}}{\sigma_{c}}-\frac{\sigma_{3}}{\sigma_{c}}\right]^{2}=1.095\left[\frac{\sigma_{1}}{\sigma_{c}}+\frac{\sigma_{3}}{\sigma_{c}}\right]$ for $T_{0}=10.02 \mathrm{MPa}$ 


\subsection{Proposed Compressive Strength Criterion}

This section presents an empirical approach to develop a compressive failure criterion for heterogeneous tuff. The multiaxial stress analysis includes the effects of rock heterogeneity, sample size and shape, and loading rate. The formulation is based upon the concept that homogeneity is relative, depending upon the scale of interest. As the scale increases, rock becomes relatively more homogeneous. The criterion is presented in a form as general as possible in order to allow correlating to other criteria. The proposed derivation method can be used to modify any existing or new criteria so that they can be applied to heterogeneous rocks. Predictive capability of the criterion has been assessed by performing biaxial compressive strength tests. Rock samples tested are prepared from the welded Apache Leap tuff. Even though the criterion derived here is for this tuff, the approach is applicable to other heterogeneous rocks.

\subsubsection{General Form of the Proposed Failure Criterion}

The second invariant of stress deviation $\left(J_{2 D}\right)^{1 / 2}$ at failure is presented as a function of the first invariant of stress $\left(I_{1}\right)$, rock volume, and key parameter:

$$
\left(J_{2 D}\right)^{1 / 2}=f\left\{I_{1}, V, \rho\right\}
$$

$$
\begin{array}{ll}
\text { where } & J_{2 D}=\left(\left(\sigma_{1}-\sigma_{2}\right)^{2}+\left(\sigma_{2}-\sigma_{3}\right)^{2}+\left(\sigma_{3}-\sigma_{1}\right)^{2}\right) / 6 \\
I_{1}=\sigma_{1}+\sigma_{2}+\sigma_{3} \\
\sigma_{1}, \sigma_{2}, \sigma_{3} \quad=\text { principal stresses at failure } \\
V=\text { volume of rock sample } \\
\rho=\text { key parameter. }
\end{array}
$$

The key parameter $\rho$ represents the most prominent physical or chemical factor affecting the rock strength for all sizes. It is incorporated to account for the heterogeneity effect on the strength. The influence of the parameter is not necessarily equally pronounced for all sizes. Some rock types may have more than one key parameter. Examples of variables whose effect may be represented by the key parameter are density (for tuff, sandstone or coal), percentage of impurities such as iron oxides or clay minerals (for salt, limestone or sandstone), grain size (for well-graded sandstone or conglomerate), welding or grain bonding (for volcanic or metamorphic rocks), porosity, pore size, moisture content, etc. The parameters are selected by investigating the results from characterization testing for various samples sizes. Mathematical (empirical) relationships between each key parameter and sample volume must be identified. Incorporation of the sample volume not only describes the variation of the heterogeneity effect with size, but also corrects for the size effect on rock strength.

The intermediate principal stress $\left(\sigma_{2}\right)$, absent in many strength criteria, may affect rock strength (Murrell, 1966; Handin et al., 1967; Mogi, 1967; Hoskins, 1969; Lundborg, 1972). The proposed criterion considers all principal stresses at failure. Even though the effect of $\sigma_{2}$ is not 
analyzed here due to lack of test data, determining the strength in terms of $\left(J_{2 D}\right)^{1 / 2}$ as a function of $\left(I_{1}\right)$ allows incorporating this effect (Desai and Siriwardane, 1984, pp. 240-282). The proposed derivation method is not limited to the strength in terms of $\left(J_{2 D}\right)^{1 / 2}$. Rock strength can be defined in several alternative forms, for example as a function of octahedral shear stress, deviatoric strain energy density, total strain energy density (Jaeger and Cook, 1979, pp. 123-125), or third stress invariant (Kim and Lade, 1984). For two-dimensional analysis, the strength can be defined in terms of the shear stress, major principal stresses, or deviatoric stress. Similarly, the effect of confining pressures or stress states under which the fallure is induced, incorporated here in $I_{1}$, can be expressed as a function of mean stress or volumetric strain energy density, and for two-dimensional analysis by confining pressure. The derivation method presented here can be used to modify any existing criteria to allow describing failure for heterogeneous rocks.

\subsubsection{Formulation of Proposed Failure Criterion}

The objective of the investigation is to derive a compressive strength criterion in terms of $\left(J_{2 D}\right)^{1 / 2}$ as a function of $I_{1}$, rock volume and key parameters. The test results used in the derivation must be isolated from the effects of other test parameters, such as loading rate, sample shape (length to diameter ratio), etc. In practice, maintaining these test parameters constant is sometimes difficult, particularly for testing on a wide range of sample sizes. The following derivation gives methods to formulate the failure criterion from the uniaxial and triaxial test results and to isolate these results from the effects of loading rate and length to diameter ratio.

\subsubsection{Heterogeneity Effect - Key Parameter}

Under an identical set of test parameters (i.e. size, shape, confining pressure, loading rate, etc.), variation of rock strength among samples is governed only by the key parameter. The $\left(J_{2 D}\right)^{1 / 2}$ at failure can therefore be presented as:

$$
\left(J_{2 D}\right)^{1 / 2}=f\{\rho\}
$$

If the rock is homogeneous, $f\{p\}$ becomes constant. For heterogeneous rocks, a mathematical relationship between $\left(J_{2 D}\right)^{1 / 2}$ and $f\{\rho\}$ must be identified. In this investigation, bulk density is selected as the key parameter governing the variation of the strength for the Apache Leap tuff. Many investigators (e.g. Knudsen, 1959; Hoshino, 1974; Price, 1983; Sammis and Ashby, 1986; Howarth, 1987; Nimick, 1988) have discovered a good correlation between compressive strength and porosity for porous rocks, including volcanic tuffs. Based upon fracture mechanics, they derive empirical relations between cohesion, friction angle and porosity, and incorporate them in the Coulomb strength criterion. In practice, it is difficult and time-consuming to obtain a precise porosity for mechanical test samples, particularly for rocks with low porosity, a large amount of unconnected (isolated) pores, and large variation of mineral composition. Influencing the mechanical heterogeneity of the 
Apache Leap tuff are not only porosity but also welding and variations in chemical and mineralogical composition. It is therefore more appropriate to consider bulk density as a key parameter. Results from the uniaxial tests indicate that the compressive strength is highly sensitive to differences in density (Figure 2.21). For all sample sizes, the strengths increase with density. For each sample size (volume), the $\left(J_{2 D}\right)^{1 / 2}$ at failure can be presented as a linear function of $p$ :

$$
\left(J_{2 D}\right)^{1 / 2}=A \rho+B
$$

Equation (2.14) is assumed valid if all samples have an identical size, or if the effect of the density variation is equally pronounced for all sizes. The relationship between $\left(J_{2 D}\right)^{1 / 2}$ and the key parameter is not limited to a linear equation; different forms of best fitted equations may be used (power, exponential, logarithmic, etc.). Based upon the proposed concept, the effect of rock heterogeneity should decrease as the scale increases. The parameters $A$ and $B$ should therefore be a function of rock volume:

$$
\begin{aligned}
& A=A^{\prime}\{V\} \\
& B=B^{\prime}\{V\}
\end{aligned}
$$

The function $A^{\prime}\{V\}$ represents the rate change of rock strength with density for various sample sizes and can be calculated from the uniaxial test results. Figure 2.22 gives the variation of $A$ with rock volume. Regression analyses show that $A$ decreases exponentially with volume and can be best represented by:

$$
A=\alpha \exp (-\lambda V)
$$

where $\alpha$ and $\lambda$ are empirical constants.

For the Apache Leap tuff, $\alpha=347.3 \mathrm{MPa}(\mathrm{g} / \mathrm{cc})^{-1}$ and $\lambda=279.4 \mathrm{~m}^{-3}$, with a coefficient of correlation (R) of 0.999. By substituting Eq. (2.15) and Eq. (2.16) into Eq. (2.12), we obtain:

$$
\left(J_{2 D}\right)^{1 / 2}=\alpha \rho \exp (-\lambda V)+B^{\prime}\{V\}
$$

To correlate the strengths from samples with identical size and shape but with different densities, Eq. (2.17) can be rewritten as:

$$
\left(J_{2 D}\right)_{a}^{1 / 2}=\alpha \rho_{a} \exp (-\lambda V)+B^{\prime}\{V\}
$$

and

$$
\left(J_{2 D}\right)_{b}^{l / 2}=\alpha \rho_{b} \exp (-\lambda V)+B^{\cdot}\{V\}
$$




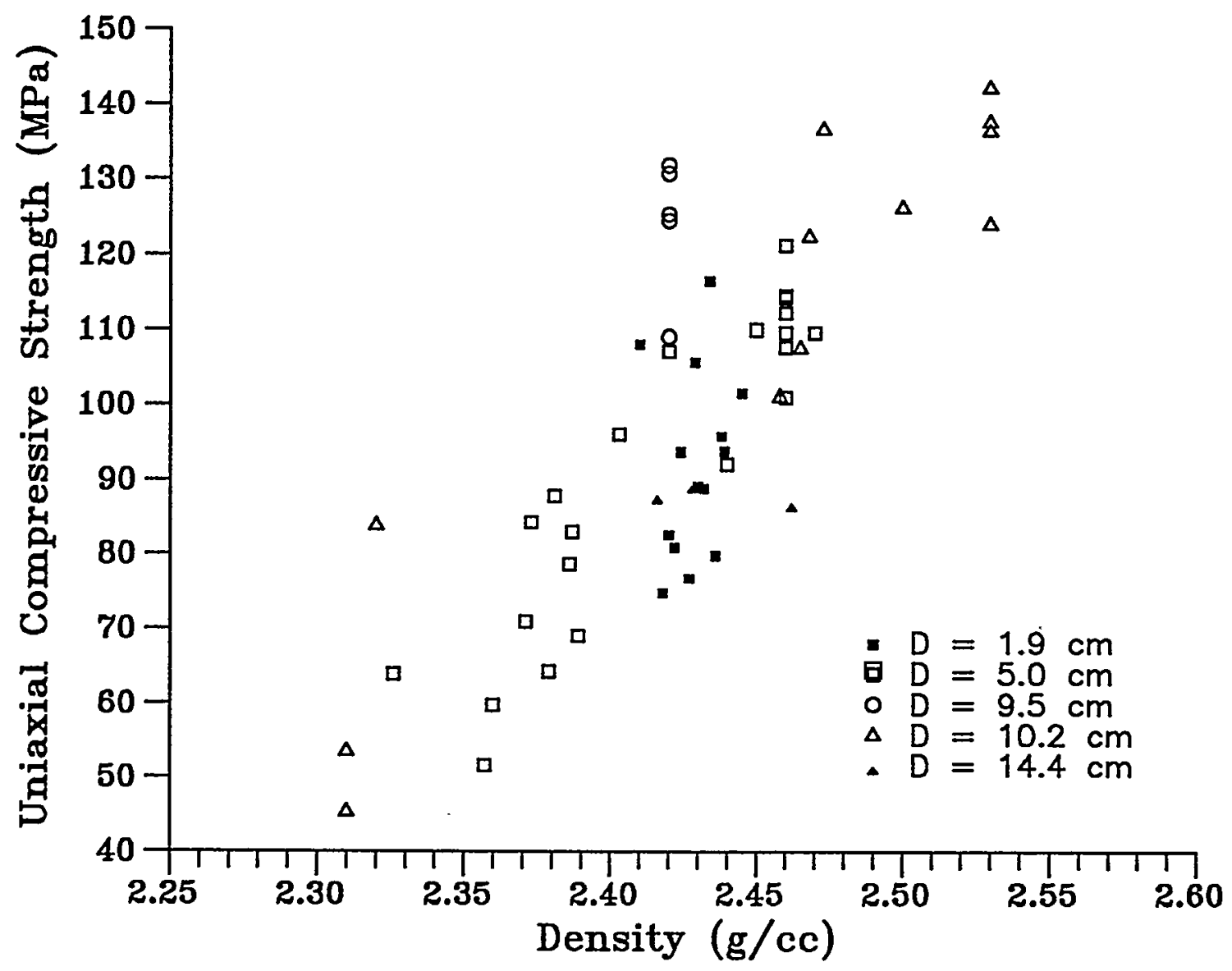

Figure 2.21 Uniaxial compressive strengths as a function of sample density for various sample diameters (D). 


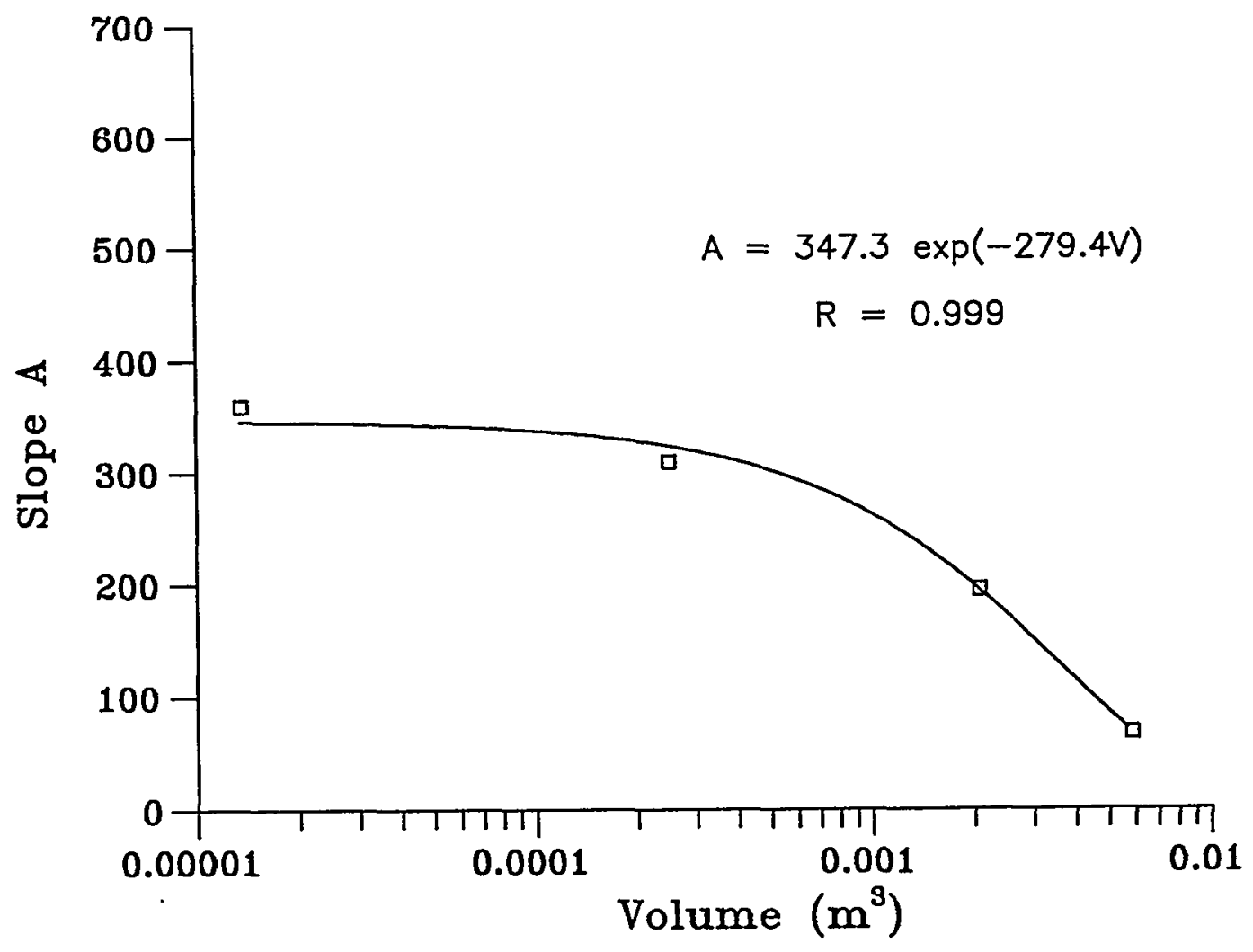

Figure 2.22 Slope A of the relation between strength $\left(J_{2 D}\right)^{1 / 2}$ and density, as a function of volume, experimental results (points) and curve fit. 
where $\left(J_{2 D}\right)_{a}^{1 / 2}=$ second invariant of stress deviation at failure for sample with volume $V$ and density $\rho_{a}$

$\left(J_{2 D}\right)_{0}^{1 / 2}=$ second invariant of stress deviation at failure for sample with volume $\mathrm{V}$ and density $\rho_{b}$

By subtracting Eq. (2.18b) from Eq. (2.18a), we obtain

$$
\left(J_{2 D}\right)_{a}^{1 / 2}=\left(J_{2 D}\right)_{b}^{1 / 2}+\alpha\left(\rho_{a}-\rho_{b}\right) \exp (-\lambda V)
$$

\subsubsection{Effect of Length-to-Diameter Ratio}

The length-to-diameter ratio (L/D) for uniaxial test samples has been maintained as close as possible to 2.5, which satisfies both ASTM (D2938-79) and ISRM (1979) standards. For large samples (10 and $14 \mathrm{~cm}$ diameters), it is difficult to obtain samples with length of 2.5 times the diameter without including major cracks and fractures. A11 large samples have therefore been prepared with $\mathrm{L} / \mathrm{D}$ ratios between 2.0 and 2.2. It is recognized that the variation of the $\mathrm{L} / \mathrm{D}$ ratios influences the mechanical responses of rock samples (i.e. end effect - Hudson et al., 1971; Turk and Dearman, 1986). Prior to correlating the strength $\left(J_{2 D}\right)^{1 / 2}$ from different sample sizes, the effect of L/D variation has been investigated. Uniaxial test data from samples tested under a strain rate of $0.29 \times 10^{-6}$ per second and having a density of $2.46 \mathrm{~g} / \mathrm{cc}$ and $L / D$ ratios between 2 and 3 are used in a linear regression. Figure 2.23 gives the test results and curve fit. The decrease of strength $\left(J_{2 D}\right)^{1 / 2}$ with increasing L/D ratio can be represented best by a logarithmic equation:

$$
\left(J_{2 D}\right)^{1 / 2}=C-\beta \ln (L / D)
$$

where $C$ and $\beta$ are empirical constants.

The regression gives $C=83.49 \mathrm{MPa}, \beta=19.64 \mathrm{MPa}$ and coefficient of correlation of 0.898 . To correlate the strengths from samples with different L/D ratios, Eq. (2.20) can be rewritten as:

$$
\left(J_{2 D}\right)_{b}^{1 / 2}=\left(J_{2 D}\right)_{c}^{1 / 2}+\beta\left\{\ln (L / D)_{c}-\ln (L / D)_{b}\right\}
$$

where $\left(J_{2 D}\right)_{b}^{1 / 2}=$ strength obtained from sample with $(L / D)_{b}$

$$
\left(J_{2 D}\right)_{c}^{1 / 2}=\text { strength obtained from sample with }(L / D)_{c} \text {. }
$$

The derivation of Eq. (2.21) is similar to that of Eq. (2.19). The heterogeneity and $L / D$ ratio effects can be combined by substituting Eq. (2.21) into Eq. (2.19):

$$
\left(J_{2 D}\right)_{a}^{1 / 2}=\left(J_{2 D}\right)_{c}^{1 / 2}+\beta\left\{\ln (L / D)_{c}-\ln (L / D)_{b}\right\}+\alpha\left(\rho_{a}-\rho_{b}\right) \exp (-\lambda V)
$$




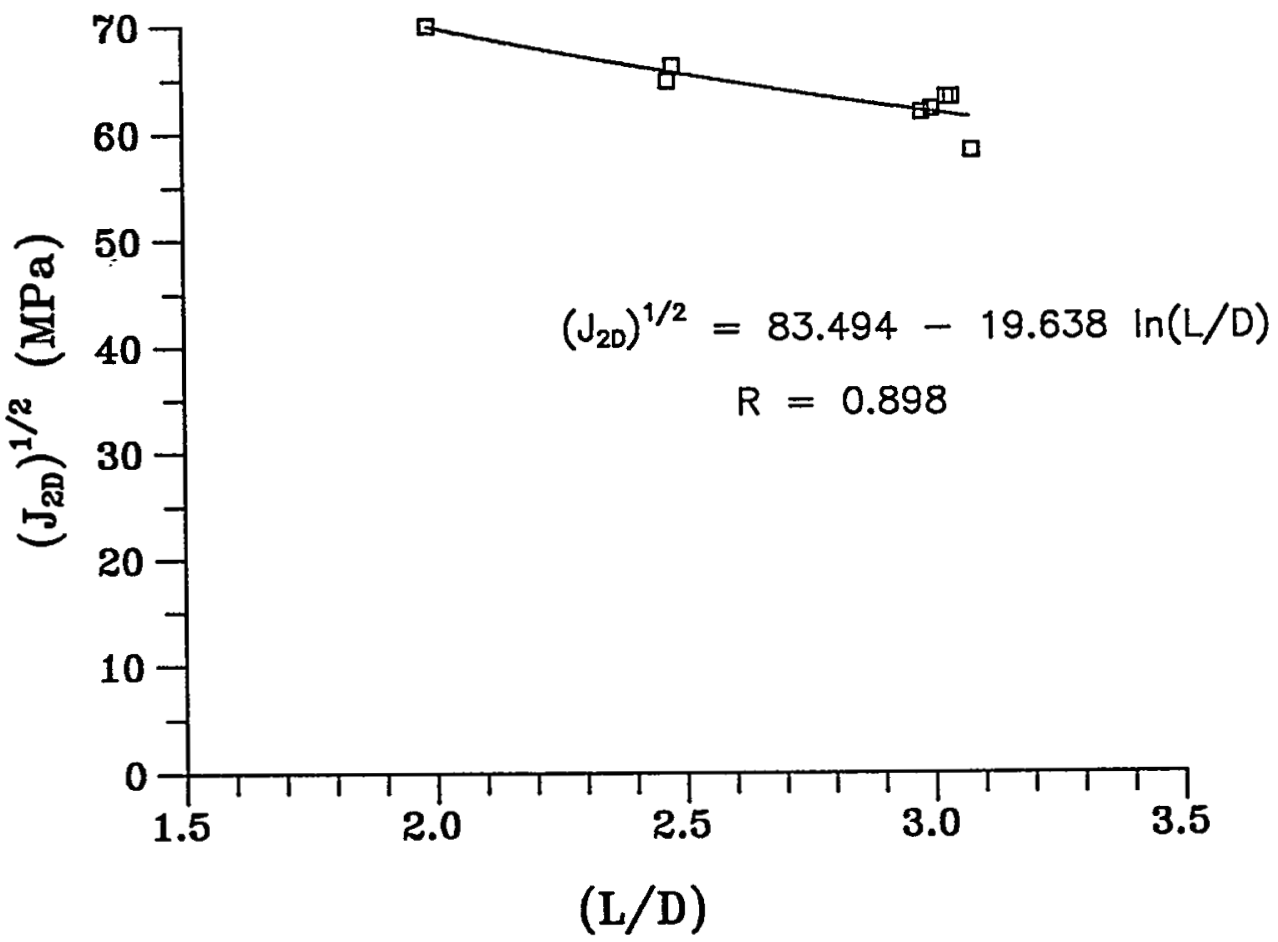

Figure $2.23\left(J_{2 D}\right)^{1 / 2}$ at failure as a function of L/D ratio, from uniaxial test samples with density of $2.46 \mathrm{~g} / \mathrm{cc}$. 
This mathematical combination assumes that the effect of density variation on strength is equally pronounced within the range of L/D ratio between 2 and 3. Equation (2.19) has been derived from samples with L/D - 2.5, Eq. (2.21) from samples with density $=2.46 \mathrm{~g} / \mathrm{cc}$. Therefore, $(L / D)_{b}$ should be set equal to 2.5 , and $\rho_{a}$ should be $2.46 \mathrm{~g} / \mathrm{cc}$. These reference values (common test parameters) link the heterogeneity effect (Eq. 2.19) to the L/D ratio effect (Eq. 2.21). Equation (2.22) can be rewritten as:

$$
\left(J_{2 D}\right)_{a}^{1 / 2}=\left(J_{2 D}\right)_{c}^{l / 2}+\beta\left\{\ln (L / D)_{c}-\ln (L / D)^{*}\right\}+\alpha\left(\rho^{*}-\rho_{b}\right) \exp (-\lambda V)
$$

where $(L / D)^{\circ}=$ reference $L / D$ ratio (taken here as 2.5 )

$$
\begin{aligned}
& \rho^{*}=\text { reference density (taken here as } 2.46 \mathrm{~g} / \mathrm{cc} \text { ) } \\
& \left(J_{2 D}\right)_{a}^{1 / 2}=\text { strength from samples with }(L / D)^{*} \text { and } \rho^{*} \\
& \left(J_{2 D}\right)_{c}^{1 / 2}=\text { strength from samples with }(L / D)_{c} \text { and } \rho_{b}
\end{aligned}
$$

All samples used in determining the constants for Eqs. (2.19) through $(2.23)$ have been tested under an axial strain rate of $0.29 \times 10^{-6} / \mathrm{s}$.

\subsubsection{Effect of Loading Rate}

Recognizing that fracture propagation in rock is time-dependent (Bieniawski, 1970; Kranz, 1983; Horii and Nemat-Nasser, 1985; Costin, 1987), the effect of loading rate on strength of the tuff has been investigated. In general, a rock sample loaded at a high rate has a higher strength than one loaded at a lower rate. Strain-rate-controlled uniaxial tests have been performed at rates from $10^{-8}$ to $10^{-3}$ per second. To investigate the time-dependent effect, the strength results must be isolated from the effects of density and I/D ratio. Equation (2.23) is used to calculate a new set of strength data isolated from those effects. In this case, $\left(J_{2 D}\right)_{c}^{1 / 2}$ represents the original strength (calculated from experimental results), a density of $\rho_{b}$ and length-todiameter ratio $(L / D)_{c} . \quad\left(J_{2 D}\right)_{a}^{1 / 2}$ represents the new (adjusted) strength corresponding to $\rho^{*}(=2.46 \mathrm{~g} / \mathrm{cc})$ and $(L / D)^{*}(=2.5)$. Figure 2.24 compares the original and adjusted strengths as a function of strain rate $\left(\epsilon_{R}\right)$. The increase of the adjusted strengths with $\epsilon_{R}$ can best be represented by a logarithmic equation:

$$
\left(J_{2 D}\right)^{1 / 2}=\kappa \ln \left(\epsilon_{R}\right)+D
$$

where $\epsilon_{R}=$ axial strain rate (microstrain)

$\kappa, D=$ empirical constants. 


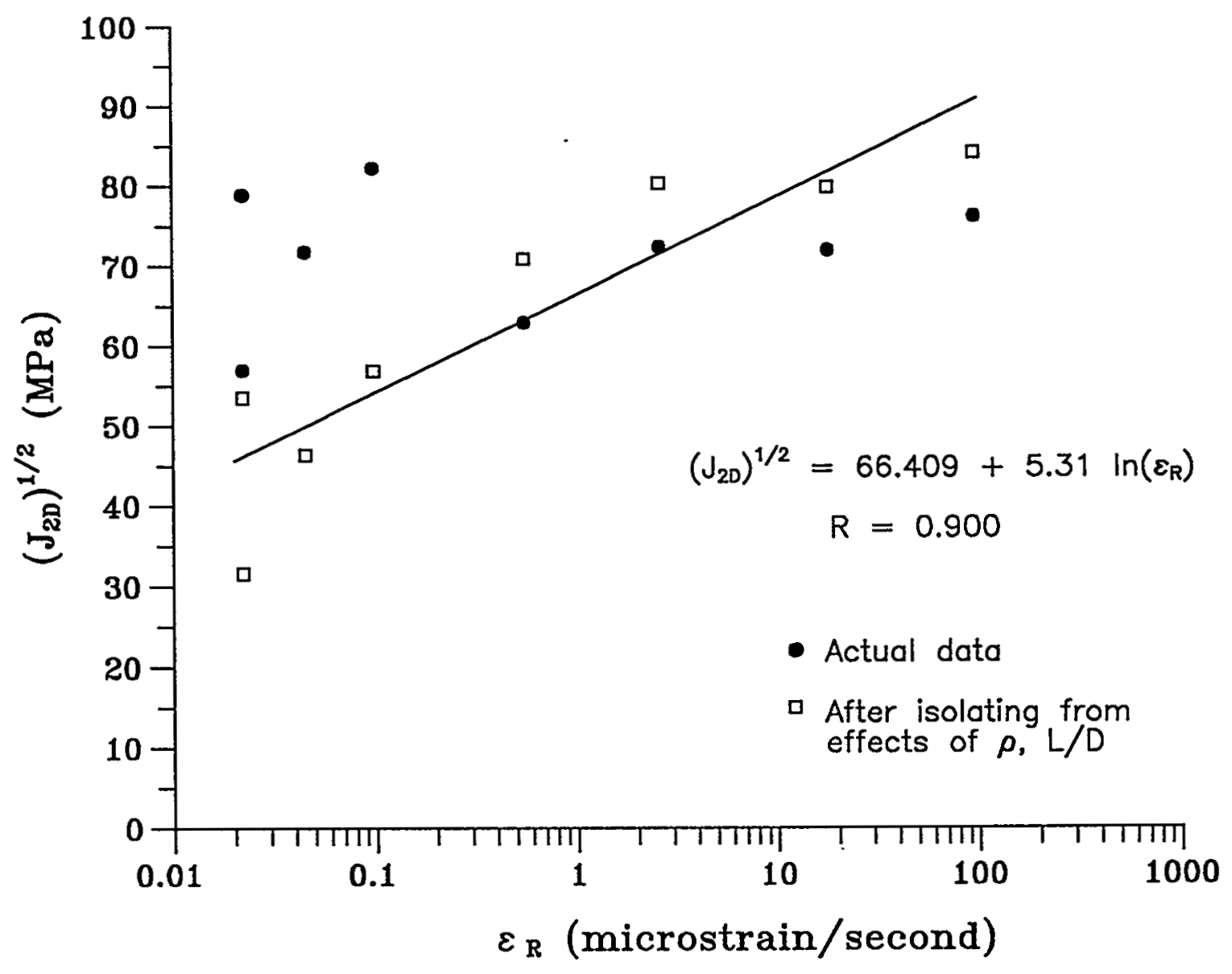

Figure 2.24 Comparison between $\left(J_{2 D}\right)^{1 / 2}$ from actual data and from those after isolating from effects of $\rho$ and $L / D$; curve fits to adjusted strength data. 
Regression gives $\kappa=5.310 \mathrm{MPa}$ and $D=66.41 \mathrm{MPa}$, with a correlation coefficient $=0.900$. Similar to Eqs. (2.19) and (2.21), Eq. (2.24) can be rewritten in a correlated form as:

$$
\left(J_{2 D}\right)_{c}^{1 / 2}=\left(J_{2 D}\right)_{d}^{1 / 2}+\kappa\left\{\ln \left(\epsilon_{R}\right)_{c}-\ln \left(\epsilon_{R}\right)_{d}\right\}
$$

where $\left(J_{2 D}\right)_{c}^{1 / 2}=$ strength from samples tested at strain rate $\left(\epsilon_{R}\right)_{c}$ $\left(J_{20}\right)_{d}^{1 / 2}=$ strength from samples tested at strain rate $\left(\epsilon_{R}\right)_{d^{*}}$

By defining $\left(\epsilon_{R}\right)_{c}$ as a reference strain rate $\left(\epsilon_{R}^{*}\right)$ equal to $0.29 \times 10^{-6} / \mathrm{s}$ (strain rate from which Eqs. (2.19) and (2.21) have been derived in this numerical example), and substituting Eq. (2.25) into Eq. (2.23), we obtain:

$$
\begin{aligned}
\left(J_{2 D}\right)_{a}^{1 / 2}= & \left(J_{2 D}\right)_{d}^{1 / 2}+\kappa\left\{\ln \left(\epsilon_{R}^{*}\right)-\ln \left(\epsilon_{R}\right)_{d}\right\}+\beta\left\{\ln (L / D)_{c}-\ln (L / D)^{*}\right\} \\
& +\alpha\left(\rho^{*}-\rho_{b}\right) \exp (-\lambda V)
\end{aligned}
$$

where $\left(J_{2 D}\right)_{a}^{1 / 2}=$ strength from sample with $\rho^{*},(L / D)^{*}, \epsilon_{R}^{*}$

$$
\left(J_{2 D}\right)_{d}^{1 / 2}=\text { strength from sample with } \rho_{a},(I / D)_{c},\left(\epsilon_{R}\right)_{d} \text {. }
$$

\subsubsection{Size Effect}

Tundborg's logarithmic expression is used to correlate the strength to sample size (Lundborg, 1967; Jaeger and Cook, 1979, pp. 196-198). Prior to investigating the size effect, all strength data from uniaxial testing have been isolated from the effects of $\rho, L / D$, and $\epsilon_{R}$, by using $E q$. (2.25). The adjusted strength data correspond to $\rho=2.46 \mathrm{~g} / \mathrm{cc}$, $L / D=2.5$ and $\epsilon_{R}=0.29 \mu / \mathrm{s}$. Figure 2.25 compares the original and adjusted strengths (averaged from each size) as a function of sample volume. The adjusted strengths decrease with increasing sample size. Lundborg's expression can be written in terms of $\left(J_{2 D}\right)^{1 / 2}$ and volume as:

$$
\left(J_{2 D}\right)^{1 / 2}=m-\eta \ln (V)
$$

where $m, \eta$ = empirical constants.

Regression on the new strength data gives $m=46.38 \mathrm{MPa}$ and $\eta=2.04$ $\mathrm{MPa}$ with a correlation coefficient of 0.899 . Equation (2.27) can be written in a correlated form as:

$$
\left(J_{2 D}\right)_{d}^{1 / 2}=\left(J_{2 D}\right)_{e}^{1 / 2}+\eta\left\{\ln \left(V_{e}\right)-\ln \left(V_{d}\right)\right\}
$$




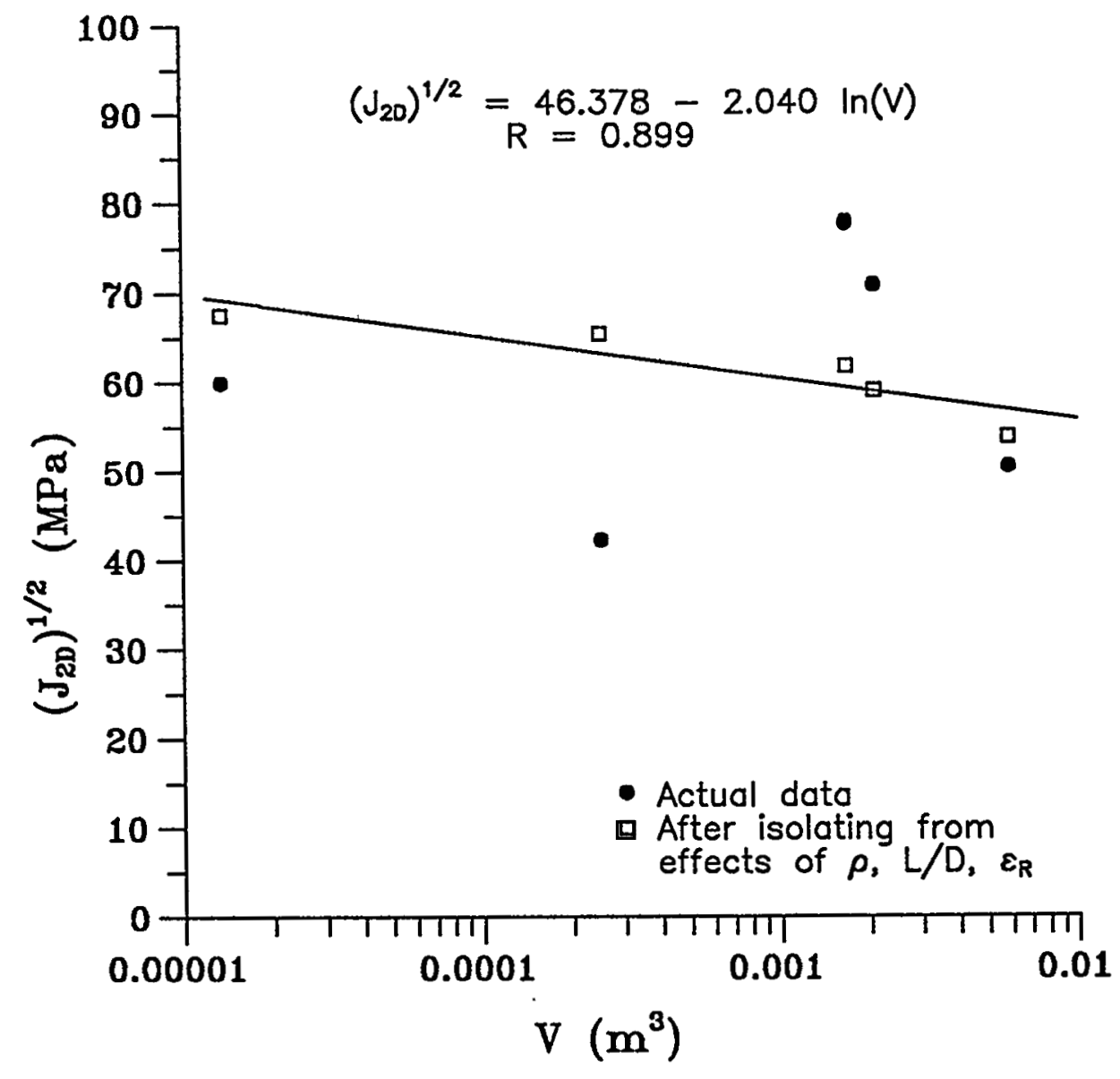

Figure 2.25 Comparison between $\left(J_{2 D}\right)^{1 / 2}$ from actual data and from those obtained by removing the effects of $\rho, L / D$ and $\epsilon_{R}$; curve fits to adjusted strength data. 
where $\left(J_{2 D}\right)_{d}^{1 / 2}=$ strength from sample with volume $V_{d}$

$$
\left(J_{2 D}\right)_{e}^{1 / 2}=\text { strength from sample with volume } V_{\text {e. }}
$$

By defining $V_{d}$ as a reference volume $V^{*}$, and equal to $2.5 \times 10^{-4} \mathrm{~m}^{3}$ (volume of samples from which Eqs. (2.19), (2.21) and (2.24) have been derived), Eq. (2.28) can be substituted into Eq. (2.26):

$$
\begin{aligned}
\left(J_{2 D}\right)_{a}^{1 / 2}= & \left(J_{2 D}\right)_{e}^{1 / 2}+\eta\left\{\ln \left(V_{e}\right)-\ln \left(V^{*}\right)\right\}+\kappa\left\{\ln \left(\epsilon_{R}^{*}\right)-\ln \left(\epsilon_{R}\right)_{d}\right\} \\
& +\beta\left\{\ln (L / D)_{c}-\ln (L / D)^{*}\right\}+\alpha\left(\rho^{*}-\rho_{b}\right) \exp \left(-\lambda V_{e}\right)
\end{aligned}
$$

where $\left(J_{2 D}\right)_{a}^{1 / 2}-$ strength from samples with $\rho^{*},(L / D)^{*}, \epsilon_{R}^{*}$, and $V^{*}$

$$
\left(J_{2 D}\right)_{e}^{1 / 2}=\text { strength from samples with } \rho_{b},\left(L / D_{c},\left(\epsilon_{R}\right)_{d} \text { and } V_{e}\right. \text {. }
$$

The second through fourth terms on the right-hand side of Eq. (2.29) represent a correction term $(C T)$ for the strength $\left(J_{2 D}\right)^{1 / 2}$ determined from uniaxial compression tests. The correction term equals zero if $\left(J_{2 D}\right)_{e}^{1 / 2}$ is obtained from samples with density $=2.46 \mathrm{~g} / \mathrm{cc}$, length to diameter ratio $=2.5$, strain rate $=0.29 \mu / \mathrm{s}$, and volume $=0.00025 \mathrm{~m}^{3}$. Equation (2.29) can be rewritten as:

$$
\left(J_{2 D}\right)_{a}^{1 / 2}=\left(J_{2 D}\right)^{1 / 2}+C T
$$

where $\left(J_{2 D}\right)^{1 / 2}=$ strength calculated from uniaxial compression results $\left(J_{2 D}\right)_{a}^{1 / 2}$ - adjusted (new) strength corresponding to reference parameters

$$
C T=\eta\left\{\ln \left(V_{e}\right)-\ln \left(V^{*}\right)\right\}+x\left\{\ln \left(\epsilon_{R}^{*}\right)-\ln \left(\epsilon_{R}\right)_{d}\right\}+\beta\left\{\ln (L / D)-\ln (L / D)_{c}^{*}\right\}
$$

$$
+\alpha\left(\rho^{*}-\rho_{0}\right) \exp (-\lambda V)
$$

\subsubsection{Effect of Confining Pressure}

The strength criterion incorporates the effect of confining pressure in terms of the first stress invariant $\left(I_{1}\right)$. The analysis uses the results from uniaxial and triaxial testing. Equation (2.30) is used to isolate $\left(J_{2 D}\right)^{1 / 2}$ from the effects of $\rho, L / D$ and $E_{R}$. This gives a new set of strengths corresponding to the reference parameters. $I_{1}$ can be isolated from the effects of test parameters for triaxial and uniaxial testing (where $\sigma_{2}=\sigma_{3}$ ), by using the relation: 


$$
I_{1}=\sigma_{1}+2 \sigma_{3}
$$

and

$$
\left(J_{2 D}\right)_{a}^{1 / 2}=\left(\sigma_{1}-\sigma_{3}\right) / \sqrt{3}
$$

or

$$
\sigma_{1}=\sqrt{3}\left(J_{2 D}\right)_{a}^{1 / 2}+\sigma_{3}
$$

By substituting Eq. (2.33) into Eq. (2.32), we obtain

$$
I_{1}=\sqrt{3}\left(J_{2 D}\right)_{a}^{1 / 2}+3 \sigma_{3}
$$

$\left(J_{2 D}\right)_{a}^{1 / 2}$ represents the strength for triaxial and uniaxial samples after removing the effects of deviations of the test parameters from the reference conditions. The $I_{1}$ calculated from Eq. (2.34) corresponds to the reference parameters. To formulate the criterion from the results of biaxial or polyaxial testing (where $\sigma_{1} \neq \sigma_{2} \neq \sigma_{3}$ ), $I_{1}$ corresponding to the reference parameters must be derived directly from the experimental results. The derivation method is similar to that for $\left(J_{2 D}\right)^{1 / 2}$, i.e. paralleling the development from Eq. (2.13) through (2.31). Figure 2.26 gives $\left(J_{2 D}\right)_{a}^{1 / 2}$ as a function of $I_{1}$ calculated from Eq. (2.34). For the Apache Leap tuff, $\left(J_{2 D}\right)_{a}^{1 / 2}$ increases linearly with $I_{1}$ and can be represented by:

$$
\left(J_{2 D}\right)_{a}^{1 / 2}=\chi I_{1}+\psi
$$

where $\chi, \psi=$ empirical constants.

Regression gives $\chi=0.293$ and $\psi=32.64 \mathrm{MPa}$ with a correlation coefficient of 0.991 . For rock types for which the relationship between $\left(J_{2 D}\right)^{1 / 2}$ and $I_{1}$ is not linear, different forms of the equation may be used. By substituting Eq. (2.35) into Eq. (2.30), a complete form of the failure criterion for uniaxial and triaxial test samples is obtained:

$$
\left(J_{2 D}\right)^{1 / 2}=\chi I_{1}+\psi-C T
$$

For generalized predictions, the correction term (CT) may be reduced to:

$$
C T=\eta\left\{\ln (V)-\ln \left(V^{*}\right)\right\}+\alpha\left(\rho^{*}-\rho\right) \exp (-\lambda V)
$$

By substituting the constants and reference parameters into Eqs. (2.36) and (2.37), the compressive strength of the intact Apache Leap tuff can be predicted from:

$$
\left(J_{2 D}\right)^{1 / 2}=0.293 I_{1}+32.64-2.04 \ln \left(\frac{V}{0.0025}\right)-347.3(2.46-\rho) \exp (-279.4 V)
$$




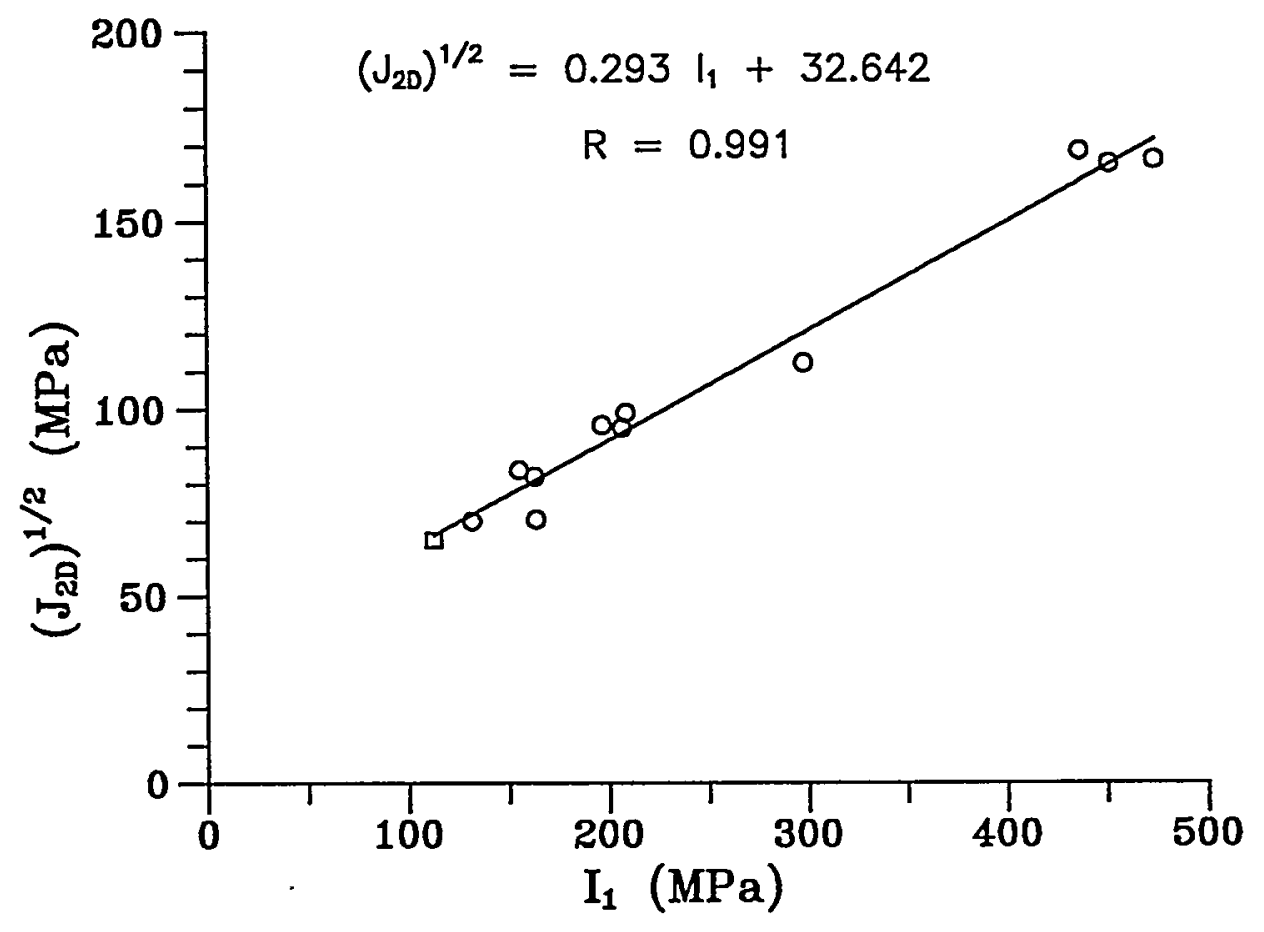

Figure 2.26 Failure envelope: $\left(J_{2 D}\right)^{1 / 2}$ as a function of first stress invariant, triaxial test samples $\rho=2.46, \mathrm{~L} / \mathrm{D}=2.5, \epsilon_{R}=$ $0.29 \times 10^{-6}$ per second. 


\subsubsection{Failure Envelopes}

Failure envelopes for the tuff can be drawn from Eq. (2.38). Figure (2.27) gives $\left(J_{2 D}\right)^{1 / 2}$ as a function of $I_{1}$, for various densities. The linear rate of increase of the strength with $I_{1}$ is the same for all densities. At a density of $2.46 \mathrm{~g} / \mathrm{cc}$, Figure 2.28 shows the variation of the strength with $I_{1}$ for various rock volumes. For this tuff, the strength is more sensitive to density variation (heterogeneity effect) than to volume variation (size effect). For $I_{1}$ equal to $112.6 \mathrm{MPa}$ (approximately under uniaxial compression), the variation of strength with size for various densities is shown in Fig. 2.29. The effect of density variation decreases with increasing sample size, and disappears when the volume exceeds $0.02 \mathrm{~m}^{3}$. This agrees with the proposed concept that rock heterogeneity depends upon the scale of interest; as the size increases, the rock becomes relatively more homogeneous. The size effect is equally pronounced for all densities.

Different failure envelopes will be obtained for different values of the reference parameters. Selection of these parameters, however, does not affect the results of failure predictions, as long as the same values are used consistently throughout the derivation and predictions. These reference parameters must be selected within the range of the test parameters used in the regression. If possible, they should represent common test parameters from which all empirical equations have been derived. The $\left(J_{2 D}\right)^{1 / 2}$ from Eq. (2.38) may therefore be considered as a relative strength for the tuff, corresponding to the reference parameters (i.e. $\rho^{*}, V$ ).

\subsubsection{An Evaluation of the Predictive Capability of the Proposed Criterion}

Biaxial compressive strength testing has been performed to assess the predictive capability of the proposed failure criterion. Rectangular blocks of Apache Leap tuff have been loaded to failure. The block volumes vary from 0.0012 to $0.002 \mathrm{~m}^{3}$. Fuenkajorn and Daemen* give detailed test and sample preparation procedures. The minor principal stress remains zero during the test. The ratio of the intermediate to major principal stresses at failure is varied from 0 to 0.1 . Figure 2.30 gives $\left(J_{20}\right)^{1 / 2}$ calculated from the principal stresses at failure as well as those predicted by the proposed criterion (Eq. 2.38) and by the Coulomb criterion. The proposed criterion predicts the strengths by calculating $I_{1}$ from the failure stresses and measuring $\rho$ and $V$ from the block samples. Since $\sigma_{3}$ is zero, $\left(J_{2 D}\right)^{1 / 2}$ predicted by the Coulomb criterion is calculated from the uniaxial compressive strength (averaged from all samples - Figure 2.21).

The proposed criterion gives better predictions than the Coulomb criterion, because it incorporates the effect of the intermediate principal

\footnotetext{
${ }^{*}$ Fuenkajorn, K. and J.J.K. Daemen, 1991, "Borehole Stability in Densely Welded Tuffs," Technical Report NUREG/CR-5687, U.S. Nuclear Regulatory Commission. (In preparation)
} 


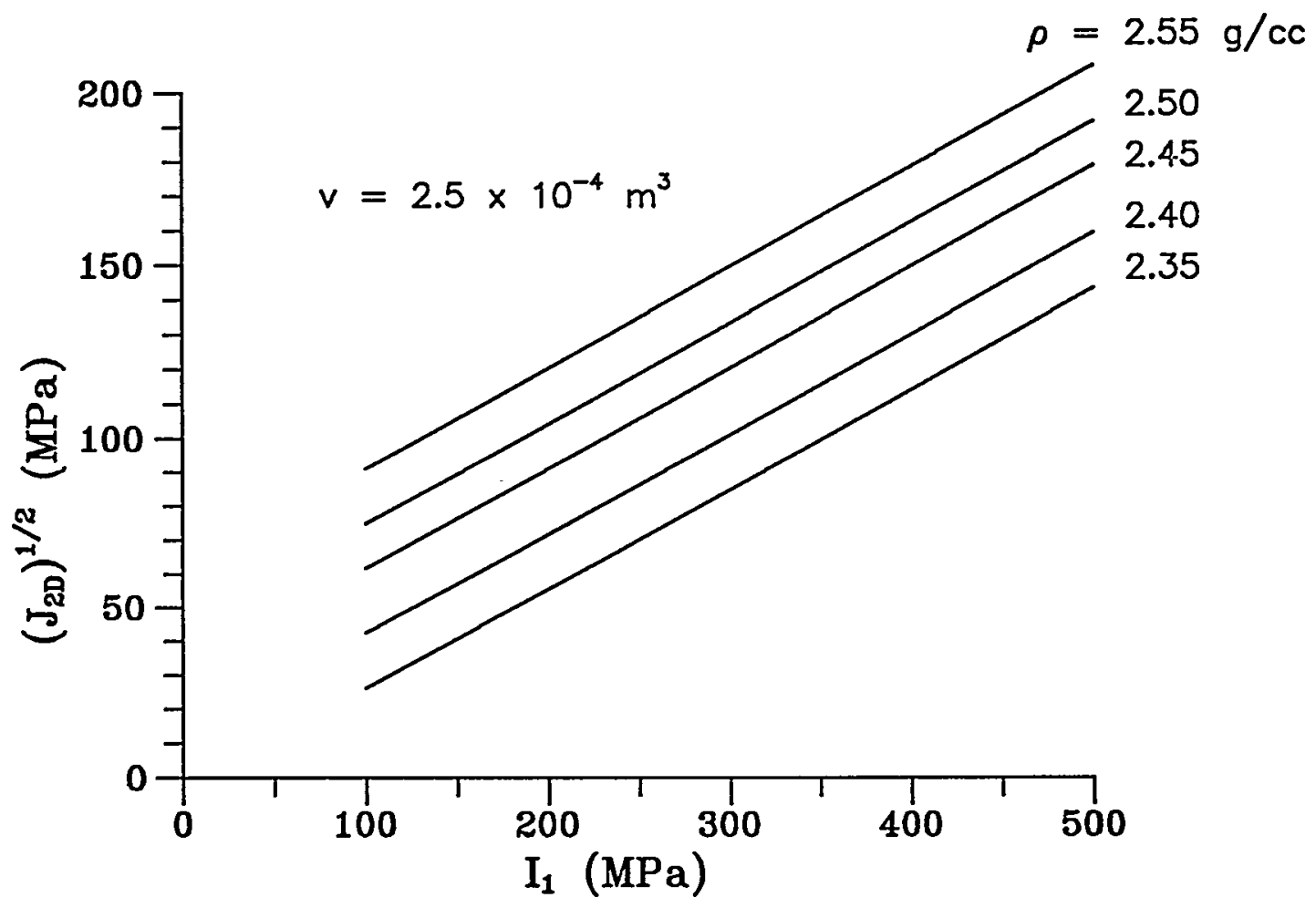

Figure 2.27 Failure envelope for tuff samples with a volume of $0.00025 \mathrm{~m}^{3}$. 


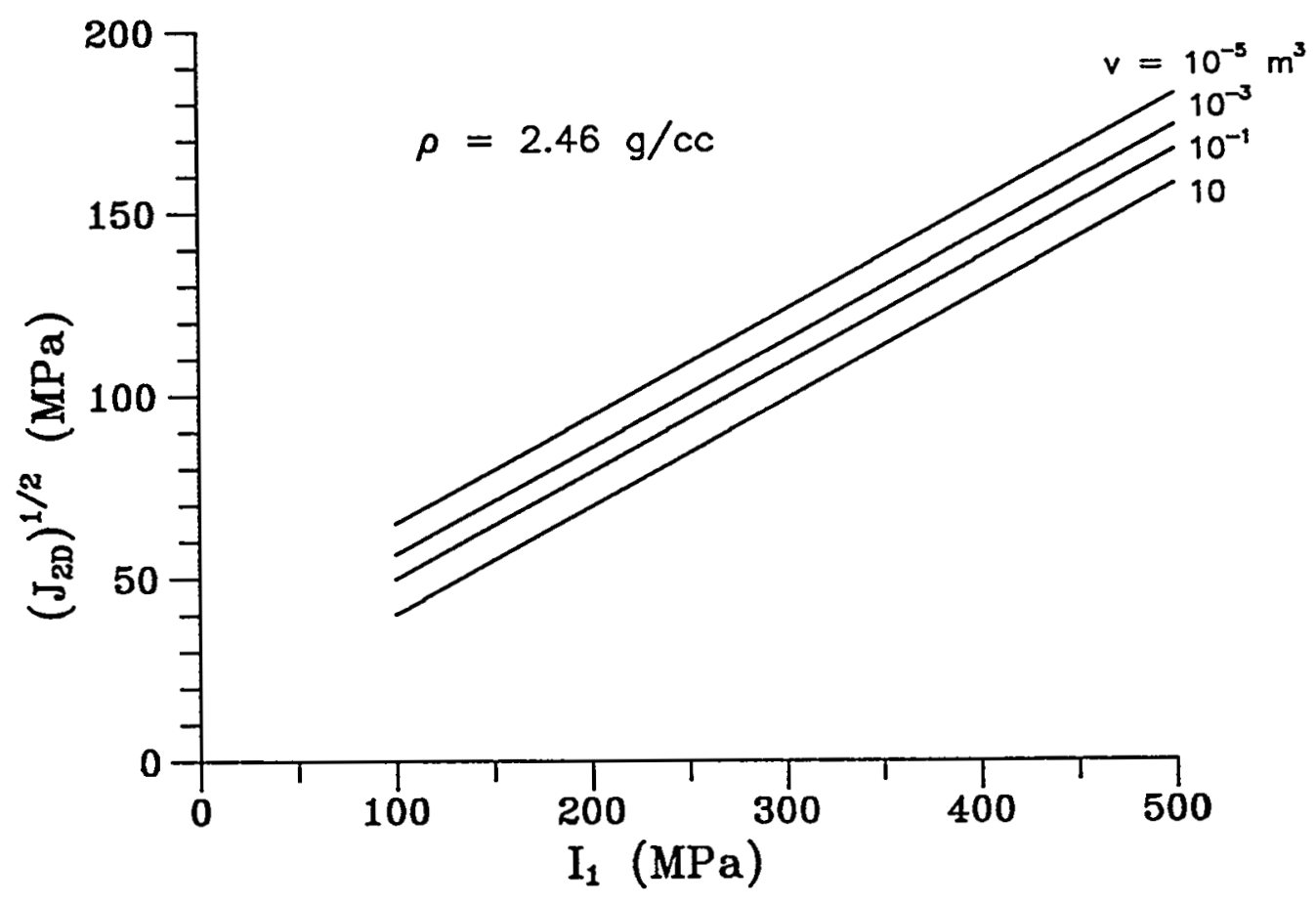

Figure 2.28 Failure envelope for tuff samples with a density of 2.46 $\mathrm{g} / \mathrm{cc}$. 


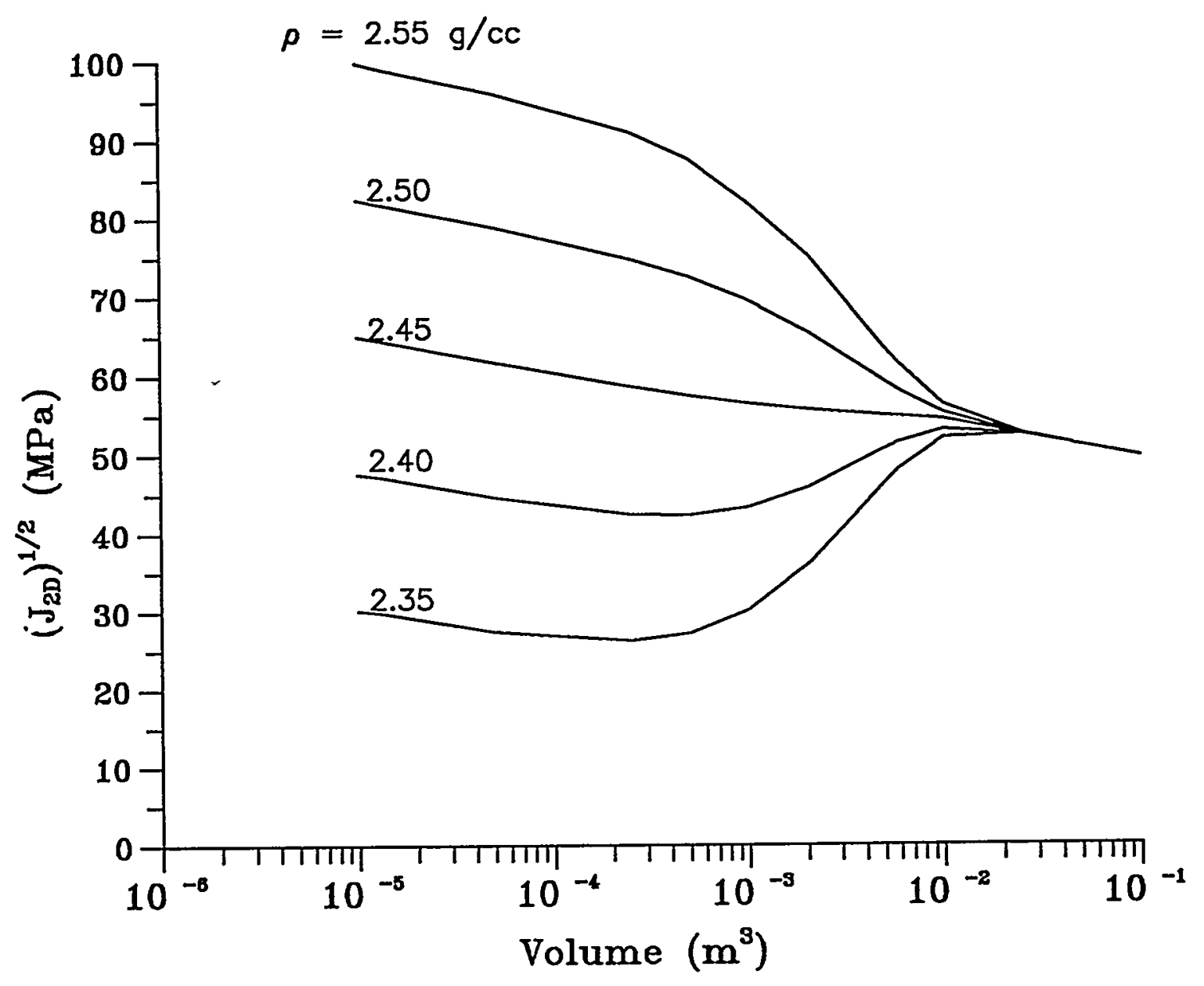

Figure 2.29 Unconfined compressive strength in term of $\left(\mathrm{J}_{2 D}\right)^{1 / 2}$ as a function of sample size for various densities. 


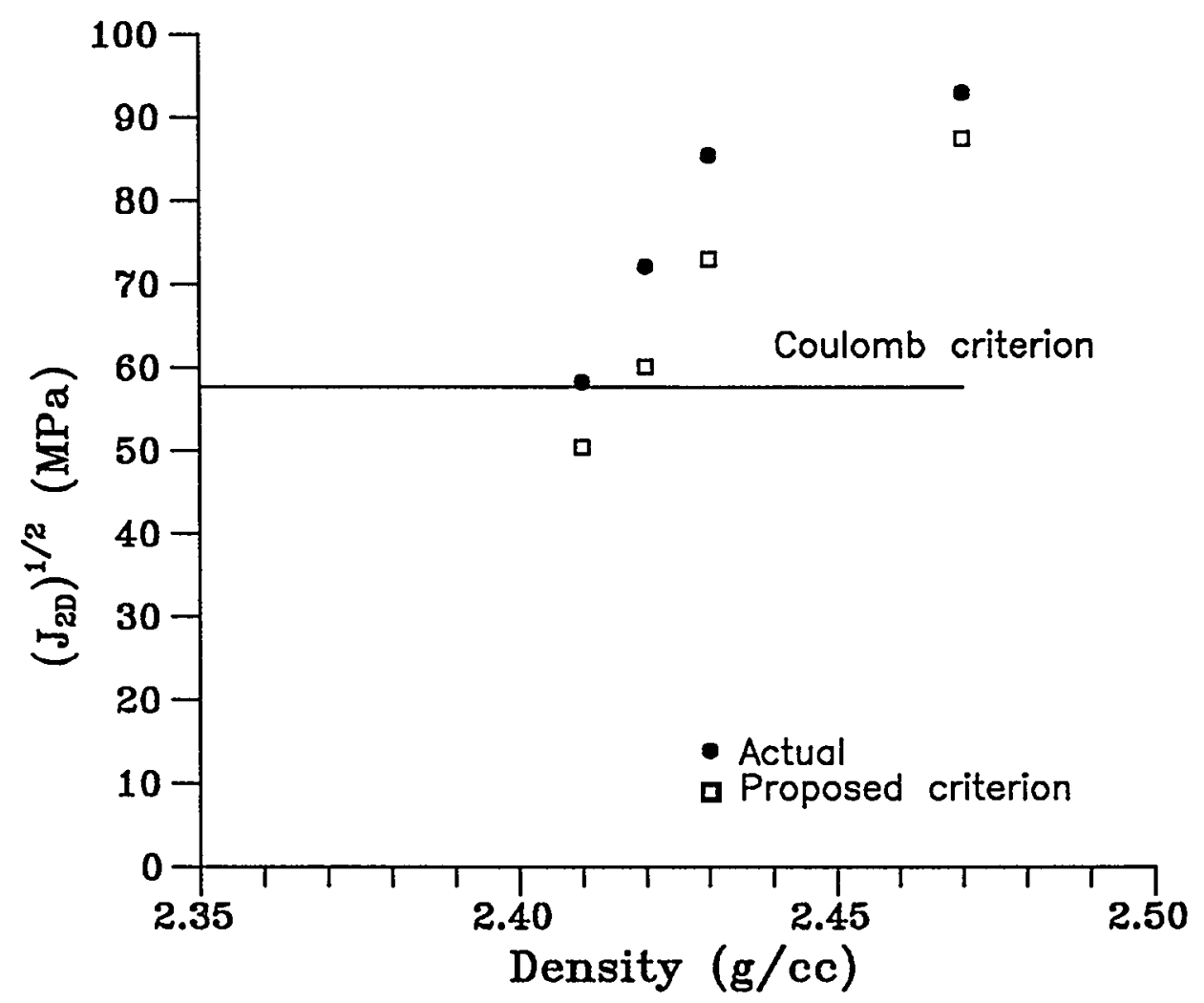

Figure 2.30 Comparison between $\left(J_{2 D}\right)^{1 / 2}$ from biaxial test results and from predictions by proposed criterion and by Coulomb criterion. 
stress, rock heterogeneity (density) and sample size. These effects are not considered in the Coulomb criterion nor in many other strength criteria. Even though the proposed criterion underestimates the actual strength by about 6 to $12 \mathrm{MPa}$; the variations for both actual and predicted strengths with $\rho$ are virtually identical. The biaxial test results provide a rigorous assessment for the predictive capability of the criterion. The comparison between the actual and predicted results indicates that the criterion derived from uniaxial and triaxial test data is capable of adequately describing the strength under biaxial stressfields. Nevertheless, a systematic bias appears to exist, and deserves further investigation.

The method derived here to predict the strength of heterogeneous rock seems to be valid. This is indicated by the fact that reasonable strength data are obtained after they have been isolated from the effect of rock heterogeneity. Figure 2.24 shows that prior to removing the effects of $\rho$ and $L / D$, the rock strength does not correlate to the strain rate. An increase of the strength with strain rate can be observed after the strengths have been isolated from these effects. Similarly, Figure 2.25 shows that size effect is not detectable from the original (raw) strength data. A decrease of the strength with increasing sample size is revealed by removing the effects of $\rho, L / D$ and $\epsilon_{R}$. Incorporation of the heterogeneity effect into the strength criterion also improves the correlation between the triaxial test results and the failure envelope (compare Figures 2.16 and 2.26).

\subsubsection{Strength Criterion for Nonlinear Heterogeneous Rocks}

The criterion given in Eq. (2.36) does not consider the effect of heterogeneity on the rock stiffness. Most heterogeneous rocks do not behave as linearly elastic materials. In addition, the heterogeneity probably induces variations of the load-deformation response among the samples. A more fundamental approach is proposed here to develop an empirical strength criterion for nonlinear heterogeneous rocks. Instead of presenting the rock strength in terms of $\left(J_{2 D}\right)^{1 / 2}$, the total strain energy density at failure is used. Equation (2.12) is replaced by:

$$
W=f\left\{I_{1}, V, \rho\right\}
$$

where $W$ = maximum strain energy density which the rock can sustain before failure.

If the rock sample is linearly elastic, the strain energy density at failure can be calculated by (Jaeger and Cook, 1979, pp. 123-125):

$$
W=\frac{1}{2}\left(\sigma_{1} \epsilon_{1}+\sigma_{2} \epsilon_{2}+\sigma_{3} \epsilon_{3}\right)
$$

where $\epsilon_{1}, \epsilon_{2}, \epsilon_{3}=$ major, intermediate and minor principal strains at failure.

Equation (2.40) shows that the strain energy density can be represented by the sum of the triangular areas under stress-strain curves measured 
in three principal directions. For nonlinear rocks, the strain energy density can be obtained by measuring the actual area under the stressstrain curves monitored during loading. The sum of these areas obtained from three principal axes gives the strain energy density required to induce failure. By repeating the derivation from Eq. (2.12) to (2.38) and replacing $\left(J_{2 D}\right)^{1 / 2}$ by $W$ measured from each sample, an empirical strength criterion for nonlinear heterogeneous rock can be derived. This approach implicitly includes the effects of nonlinear behavior and stiffness variation into the criterion. The failure criterion in terms of $W$ can not be derived for the Apache Leap tuff because insufficient stress-strain curves have been obtained from the uniaxial and triaxial test samples.

\subsubsection{Discussion}

Accuracy and reliability of the proposed criterion depend upon the range of parameters used in the rock characterization testing, and upon how good the empirical equations, linking $\rho$ and $V$ to $\left(J_{2 D}\right)^{1 / 2}$, fit sets of test data. As shown in Figure 2.26, the strength is highly sensitive to the density variation. Rock testing should be conducted over the full range of key parameters. Predictions of the rock strength far outside the range of a key parameter may not be valid. The strength of the tuff is not very sensitive to size (Figure 2.27). Since the criterion is derived for intact rock, extrapolation toward in-situ scale is limited by the discontinuities. The maximum size for which the criterion is valid, is governed by the joint spacing.

The underpredictions of the criterion for the biaxial testing may be due to the fact that density is not the only key parameter governing the strength variation. Derivation of a strength criterion containing two or more key parameters could be very complex because a mathematical relationship between strength and each key parameter must be incorporated. The number of key parameters used in the criterion derivation therefore depends on the desired accuracy. Biaxial or polyaxial strength testing should be performed to assess the predictive capability of the criterion. A wide range of stress ratios and of $I_{1}$ should be used. Samples should have wide ranges of key parameters and sizes.

\subsubsection{Conclusions}

An empirical criterion has been formulated to describe compressive failure for intact heterogeneous rocks. The criterion is presented in terms of the second invariant of stress deviation at failure as a function of first stress invariant, rock density and volume. A heterogeneous welded tuff has been used in the investigation. Uniaxial and triaxial compressive strengths are used in the regression to determine the empirical constants. The effects of $L / D$ ratio and of loading rate are incorporated. Inclusion of all principal stresses at failure allows the criterion to describe the strength of rock under various stress conditions. The rock density is included as a key parameter to minimize the effect of heterogeneity caused by nonuniform distribution of pores, inclusions, mineralogy, welding and grain bonding. The volume variable is incorporated to allow predicting rock strength for various sizes. Predictive capability of the criterion has been assessed by performing biaxial compressive strength tests. The criterion adequately predicts 
the strength of biaxial samples, although some as yet unexplained systematic error remains. The derivation method has improved considerably the correlation between the test results and the failure envelope. Accuracy and reliability of the predictions depend upon the range of the test parameters $(\rho, V)$ used in determining the empirical constants.

\subsection{Discussion of the Characterization Test Results}

\subsubsection{Heterogeneity of the Apache Leap Tuff}

Large variations of the mechanical properties of Apache Leap tuff lead to a question as to how well the results obtained by the ASTM standard methods can represent the actual properties of rock, particularly for large-scale (e.g. in-situ) conditions. The variations are probably caused by the effects of inclusions, flow layers, degree of welding and porosity of the rock. These tuff characteristics increase the anisotropy and inhomogeneity of the rock, particularly for the sample sizes specified by the ASTM test methods (as 49-50 mm diameters with length to diameter ratios between 2.0 and 2.5). The inclusions in the tuff usually appear lenticular, with the major axes parallel to the flow layers. The shape of the Apache Leap tuff inclusions relates to the depth at which they occur. The length to thickness ratio of the inclusions increases with depth and degree of welding (Peterson, 1961; Ross and Smith, 1960). The average sizes range from $1 \times 2$ micrometers to $10 \times 25$ millimeters (Figure 2.31). Sizes larger than $100 \times 100 \mathrm{~mm}$ are common. They are not uniformly distributed throughout the rock. The petrographic studies indicate that mineral compositions of the inclusions and of the rock matrix are similar, but that the inclusions contain finer grains and slightly lesser amounts of magnetite and iron oxides. This observation agrees with Peterson (1961). Some inclusions are softer than the rock matrix and appear to have a higher degree of weathering. Observation of some post-test specimens shows that the inclusions may affect the failure characteristics of tuff. Some uniaxial and triaxial samples tend to fail along the plane that has the highest concentration of soft inclusions. This implies that the stress distribution within the samples may not be homogeneous and the calculated strength of the samples may not be accurate.

The flow layers of Apache Leap tuff can be recognized by alignments of quartz and feldspar grains (light bands) and by orientation of the lenticular inclusions and vesicles. The flow layers do not usually appear as a perfect plane. Twisting and curly characteristics are observed from the scale of $1 \times 1 \mathrm{~mm}$ to $50 \times 50 \mathrm{~cm}$. The effect of the flow layers on the mechanical properties of the rock has not been quantitatively determined. The tuff tends to be weaker in the direction of the flow layers as observed during sample collection and preparation. Undoubtedly, the existence of the flow layers increases the inhomogeneity of the rock and induces large variations of the mechanical properties.

The rock unit of the Apache Leap tuff used in this research has been classified as a densely welded ash flow (Evans, 1983; Vogt, 1988). Visual observation from the block and core surfaces shows that the degree of welding is not uniform. The degree of welding relates to the porosity of the rock and connectivity of voids and pore spaces (Vogt, 


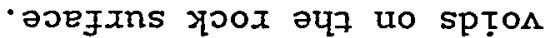

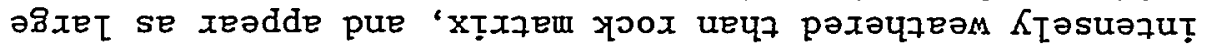

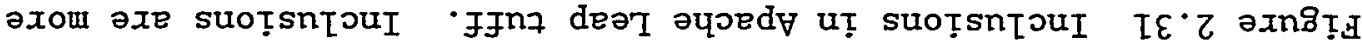
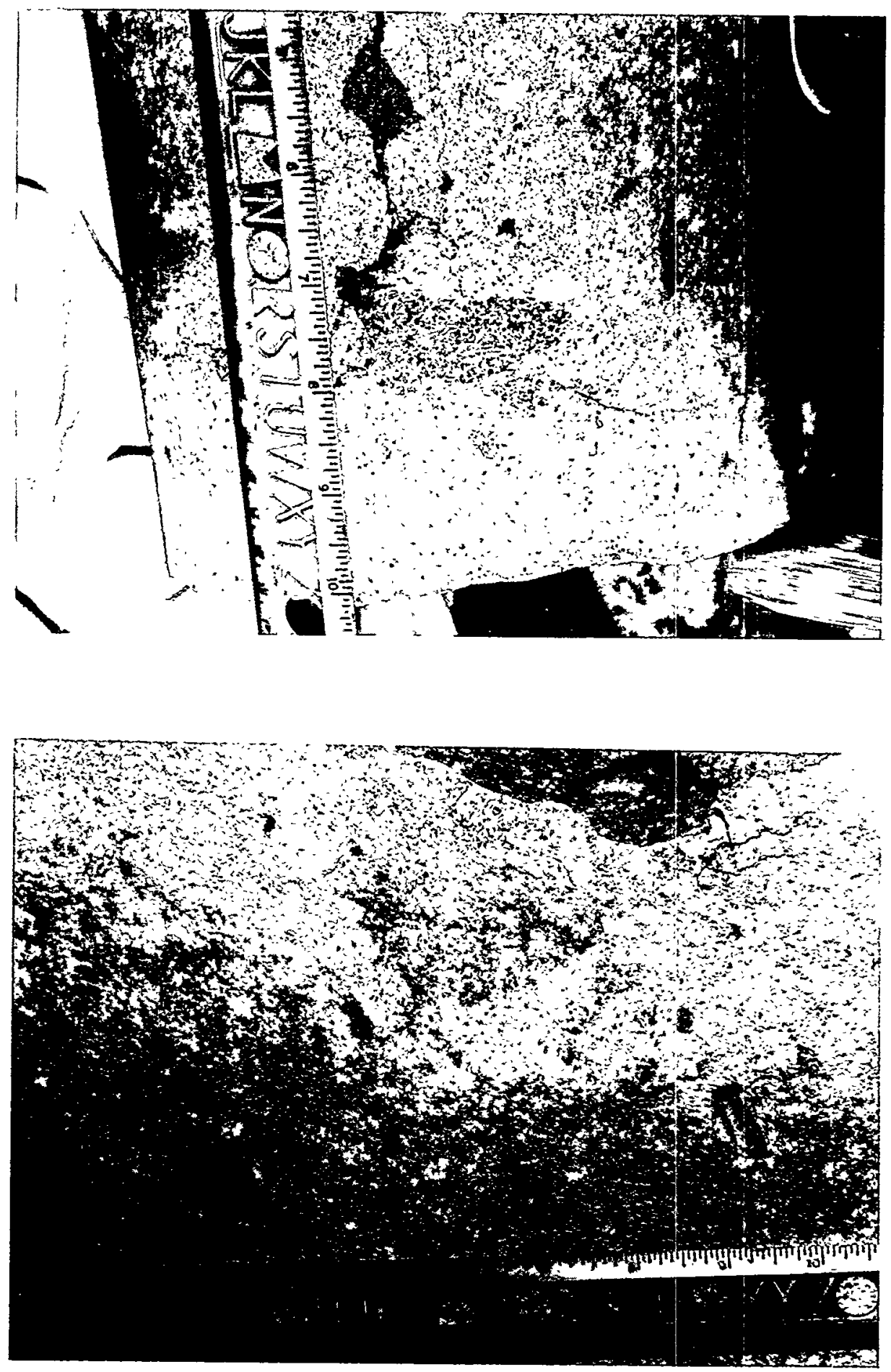
1988). A higher degree of welding reduces connectivity and may decrease the porosity. This affects the mechanical behavior and hydrological properties of the rock. The nonuniform distribution of the pore spaces increases the effect of sample size on the mechanical properties (Jaeger and Cook, 1979, pp. 196-197). Even though the size effect has not been clearly observed from the test results, probably due to coupled effects of inclusions and flow layers, the elastic and strength parameters previously determined may significantly overestimate the actual properties of the rock under in-situ conditions.

The heterogeneity of tuff affects sample preparation. Most tuff samples. do not fully satisfy the smoothness and perpendicularity requirements of the ASTM standards. This is due to the presence of inclusions and voids on the sample surfaces and due to the methods of sample preparation (i.e. drilling, cutting and grinding). Inclusions and pore spaces make the sample surfaces rough. Some inclusions are softer than the rock matrix and are sheared off during grinding. Coring in tuff with some poorly bonded inclusions creates vibrations in the drill and therefore generates rough core surfaces. This is observed in both laboratory and field drilling.

\subsubsection{Comparison Between Topopah Spring and Apache Leap Tuffs}

Table 2.23 summarizes the mechanical properties of Apache Leap tuff determined here and those for Topopah Spring tuff given by Scully (1984), Zimmerman (1982), Anderson (1981), Price et al. (1982), Price (1983, 1986), and Price and Bauer (1985). Apache Leap tuff has lower uniaxial compressive strength and Brazilian tensile strength than does Topopah Spring tuff. Poisson's ratio and elastic modulus of Apache Leap tuff are slightly lower than those for Topopah Spring tuff. Both tuffs show large variations in properties. Price and Bauer (1985) show that the elastic modulus and compressive strength of Yucca Mountain tuff (Paintbrush tuff, tuffaceous beds, and crater flat tuff: Anderson, 1981; Price, 1983) decrease as the rock porosity increases. The porosity of Yucca Mountain tuff ranges from 5 to 528 . This range covers both welded and nonwelded tuffs. The Topopah Spring member gives a narrower range of porosity ( 6 to 20\%). The porosity of the densely welded brown unit of the Apache Leap tuff calculated from dry bulk density and solid density (after grinding) falls between 7 and 10\%. The dry density of Apache Leap tuff averages $2.37 \pm 0.42 \mathrm{~g} / \mathrm{cc}$. The dry density of the Topopah Spring member ranges from 2.0 to $2.3 \mathrm{~g} / \mathrm{cc}$.

Results of chemical analysis indicate that the Topopah Spring specimen contains a higher percentage of quartz $\left(\mathrm{SiO}_{2}\right)$ than do the Apache Leap specimens. This helps explain why the Topopah Spring tuff is stronger than the Apache Leap tuff. Both rocks tend to have comparable amounts of calcium, sodium, potassium and magnesium oxides. Apache Leap tuff contains approximately three times more iron oxide than does Topopah Spring tuff. The iron oxides $\left(\mathrm{Fe}_{2} \mathrm{O}_{3}\right.$ and $\mathrm{FeO}$ ) result from an alteration of olivine and magnetite. 
Table 2.23 Mechanical and Physical Properties of Brown Unit of Apache Leap Tuff and of Topopah Spring Tuff

\section{Apache Leap Tuff Topopah_spring Tuff*}

Uniaxial Compressive Strength (MPa)

$$
73.2 \pm 16.5
$$

$95.9 \pm 35.5$

Elastic Modulus

$22.6 \pm 5.7$

$26.7 \pm 7.7$

Poisson's Ratio

$0.20 \pm 0.03$

$0.14 \pm 0.05$

Brazilian Tensile

Strength (MPa)

$5.72 \pm 1.2$

$12.8 \pm 3.5$

P-Wave Velocity $(\mathrm{km} / \mathrm{s})$

$6.4 \pm 1.5$

$4.1-4.6$

Internal Friction

Angle (degrees)

43

67

Cohesion

16

18

Dry Density (g/cc)

$2.37 \pm 0.42$

1.32 (nonwelded)

2.0-2.3 (welded)

Porosity $(8)$

$7-10$

$6-20$

\footnotetext{
${ }^{*}$ The properties of Topopah Spring tuff are obtained from Scully (1984), Price and Bauer (1985), Zimmerman et al. (1985), and Anderson (1981).
} 
GHAPTER THREE

SUMMARY, CONCLUSIONS AND RECOMMENDATIONS FOR FUTURE RESEARCH

\subsection{Summary of Test Results}

The uniaxial compressive strength seems to be insensitive to the axial strain rates used (ranging from $10^{-8}$ to $10^{-4}$ per second). The strength slightly increases with increasing $\mathrm{L} / \mathrm{D}$ ratio. Long cylindrical samples (L/D near 3) tend to give more consistent strength results than the shorter ones. The Young's modulus and Poisson's ratio measured at 508 compressive strength are $22.6 \neq 5.7 \mathrm{GPa}$ and $0.20 \neq 0.03$, respectively. The stress-strain curves are linear. The lateral strain-axial strain curves are not. The tuff fails in a brittle mode. The compressive strength averaged from all samples is $97.5 \mathrm{MPa}$.

The Brazilian tensile strength measured from $50 \mathrm{~mm}$ diameter disks (ASTM standard size) averages $5.7 \pm 1.2 \mathrm{MPa}$. Statistically, the strength decreases as sample size increases. The Young's modulus measured from $181 \mathrm{~mm}$ diameter Brazilian disks is $127.1 \pm 94.7 \mathrm{GPa}$ at $50 \%$ strength and is $112.5 \pm 63.0 \mathrm{GPa}$ at $10 \%$ strength. The dynamic Young's modulus and Poisson's ratio obtained from the seismic velocity measurements are 35.7 $\pm 9.9 \mathrm{GPa}$ and $0.39 \pm 0.10$, respectively. There is no correlation between static and dynamic Young's moduli and rock density.

The Coulomb strength criterion adequately represents the strength of the Apache Leap tuff under confining pressures from 0 to $62 \mathrm{MPa}$. The coefficient of correlation is 0.973 . The rock has a cohesion of $16 \mathrm{MPa}$ and an internal friction angle of $43^{\circ}$. The dry density of the brown unit of the Apache Leap tuff measured from all characterization test samples ranges from 2.3 to $2.5 \mathrm{~g} / \mathrm{cc}$.

The brown unit of the Apache Leap tuff is highly nonhomogeneous as suggested by visual observation and confirmed by the large variations of the mechanical properties. It is believed that the high intrinsic variability of the rock is caused by the flow layers and by nonuniform distributions of the inclusions, voids and degree of welding. The nonuniformity occurs on a scale much larger than the size of the samples used in the characterization testing.

The proposed empirical strength criterion adequately fits the compressive strength data. Incorporation of the effects of size, L/D ratio, strain rate and density variations improves the correlation between test results and failure envelope, and reveals relationships between the tuff strength and test parameters. The strength tends to increase linearly with density. After the test data have been adjusted for the effect of density variation, the tuff strength decreases with increasing sample size and L/D ratio, and increases with increasing strain rate. 


\subsection{Recommendations for Future Tuff Characterization}

In order to determine the effects of inclusions, flow layers, welding and porosity on the mechanical properties of tuff, and to improve the representativeness of the experimental results, additional test parameters and test methods are suggested beyond the standard test procedures. Tuff cylinders for mechanical property testing should be at least $250 \mathrm{~mm}$ in diameter. This suggested diameter is ten times larger than the average size of the inclusions $(10 \times 25 \mathrm{~mm})$ in the Apache Leap tuff. For the uniaxial compressive strength test, the axial and circumferential deformations of the specimen should be monitored at several points around the cylinder to assess the homogeneity of the rock. During and after failure, samples should be inspected to visually assess the influence of inclusions on failure.

Coring and grinding of the Apache Leap tuff usually produces rough surfaces, due to the presence of soft inclusions in the stronger rock matrix. This is why most samples do not satisfy ASTM perpendicularity and smoothness requirements. Obtaining samples satisfying the ASTM standards for highly nonhomogeneous rock such as Apache Leap tuff is difficult. Coring and grinding may not be sufficient to obtain ASTM required samples. A lathe may be required to machine the samples.

The anisotropic behavior of the rock caused by the flow layers should be determined experimentally. The mechanical anisotropy should be tested in terms of compressive and tensile strengths, static and dynamic Young's modulus and Poisson's ratio, and mode of failure. Determination of mechanical anisotropy should be accompanied by assessments of hydrological anisotropy and by petrographic mineralogical, microfracture and microfabric pattern studies. Such an effort would require a large number of rock samples and experiments. The rock samples should be prepared to have flow layers perpendicular and parallel to the direction of applied load and to the expected failure plane. If such $90^{\circ}$ measurements confirm anisotropy, additional determinations at intermediate orientations (e.g. $30^{\circ}, 60^{\circ}$ ) would be desirable (Hoek and Brown, 1980, (h. 6).

The tuff has a relatively high porosity $(7-10 \%)$. The void and pore space distribution may not be uniform; therefore, at least three sample sizes should be used for each characterization test. The smallest size should be about $250 \mathrm{~mm}$ in diameter. The test results might indicate how significantly the sample size affects the rock properties. This would allow an extrapolation of laboratory test results to the larger scale (toward in-situ conditions). The relationship between rock density, porosity and the mechanical properties should be investigated (Rippa and Vinale, 1983; Price and Bauer, 1985). Such relations have been found very useful for Yucca Mountain tuffs. The density range of the Apache Leap tuff tested to date is so narrow as to virtually preclude such correlations. 
A wide range of test parameters $(\rho, V)$ should be used to determine the empirical constants of the proposed strength criterion. Biaxial and polyaxial strength testing should be performed to assess the predictive capability of the criterion. The tests should be conducted under various stress ratios and for different values of $I_{1}$.

Chemical compositions of the rock matrix and of the inclusions should be determined. Since the rock volume used in the chemical analysis is relatively small $\left(i \mathrm{~cm}^{3}\right)$, several samples should be collected across the flow layers and at several locations within the rock unit.

The effect of water content (pore pressure) within the rock on the mechanical behavior should be investigated (Abey, 1981). At the Yucca Mountain repository site, even though the repository horizon is above the ground water table, the tuff still has relatively high saturation (up to 80\%: Zimmerman et al., 1985). The mechanical properties should be determined at various degrees of saturation. 
Abey, A.E., 1981," A Computer Model for Stress-Volume Relationships of Porous Rocks with Various Saturations," Rock Mechanics, Vol. 13, pp. 235-244, Springer-Verlag.

Anderson, L.A., 1981, "Rock Property Analysis of Core Samples from the Yucca Mountain UE25a-1 Borehole, Nevada Test Site, Nevada, " Open-File Report 81-1338, prepared by the U.S. Geological Survey, for Nevada Operations Office, U.S. Dept. of Energy.

ASTM D2664-80, "Standard Test Method for Triaxial Compressive Strength of Undrained Rock Core Specimens without Pore Pressure Measurements," Annual Beok of ASTM Standards, Section 4, Construction, Vol. 04.08, Soil and Rock; Building Stones, American Society for Testing and Materials, Philadelphia. (Also standardized as ANSI/ASTM D2664-80)

ASTM D2938-79, "Standard Test Method for Unconfined Compressive Strength of Intact Rock Core Specimens," Annual Book of ASTM Standards, Section 4, Construction, Vol. 04.08, Soil and Rock; Building Stones, American Society for Testing and Materials, Philadelphia. (Also standardized as ANSI/ASTM D2938-79)

ASTM D3184-86, "Standard Test Method for Elastic Moduli of Intact Rock Core Specimens in Uniaxial Compression," Annual Book of ASTM Standards, SEction 4, Construction, Vol. 04.08, Soil and Rock; Building Stones, American Society for Testing and Materials, Philadelphia.

ASTM D3967-81, "Standard Test Method for Splitting Tensile Strength of Intact Rock Core Specimens," Annual Book of ASTM Standards, Section 4, Construction, Vol. 04.08, Soil and Rock; Building Stones, American Society for Testing and Materials, Philadelphia.

Bieniawski, Z.T., 1970, "Time Dependent Behavior of Fractured Rock," Rock Mech., Vol. 7, pp. 123-137.

Bieniawski, Z.T., et al., 1978, "Suggested Methods for Determining the Uniaxial Compressive Strength and Deformability of Rock Materials," International Society for Rock Mechanics, Commission on Standardization of Laboratory and Field Tests, Committee on Laboratory Tests, September, published in International Journal of Rock Mechanics and Mining Sciences and Geomechanics Abstracts, Vol. 16, No. 2, pp. 135-140 (1979). Also in Reck Characterization Testing and Monitoring, ISRM Suggested Methods, pp. 111-116, E.T. Brown, ed., Pergamon Press, Oxford, 1981. 
Bieniawski, Z.T. and I. Hawkes, 1978, "Suggested Methods for Determining Tensile Strength of Rock Materials," International Journal of Rock Mechanics and Mining Sciences \& Geomechanics Abstracts, Vo1. 15, No. 3, pp. 99-103.

Brady, B.H.G. and E.E. Brown, 1985, Beck Mechanies for Underground Mining, George Allen \& Unwin, Ltd., London.

Costin, L.S., 1987, "Time-Dependent Deformation and Failure," B.K. Atkinson (Editor), Fracture Mechanics of Rock, Academic Press, London, $534 \mathrm{pp}$.

Daemen, J.J.K., D.L. South, W.B. Greer, J.C. Stormont, S.A. Dischler, G.S. Adisoma, N.I. Colburn, K. Fuenkajorn, D.E. Miles, B. Kousari, and J. Bertuca, 1983, "Annual Report, Rock Mass Sealing, June 1, 1982 - May 31, 1983," NUREG/CR-3473, prepared for the U.S. Nuclear Regulatory Commission, Office of Nuclear Regulatory Research, Division of Health, Siting and Waste Management, by the Department of Mining and Geological Engineering, University of Arizona, Tucson.

Desai, C.S. and H.J. Siriwardane, 1984. Constitutive Laws for Engineering Materials with Emphasis on Geologic Materials, PrenticeHall, New Jersey, 468 pp.

Evans, D.D., 1983, "Welded Tuff Characteristics at the Nevada Test Site and Near Superior, Arizona," Technical Report prepared for U.S. Nuclear Regulatory Commission, Division of Health, Siting and Waste Management, Office of Research, by Department of Hydrology and Water Resources, University of Arizona, Tucson.

Franklin, J.A. and M.B. Dusseault, 1989, Bock Engineering, McGraw-Hill Pub. Co., New York.

Fuenkajorn, K. and J. J. K. Daemen, 1986, "Experimental Assessment of Borehole Wall Drilling Damage in Basaltic Rocks," Technical Report, NUREG/CR-4641, prepared for the U.S. Nuclear Regulatory Commission, Division of Radiation Programs and Earth Sciences, Office of Nuclear Regulatory Research, by the Department of Mining and Geological Engineering, University of Arizona, Tucson.

Goodman, R.E., 1980, Introduction to Rock Mechanics, John Wiley \& Sons, New York.

Griffith, A.A., 1924, "Theory of Rupture," Proceedings of the First International Congress on Applied Mechanics, Vol. 1, Delft, pp. 55-63.

Handin, J., H.C. Heard, and J.N. Magouirk, 1967, "Effects of the Intermediate Principal Stress on the Failure of Limestone, Dolomite, and Glass at Different Temperatures and Strain Rates," J. Geophys. Res., Vol. 72, no. 2, pp. 611-640. 
Hobbs, D.W., 1964, "The Tensile Strength of Rocks," International Journal of Rock Mechanics and Mining Sciences, Vol. 1, no. 3, pp. 385-394.

Hoek, E. and E. T. Brown, 1980, Underground Excavations in Rock, The Institution of Mining and Metallurgy, London.

Hondros, G., 1959, "The Evaluation of Poisson's Ratio and Young's Modulus of Materials of a Low Tensile Resistance by the Brazilian (Indirect Tensile) Test with Particular Reference to Concrete," Australian Journal of Applied Sciences, Vol. 6, No. 1, pp. 243-268.

Horii, H. and S. Nemat-Nasser, 1985, "Compression-Induced Microcrack Growth in Brittle Solids: Axial Splitting and Shear Failure," J. Geophys. Res., Vol. 90, pp. 3105-3125.

Hoshino, K., 1974, "Effect of Porosity on the Strength of the Glastic Sedimentary Rocks. In: Proc. 3rd Cong. Rock Mech., Vol. IIA, pp. $511-516$.

Hoskins, E.R., 1969, "The Failure of Thick-Walled Hollow Cylinders of Isotropic Rock," Int. J. Rock Mech. Min. Sci., Vo1. 6, pp. 99-125.

Howarth, D.F., 1987, "The Effect of Pre-Existing Microcavities on Mechanical Rock Performance in Sedimentary and Crystalline Rocks," Int. J. Rock Mech. Min. Sci. Geomech. Abstr., Vol. 24, no. 4, pp. 223-233.

Hudson, J.A., E.T. Brown, and C. Fairhurst, 1971, "Shape of the Complete Stress-Strain Curve for Rock," Proc. 13th U.S. Sym. Rock Mech., pp. 773-795.

ISRM, 1979, "Suggested Methods for Determining the Uniaxial Compressive Strength and Deformability of Rock Materials, " Int. J. Rock. Mech. Min. Sci. Geomech. Abstr., Vol. 16, pp. 135-140.

Jaeger, J.C. and N.G.W. Cook, 1979, Fundamentals of Reck Mechanics, Third Edition, Chapman and Hall, London.

Kim, M.K. and P.V. Lade, 1984, "Modelling Rock Strength in Three Dimensions," Int. J. Rock Mech. Min. Sci., Vo1. 21, pp. 21-33.

Knudsen, F.P., 1959, "Dependence of Mechanical Strength of Brittle Polycrystalline Specimens on Porosity and Grain Size," J. American Ceramic Society, Vo1. 42, pp. 376-387.

Kranz, R.L., 1983, "Microcracks in Rocks: a Review," Tectonophysics, Vo1. 100 , pp. 449-480.

Lundborg, N., 1967, "The Strength-Size Relation of Granite," Int. J. Rock Mech. Min. Sci., Vol. 4, pp. 269-272. 
Lundborg, N., 1972, "A Statistical Theory of the Polyaxial Compressive Strength of Materials," Int. J. Rock Mech. Min. Sci., Vol. 9, pp. 617-624.

Malek, R.I.A. and D.M. Roy, 1985, "Dissolution Kinetics of Tuff Rock and Mechanism of Chemical Bond Formation at the Interface with Cement Grout," Scientific Basis for Nuclear Waste Management VIII, Material Research Society Symposium Proceedings, Vo1. 44, pp. 943-950.

Mogi, K., 1967, "Effect of the Intermediate Principal Stress on Rock Failure," J. Geophys. Res., Vol. 72, no. 20, pp. 5117-5131.

Murrel1, S.A.F., 1966, "The Effect of Triaxial Stress Systems on the Strength of Rock at Atmospheric Temperatures, " Geophys. J., Vo1. 10, pp. 231-281.

Nappi, G. and M. Ottaviani, 1986, "Geological and Geotechnical Characteristics of Volcanic Tuffs of Central and Southern Italy," Proc. 5th Int. Assoc. Eng. Geol. Congr., Buenos Aires, pp. 455-464.

Nimick, F.B., 1988, "Empirical Relationships Between Porosity and the Mechanical Properties of Tuff," Cundall et al. (Editors), Key Question in Rock Mechanics, Balkema, Rotterdam, pp. 741-742.

Peterson, D.W., 1961, "Flattening Ratios of Pumice Fragments in an AshFlow Sheet near Superior, Arizona," Geological Survey Research, Short Papers in the Geologic and Hydrologic Sciences, Geological Survey Professional Paper 424-D, pp. D82-D84, U.S. Government Printing Office, Washington, DC.

Peterson, D.W., 1968, "Zoned Ash-Flow Sheet in the Region Around Superior, Arizona," Southern Arizona Guidebook, Geological Society of Arizona, S.R. Titley, ed.

Price, R.H., 1983, "Analysis of Rock Mechanics Properties of Volcanic Tuff Units from Yucca Mountain, Nevada Test Site," Technical Report SAND82-1315, prepared by Sandia National Laboratories, Albuquerque, NM, for the U.S. Department of Energy.

Price, R.H., 1986, "Effect of Sample Size on the Mechanical Behavior of Topopah Spring Tuff, "Technical Report SAND85-0709, August, prepared by Sandia National Laboratories, Albuquerque, NM, for the U.S. Department of Energy.

Price, R.H., K.G. Nimick, and J.A. Zirzow, 1982, "Uniaxial and Triaxial Compression Test Series on Topopah Spring Tuff," Technical Report SAND82-1723, October, prepared by Sandia National Laboratories, Albuquerque, NM, for the U.S. Department of Energy. 
Price, R.H. and S.U. Bauer, 1985, "Analysis of the Elastic and Strength Properties of Yucca Mountain Tuff, Nevada," Proceedings of the 26 th U.S. Symposium on Rock Mechanics, Rapid City, SD, June 26-29, pp. 89-96.

Rippa, F. and F. Vinale, 1983, "Structure and Mechanical Behavior of a Volcanic Tuff," Proceedings of the 5th Congress of the International Society for Rock Mechanics, Melbourne, Australia, April 10-15, pp. B33-B40, A.A. Balkema, Rotterdam, The Netherlands.

Ripperger, E.A. and N. Davids, 1947, "Critical Stresses in a Circular Ring, "Transactions of the American Society of Civil Engineering, Vo1. 112, no. 2308, pp. 619-627.

Ross, C.S. and R.L. Smith, 1960, "Ash-Flow Tuffs: Their Origin, Geologic Relations and Identification," Geological Survey Professional Paper 366.

Sammis, C.G. and M.F. Ashby, 1986, "The Failure of Brittle Porous Solids under Compressive Stress States," Acta Metall., Vol. 34, no. 3, pp. 511-526.

Scully, L.W., 1984, "Design Considerations to Minimize the Impact of a Repository on a Host Rock," Scientific Basis for Nuclear Waste Management VII, Materials Research Society Symposia Proceedings, Vol. 26, F.G. McVay, ed., Boston, MA, Nov. 14-17, 1983, North-Holland, New York, pp. 293-300.

Smith, R.I., 1960, "Zones and Zonal Variations in Welded Ash Flows," Geological Survey Professional Paper 354-F, United States Government Printing Office, Washington.

Turk, N. and W.R. Dearman, 1986, "A Correction Equation on the Influence of Length-to-Diameter Ratio on the Uniaxial Compressive Strength of Rocks," Eng. Geol., Vol. 22, pp. 293-300, Elsevier Science Pub.

Vogt, G.T., 1988, "Porosity Pore-Size Distribution and Pore Subsurface Area of the Apache Leap Tuff Near Superior, Arizona, Using Mercury Porosimeter," Master's Thesis, University of Arizona, Tucson.

Yudhbir, W. Lemanza, and F. Prinzl, 1983, "An Empirical Failure Criterion for Rock Masses," Proceedings of the 5th International Congress of Rock Mechanics, Melbourne, Australia, Vol. B, PP. $1-8$.

Zimmerman, R.M., 1982, "Issues Related to Field Testing in Tuff," Proceedings of the 23rd U.S. Symposium on Rock Mechanics, Goodman and Heuze, eds., Ch. 88, pp. 872-880. 
Zimmerman, R.M., 1983, "First Phase of Small Diameter Heater Experiments in Tuff," Proceedings of the 24th U.S. Symposium on Rock Mechanics, Texas A \& M University, June 20-23, 1983, C.C. Mathewson, ed., pp. 271-282, by the Association of Engineering Geologists, Dallas, TX.

Zimmerman, R.M., F.B. Nimick, and M.P. Board, 1985, "Geoengineering Characterization of Welded Tuffs from Laboratory and Field Investigations," Scientific Basis for Nuclear Waste Management VIII, Vol. 44, Materials Research Society Symposia Proceedings, Pittsburgh, PA, pP. 547-554. 


\section{APPENDIX A \\ PROPERTIES OF NON-WELDED UNIT OF THE A-MOUNTAIN TUFF}

A-Mountain tuff is collected at Sentinel Peak, the easternmost edge of the Tucson Mountains, in the southwestern part of Tucson, Arizona. General geology of the site and the location where the tuff samples are obtained are described in detail by Daemen et al. (1983, Section 4.2). Ten tuff blocks have been collected.

\section{A.1 Mechanical Properties of A-Mountain Tuff}

Uniaxial compression, Brazilian tension, ring tension and seismic velocity measurements have been performed.

\section{A.1.1 Uniaxial Compressive Strength of A-Mountain Tuff.}

Uniaxial compression tests have been performed on ten A-Mountain tuff specimens. Sample preparation, test procedure, and method of calculation follow the ASTM standard D2938. All specimens are prepared from tuff block no. T1. Flow layers are perpendicular to the core axis. The nominal diameter and length of the samples are 50 and $100 \mathrm{~mm}$, respectively. The samples are axially loaded to failure at a constant stress rate of $390 \mathrm{kPa} /$ second.

The mean and standard deviation of the uniaxial compressive strength are $36.21 \mathrm{MPa}$ and 5.60 $\mathrm{MPa}$, respectively. The failure planes make an angle of approximately $20^{\circ}$ with the core axis. Elastic (tangent) modulus measured from stress-strain curves (at 508 failure stress) averages 3.89 $\mathrm{GPa}$ with a standard deviation of $0.35 \mathrm{GPa}$ and a coefficient of variation of 98 . Bulk density averages $1,790 \mathrm{~kg} / \mathrm{m}^{3} \pm 30 \mathrm{~kg} / \mathrm{m}^{3}$.

\section{A.1.2 Brazilian Tensile Strength of A-Mountain Tuff}

Brazilian tension tests are performed to determine the splitting tensile strength. Sample preparation, test procedure and method of calculation are performed in accordance with ASTM standard D3967.

Eleven disk specimens have been prepared from block no. T1. The samples have a nominal diameter of $5 \mathrm{~cm}$ with a length to diameter ratio of 0.5 . The flow layers are perpendicular to the core axis. The specimens are loaded to failure at a rate of $3.5 \mathrm{MPa} / \mathrm{min}$.

The average Brazilian tensile strength, standard deviation, and coefficient of variation are $5.57 \mathrm{MPa}, 0.82 \mathrm{MPa}$, and 158 , respectively. All samples failed in tension along the loading diameter. 


\section{A.1.3 Ring Test Tensile Strength of A-Mountain Tuff}

Tension tests have been performed on three disk sizes (50, 152 and 282 $\mathrm{mm}$ diameter). The samples are prepared from tuff block nos. T1, T2 and T3. The cores are drilled perpendicular to the flow layers. Fuenkajorn and Daemen (1986, sections 3.2 and 3.3, pp. 44-58) give test methods and sample preparation. The ring tensile strength is calculated using a solution given by Ripperger and Davids (1947):

$$
\sigma_{R}=(2 P K) /(\pi D t)
$$

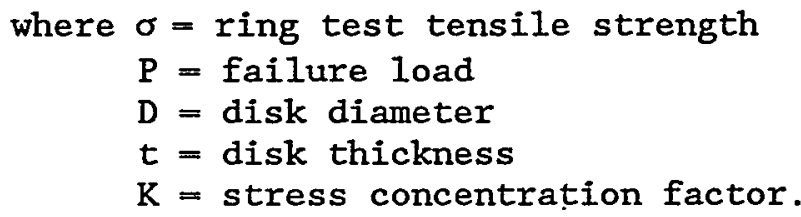

Hobbs (1964, p. 387) gives an approximate value of the stress concentration factor as:

$$
\mathrm{K}=6+38(\bar{r})^{2} ; \text { for } 1.0>\bar{r} 0.1
$$

Table A.1 gives the results. The tensile strength decreases as the sample size increases. Figure A.I gives the ring tensile strength as a function of disk diameter. A relationship between the tensile strength and specimen size can be established by using an empirical equation given by Fuenkajorn and Daemen (1986, pp. 90-91):

$$
\sigma_{R}=N(D)^{-\lambda^{\circ}}
$$

where $N=$ strength coefficient

$$
\lambda^{\prime}=\text { size coefficient. }
$$

The size coefficient, $\lambda^{\prime}$, ranges from 0 to 1 . A lower value of $\lambda^{\prime}$ indicates a smaller effect of the sample size on the tensile strength. Table A. 2 compares the size and strength coefficients of A-Mountain tuff with those of Grande basaltic andesite and Pomona basalt.

\section{A.1.4 Dynamic Young's Modulus and Poisson's Ratio of A-Mountain Tuff}

Seismic velocity measurements are performed to determine the dynamic Young's modulus and dynamic Poisson's ratio of A-Mountain tuff. Twentythree disks have been tested. The samples have a nominal diameter of $100 \mathrm{~mm}$ with thickness to diameter ratio of 0.25 . A11 specimens are cut from tuff block no. T5. The test procedure (Appendix B) follows a method given by the Structural Behavior Engineering Laboratories, Inc. The rock density averages $1.924 \neq 0.034 \mathrm{~g} / \mathrm{cc}$. The velocities of primary and secondary waves are $3842 \pm 1047 \mathrm{~m} / \mathrm{s}$ and $1993 \pm 624 \mathrm{~m} / \mathrm{s}$, respectively. Dynamic Young's modulus and dynamic Poisson's ratio are 20.5 $11.7 \mathrm{GPa}$ and $0.28 \pm 0.14$, respectively. 
Table A.1 Mechanical Properties of A-Mountain Tuff

$$
\begin{gathered}
\text { Mean } \pm \text { Standard } \\
\text { Deviation }
\end{gathered}
$$

Uniaxial Compressive

Strength ( $\mathrm{MPa}$ )

Tangent Young's

Modulus ( $\mathrm{GPa}$ )

Brazilian Tensile

Strength

Ring Tensile Strength $(\mathrm{MPa})$

$$
5.57 \pm 0.82
$$

$$
36.21 \pm 5.60
$$

$$
3.89 \pm 0.35
$$

$12.79 \pm 1.99 \quad(50 \mathrm{~mm}$ diam. $)$

$9.82 \pm 1.36$ (150 mm diam.)

$8.67 \pm 0.28$ (280 $\mathrm{mm}$ diam.)
Coefficient of Variation

Dynamic Young's

Modulus ( $\mathrm{GPa}$ )

$20.5 \pm 11.7$

578

Dynamic Poisson's

$$
\text { Ratio }
$$

$0.28 \pm 0.14$

158

98

158

158

148

38 


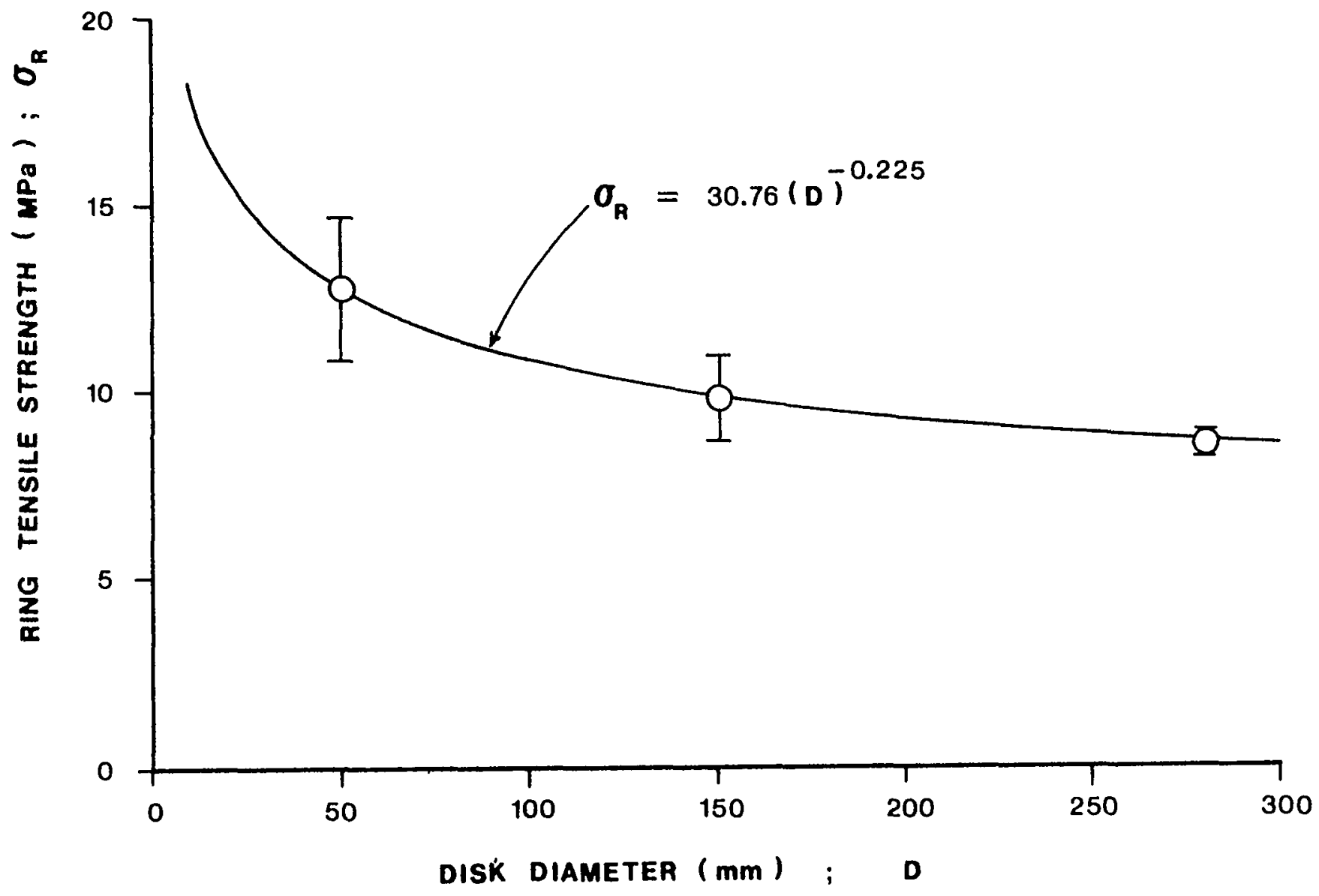

Figure A.1 Experimental results (mean and standard deviation) and curve fitting of the ring tension test on A-Mountain tuff. Ring test tensile strength as a function of the disk diameter. The strength decreases as sample size increases. The curve fit gives a correlation coefficlent $\left(\mathrm{R}^{2}\right)$ of 0.998 . 


\section{A.2 Mineralogy and Chemical Composition of A-Mountain Tuff}

Mineral composition and petrographic features (grain, size, flow layer, vesicles and cavities) of the nonwelded unit of the A-Mountain tuff are determined by means of a petrographic microscope. Four thin sections are cut from tuff block no. T5. Each section covers an area of $2 \times 4$ $\mathrm{cm}$. Two sections are cut perpendicular to flow layers; the others are cut parallel to the flow layers. The investigation is made at magnifications of 10 to 320 diameters (i.e. the image is enlarged 10 to 320 times).

Table A.3 gives the results of the petrographic studies of A-Mountain tuff. The rock is composed of plagioclase and quartz (in phenocryst and groundmass form), magnetite, olivine, and hematite (alteration product of magnetite). The flow layers are obvious and can be determined from the trend of hematite minerals. All minerals, except plagioclase, seem to be nonuniformly distributed within the rock. Table A.4 gives the chemical composition of the A-Mountain tuff. 
Table A.3 Mineral Composition of A-Mountain Tuff

\begin{tabular}{|c|c|c|c|c|c|}
\hline & $\begin{array}{l}\text { Average } \\
\text { Grain } \\
\text { Size }\end{array}$ & $\begin{array}{l}\text { T5-1- } \\
12-\mathrm{MI} 1\end{array}$ & $\begin{array}{l}\text { Sample } \\
\text { T5-1- } \\
\text { 12-MI2 }\end{array}$ & $\begin{array}{c}\text { Number } \\
\text { T5-1- } \\
\text { 12-MI3 }\end{array}$ & $\begin{array}{l}\text { T5-1- } \\
12-M I 4\end{array}$ \\
\hline Olivine & $5 \times 5 \mu \mathrm{m}$ & $10 \%$ & $0.5 \%$ & $5 \%$ & $2 \%$ \\
\hline $\begin{array}{l}\text { Plagioclase + } \\
\text { Quartz Phenocryst }\end{array}$ & $1 \times 1 \mathrm{~mm}$ & $10 \%$ & $20 \%$ & $15 \%$ & $15 \%$ \\
\hline $\begin{array}{l}\text { Plagioclase }+ \\
\text { Quartz Groundmass }\end{array}$ & $4 \times 8 \mu \mathrm{m}$ & $23 \%$ & $50 \%$ & $30 \%$ & $30 \%$ \\
\hline Magnetite & $30 \times 10 \mu \mathrm{m}$ & $17 \%$ & $5 \%$ & $15 \%$ & $15 \%$ \\
\hline Hematite & $0.5 \times 0.5 \mu \mathrm{m}$ & $25 \%$ & $25 \%$ & $30 \%$ & $20 \%$ \\
\hline $\begin{array}{l}\text { Vesicles/ } \\
\text { Cavities }\end{array}$ & $1 \times 1 \mu m$ & $15 \%$ & $20 \%$ & $15 \%$ & $20 \%$ \\
\hline
\end{tabular}

Table A.4 Chemical Composition of A-Mountain Tuff

(8)

$\mathrm{SiO}_{2}$

76.9

$\mathrm{Na}_{2} \mathrm{O}$

3.7

$\mathrm{K}_{2} \mathrm{O}$

3.9

$\mathrm{CaO}$

0.4

MgO

0.21

$\mathrm{Al}_{2} \mathrm{O}_{3}$

12.2

$\mathrm{Fe}_{2} \mathrm{O}_{3}$

1.0

$\mathrm{FeO}$

0.05 


\author{
APPENDIX . B \\ Procedure for Seismic Velocity Measurements
}

\title{
B.1 Objective
}

Seismic velocity testing is performed to determine the $\mathrm{P}$-wave and $\mathrm{S}$-wave velocities. These values are used to obtain dynamic elastic constants (Young's modulus and Poisson's ratio).

\section{B.2 Apparatus}

SBEL $2007 \mathrm{H}$ Seismic Analyzer with P-and S-wave emitter/detector transducers, an oscilloscope, and extremely viscous coupling material (SBEL accoustic couplant \#7, vaseline, or grease).

\section{B. 3 Test Specimen}

Requirement:

- A circular disk with a minimum diameter of $10 \mathrm{~cm}$ is generally used to match transducer diameter. However, different specimen shape, such as a cube, can be used.

- Thickness of the disk should be approximately $2.5 \mathrm{~cm}$. Thicker disks can be used but may result in poor $S$-wave signal transmission.

- End surfaces should be ground smooth (to within $0.25 \mathrm{~mm}$ ) and parallel (to within $0.25^{\circ}$ ).

Measurement:

- Diameter: 3 measurements at $60^{\circ}$ from each other, to the rearest $0.25 \mathrm{~mm}$ (0.01 in).

- Thickness: 4 measurements at $90^{\circ}$ from each other, to the nearest $0.25 \mathrm{~mm}(0.01 \mathrm{in})$.

- Weigh specimen to an accuracy of 0.018 .

Description:

- Obvious lithological and structural features.

- Approximate mineral grain size.

\section{B.4 Procedure}

Note: refer to "Operating Instructions for $2007 \mathrm{H}$ Seismic Analyzer" write up for detailed instructions. 
1. Connect cables from seismic analyzer to oscilloscope and transducers (see cable hook-up data in the "Instructions").

2. Determine delay time without specimen.

- Place transducers face to face with adequate amount of coupling material. Alignment marks (arrow mark) in the transducers should coincide.

- Obtain face to face delay time both for $P$-wave $\left(\Delta \mathrm{P}_{0}\right)$ and for $S$-wave $\left(\Delta S_{0}\right)$.

- Try both manual and auto modes.

3. Determine delay time with specimen

- Place specimen in between the transducers.

- Check that proper alignment of the transducers and good coupling are obtained.

- Determine delay time for the specimen of thickness $t$, for both $\mathrm{P}$-wave and $\mathrm{S}$-wave. Use manual mode and auto mode.

\section{B. 5 Calculations}

1. P-wave velocity:

$$
\begin{array}{ll}
\text { P-wave delay } & T_{p}=\Delta P_{t}-\Delta P_{0} \quad(\mu S) \\
\text { P-wave velocity } \quad V_{p}=\frac{1}{r_{p}} \quad(\mathrm{~m} / \mathrm{s} \text { or } \mathrm{ft} / \mathrm{s})
\end{array}
$$

2. S-wave velocity:

$$
\begin{aligned}
& \text { S-wave delay } \quad T_{s}=\Delta S_{1}-\Delta S_{0} \quad(\mu s) \\
& \text { S-wave velocity } \quad V_{s}=\frac{1}{T_{s}} \quad(\mathrm{~m} / \mathrm{s} \text { or } \mathrm{ft} / \mathrm{s}) \\
& \text { where } t=\text { specimen thickness. }
\end{aligned}
$$

3. Dynamic Young's modulus:

$$
E_{d}=\frac{\gamma V_{s}^{2}\left(3 V_{p}^{2}-4 V_{s}^{2}\right)}{g\left(V_{p}^{2}-V_{s}^{2}\right)}
$$

4. Dynamic Poisson's ratio:

$$
v_{d}=\frac{V_{p}^{2}-2 V_{s}^{2}}{2\left(V_{p}^{2}-V_{s}^{2}\right)}
$$


where: $\gamma=$ unit weight of the specimen $g$ - acceleration of gravity $\left(32,2 \mathrm{ft} / \mathrm{s}^{2}\right.$ or $\left.9.81 \mathrm{~m} / \mathrm{s}^{2}\right)$. 


\section{APPENDIX C}

ROCK SAMPLE DESIGNATION CODING SYSTEM

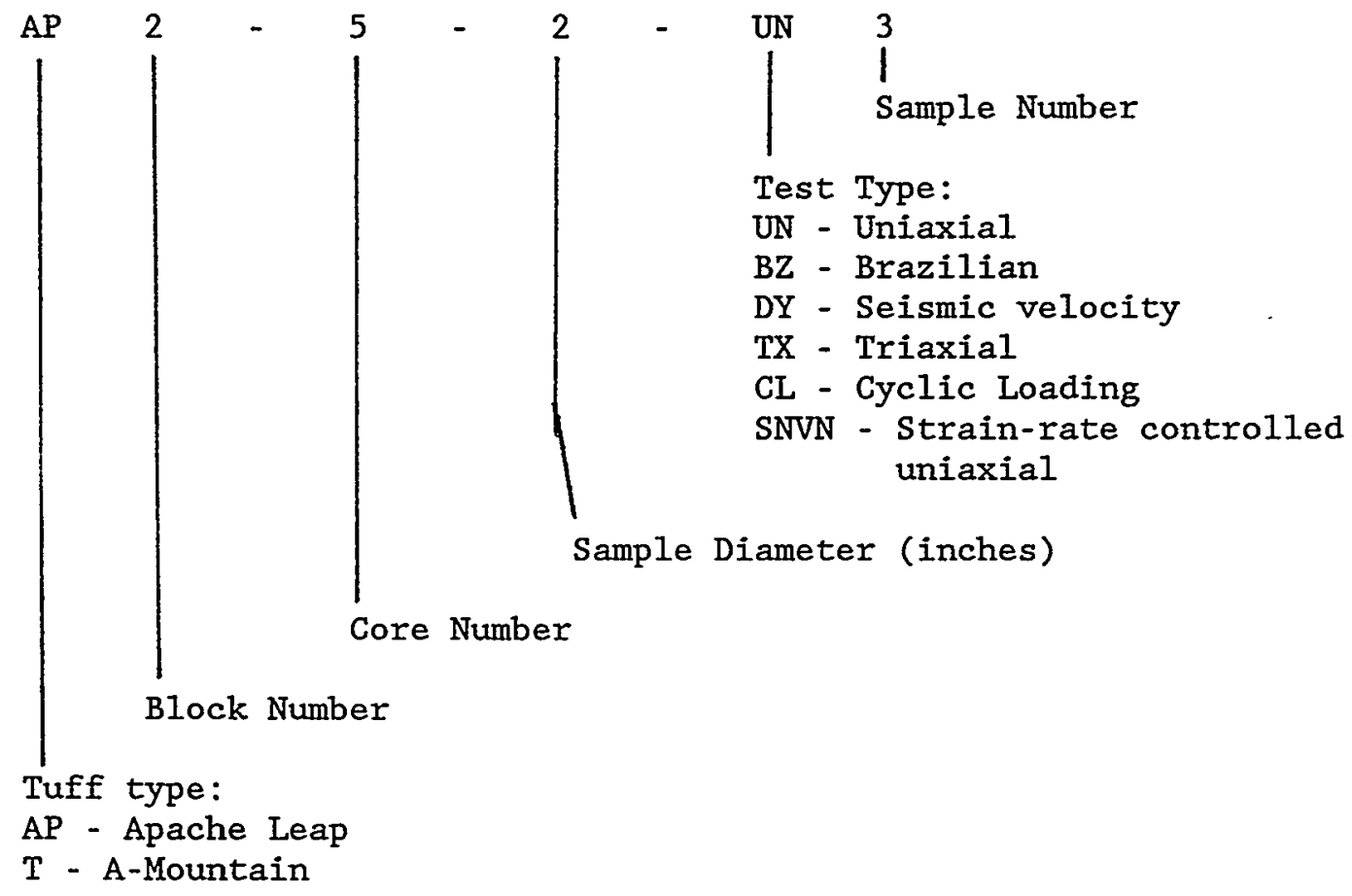


2. TITLE AND SUBTITLE

Mechanical Characterization of Densely Welded Apache Leap Tuff

\section{AUTHOR(S)}

K. Fuenkajorn, J. J. K. Daemen

NUREG/CR-5688

\section{3.}

3. DATE REPORT PUBLISHED \begin{tabular}{l|l} 
MONTH & YEAR \\
\hline JEA
\end{tabular}

June 199

4. FIN OR GRANT NUMBER

L 1476

6. TYPE OF REPORT

Technical

7. PERIOD COVERED (Inclusive Dates)

1987-1990

8. PERFORMING ORGANIZATION - NAME AND ADDRESS (If NRC, provide Division, Office or Region, U.S. Nuclear Regulatory Commission, and mailing address, if contractor, provide name and mailing oddress.)

Department of Mining and Geological Engineering

University of Arizona

Tucson, AZ 85721

9. SPONSORING ORGANIZATION - NAME AND ADDRESS III NRC, type "Same as above": il contractor, provide NRC Division, Office or Region, U.S. Nuclear Regulatory Commission, and mailing address.)

Division of Engineering

Office of Nuclear Regulatory Research

U.S. Nuclear Regulatory Commission

Washington, DC 20555

\section{SUPPLEMENTAAY NOTES}

11. ABSTRACT 1200 vords or lessl An empirical criterion is formulated to describe the compressive

strength of densely welded Apache Leap tuff. It incorporates the effects of size, L/D

ratio, loading rate and density variations, and improves the correlation between the test results and the failure envelope. Uniaxial and triaxial compressive strengths, Brazilian tensile strength and elastic properties of the densely welded brown unit of Apache Leap tuff have been determined using the ASTM standard test methods. All tuff samples are tested dry at room temperature with the core axis normal to the flow layers. The uniaxial compressive strength is $73.2+16.5 \mathrm{MPa}$. The Brazilian tensile strength is $5.12+$ 1.2 $\mathrm{MPa}$. The Young's modulus and Poisson's ratio are $22.6 \pm 5.7 \mathrm{GPa}$ and $0.20 \pm 0.03$. Smoothness and perpendicularity do not fully meet ASTM requirements for all samples, due to voids and inclusions on the sample surfaces and the sample preparation methods. The investigations of loading rate, L/D ratio and cyclic loading effects on compressive strength and of the size effect on tensile strength are not conclusive. The Coulomb strength crterion adequately represents the failure envelope of the tuff under confining pressures from 0 to $62 \mathrm{MPa}$. The tuff is highly heterogeneous as suggested by large variations in the results. The variability is probably caused by flow layers and by nonuniform distributions of inclusions, voids and degree of welding. Similar variability of properties has been reported elsewhere for the Topopah Spring tuff at Yucca Mountain.

12. KEY WORDS/DESCR!PTORS IList words or phrases that will assist researchers in locating the reoort. 1

compressive strength density

tensile strength

elastic modulus

dynamic modulus

failure criteria

heterogeneity

Young 's modulus

Coulomb criterion

loading rate

size effects

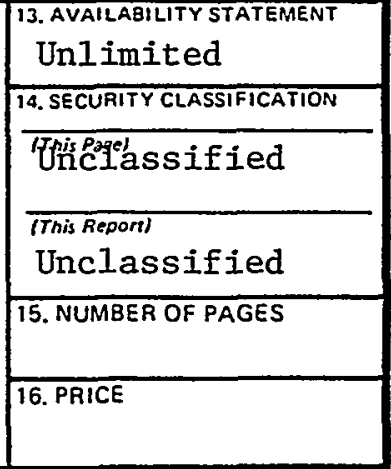

